\title{
COMPACTAÇÃO DO SOLO POR PATINAGEM DA RODA MOTRIZ DE UM TRATOR AGRICOLA
}

\author{
JOSÉ VALDEMAR GONZALEZ MAZIERO \\ Engenheiro Agrônomo \\ Orientador: Prof'. Dr. LUIZ GERALDO MI ALHE \\ Dissertação apresentada à Escola \\ Superior de Agricultura "Luiz de \\ Queiroz". da Universidade de São \\ Paulo. para obtenção do Título \\ de Mestre em Agronomia. Área de \\ Concentração: Máquinas Agrícolas.
}

\footnotetext{
P I R A e I e A B A

Estado de São Paulo - Brasil DEZEMBRO - 1993
} 
Ficha catalográfica preparada pela se âo de Livros da Divisâo de Biblioteca e Documenta âo - PCLQ/USP

\footnotetext{
Gonzalez Maziero, José Valdemar

G643c Compacta o do solo por patinagem da roda motriz

de um trator agrícola. Piracicaba 1993. $105 \mathrm{p}$.

Diss. (Mestre) - ESALO

Bibliografia.

1. Mecaniza;âo agrícola 2. Solo - Compacta; o 3. Trator agricola 1. Escola Superior de Agricultura Luiz de Queiroz Piracicaba 


\section{COMPACTAÇÃO DO SOLO POR PATINAGEM DA RODA MOTRIZ DE UM TRATOR AGR! COLA}

Aprovado em : 07/03/1994

Comissão julgadora:

Prof. Dr. Luiz Geraldo Mialhe ESALQ, /USP

Prof. Dr. Marcos Milan ESALQ, /USP

Dr. Cesar de Mello Mesquita

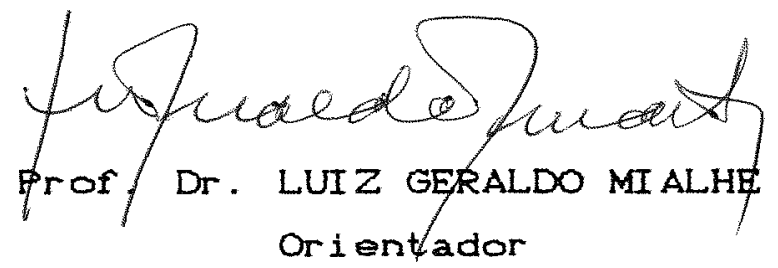




\section{OFEREÇO}

Ao meu paí. José

A minha mãe. Adelaíde

Ao meu irmão. Wilson

DEDICO esta dissertação à minha esposa.
Maria Angélica e aos meus ilhes. Camila
e Gustavo dos quais urtei diversas horas
de convívio em prol da preparação desta.




\section{AGRADECIMENTOS}

Ao Instituto Agronòmico, pela oportunidade

concedida.

Ao Prof. Dr. Luiz Geraldo Mialhe, pelas sugestões e orientação nas etapas de execução e el aboração deste trabalho.

Ao Pesquisador Cientifico Dr. Gastão Moraes da Silveira, pelo incentivo para realização do curso.

Ao Pesquisador Científico Joß̋o Aureliano de Souza Costa pela ajuda nas discussões sobre metodologia estatistica aplicada no trabalho.

A Pesquisadora Cientifica Il a Maria Corrèa pelas sugestões e auxilio nas análises dos dados.

\section{Ao Pesquisador Cientifico Kyioshi Yanai}

pela ajuda no preparo do material e na fase experimental de campo.

Ao Pesquisador Cientifíco João Floríano de Menezes com gratidão pela nossa acolhida na Seção de Máqui nas de Traçăo e de Potência.

Ao Pesquisador Cientifico Cláudio Alves Moreira pela concessấo do trator utilizado no experimento. Ao Pesquisador Cientifico Afonso Peche Filho pelas discussões e orientação referente a solos. Aos demais colegas de serviço da Divisão de Engenharia Agrícola - IAC pelo apoio, incentivo e 
amizade.

Ao técnico de apoio Olavo de Freitas
Caires e aos oficiais de apoio José Ribeiro Nogueira e
Olivio Ferrer, pela ajuda e dedicaçáo prestada durante toda
fase de preparaça de material e equipamentos e
experimental.

A técnica de apoto Maria A. Ferreira pelos servicos de datilogratia.

A oflcial de apoio Elisabete V. Machado pelos servicos de xerografia. 
LISTA DE FIGURAS. ......................

LISTA DE TABELAS $\ldots \ldots \ldots \ldots \ldots \ldots \ldots \ldots \ldots \ldots \ldots \ldots \ldots \ldots \ldots \ldots$

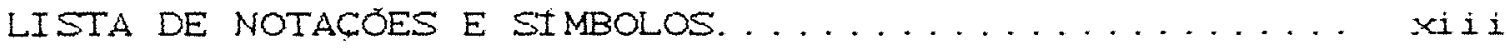

RESUMO $\ldots \ldots \ldots \ldots \ldots \ldots \ldots \ldots \ldots \ldots \ldots \ldots \ldots \ldots \ldots \ldots \ldots \ldots$

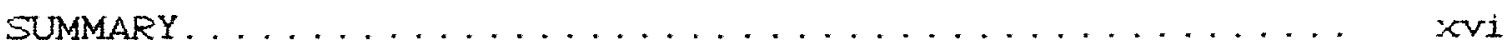

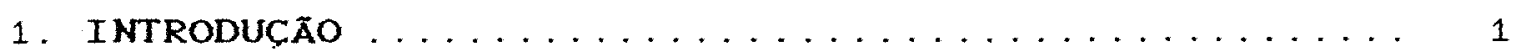

2. REVISAO BIBLIOGRAFICA $\ldots \ldots \ldots \ldots \ldots \ldots \ldots \ldots \ldots \ldots \ldots \ldots$

2.1 Processos de compactacáo do solo ........... 3

e. 2 Forças que causam a compactaça ........... 4

2. 3 Compactaçáo sob pneus agricolas .......... 4

2.3.1 Efeito da distribuiçăo de tensão

sob a área de contato ............ 5

2.3.2 Efeito das dimensóes do pneu e estrutura da carcaça ............ 7

2.3.3 Efeito do tipo de construçăo do pneu .......................

2.3.4 Efeito da pressão de inflacáo......... 10

2.3.5 Efeito da intensidade de tráfego....... 11

2.3.6 Efeito da velocidade de deslocamento ................... 12 
¿.4. Patinagem e tensăo de cisalhamento......... 12

2.5 Alguns efeitos da compactação............. 16

2.6 Custos e energia para recuperaça do solo.... 19

2.7 Métodos utilizados para determinar a

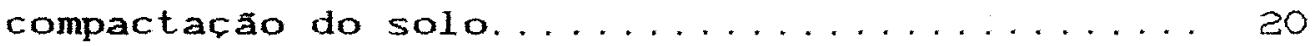

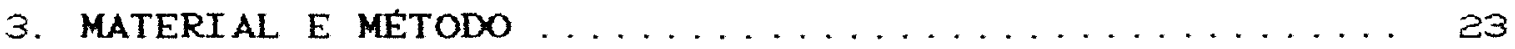

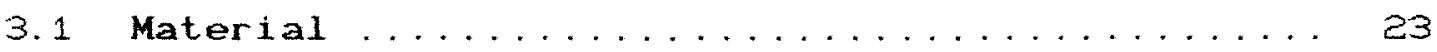

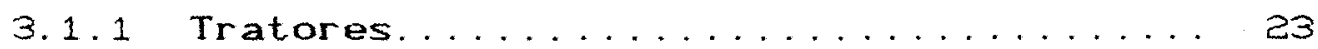

3.1.e Equipamentos de mensuração........ e4

3.1.2.1 Mensuração de força de

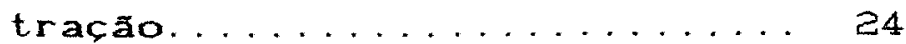

3.1.2.2 Mensuraça da patinagem...... es

3.1.2.4. Resistência do solo à

penetraçáo................ 27

3.1.3 Equipamentos para caracterizacáo

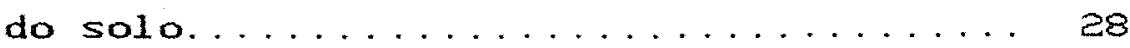

3.1.3.1 Densidade................

3.1.3.2 Umidade................. 28

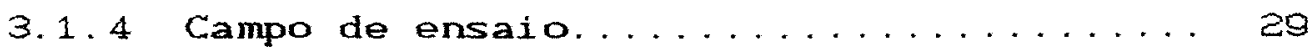

3.1.5 Caracterizaçáo da banda de

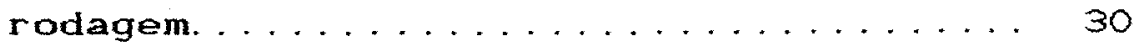

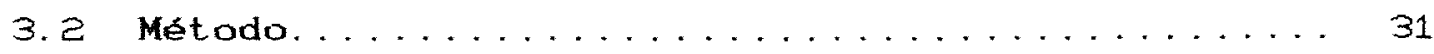

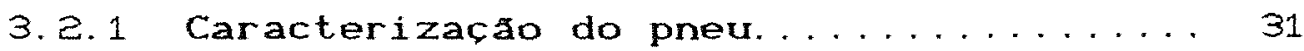

3.2. 2 Preparo da área para ensaio......... 31

3. 2. 3 Avaliaça da compactacao................

3.2. 4 Caracteristicas ponderais e 


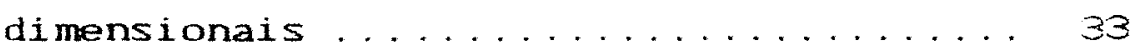

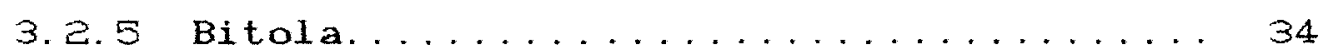

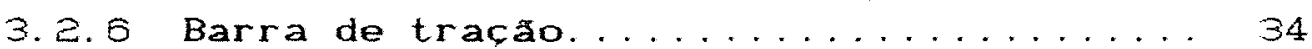

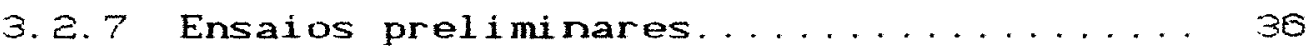

3.2.7.1 Determi naçăo das cargas para obtençáo dos níveis de patinagens.............. 36

3.2.7.2 Araliaça da variação da área de contato do pneu ..... 38

3. 2. 8. Metodo de ensaio de campo.......... 41

3. 2. 9. Análise estatistica............. 42

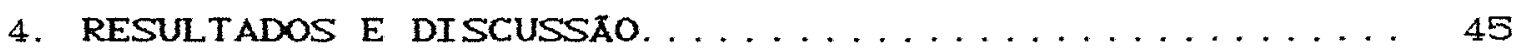

4.1. Força de traçăo e patinagem.............. 45

4. 2. Area de contato e pressão sobre o

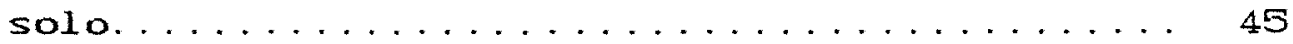

4.3. Valores de Indice de cone................48

4.4. Análise estatistica dos dados............ 51

4. 4.1. Análise estatistica dos dados obtidos ao 1 ado do rasto do pneu. ................... 51

4. 4. 2. Analise estatistica dos dados obtidos no rasto

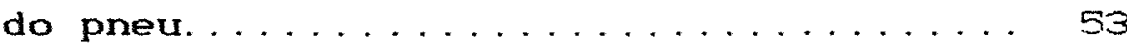

4. 4. 3 Análise estatistica dos dados 1 iquidos de indice

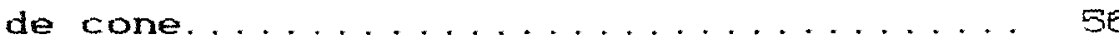




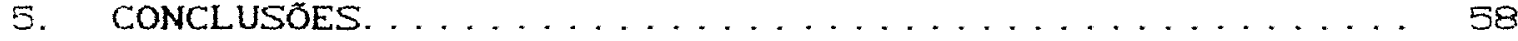

REFERENCIAS BIBLIOGRAFICAS. . . . . . . . . . . . 59

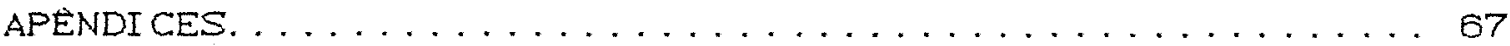




\section{LISTA DE FI GURAS}

Página

Figura 1 - Esquema da disposição dos equipamentos instalados no trator . ............ 27

Figura 2 - Esquema da barra de tração invertida e - dispositivo, com a finalidade de diminuir a altura de engate à barra...... 35

Figura 3 - Relação patinagem - força de tração determinada preliminarmente. ......... 37

Figura 4 - Representação gráfica da equacão da área de contato em função da carga di nâmica sobre os pneus..............40

Figura 5 - Esquema da localização das amostragens dos valores de indtce de cone em cada parcela.................... 42

Figura 6 - Area de contato e pressão média em função da carga dinâmica, valores estimados a partir dos valores de força de tração na barra, para cada tratamento...........47 
Figura 7 - Variação dos valores médios de indice de cone em funcão da profundidade, para os diferentes níveis de patinagens no rasto do pneu $e$ ao 1 ado..................... 49

Figura 8 - Médias da diferenças de índice de cone no rasto do preu e ao 1 ado. ............ 50

Figura 9 - Valores de índice de cone em funcão dos níveis de patinagens para as profundidades estudadas............. 56 


\section{LISTA DE TABELAS}

Página

Tabela 1 - Valores de força de tração média e patinagem em cada parcela, obtidos durante o ensaio. ............... 45

Tabela 2 - Análise de variancia fixando o nível SEM do fator A C compactação $2 \ldots . . \ldots \ldots$ Se

Tabela 3 - Análise de variância fixando o nível COM do fator A C compactação ) .......... 53

Tabela 4 - Análise de variância das diferenças de médias, entre os dados de indice de cone obtidos no rasto do pneu e ao $\quad 1$ ado............................ 57 


\section{LISTA DE NOTAGOES E SIMBOLOS}

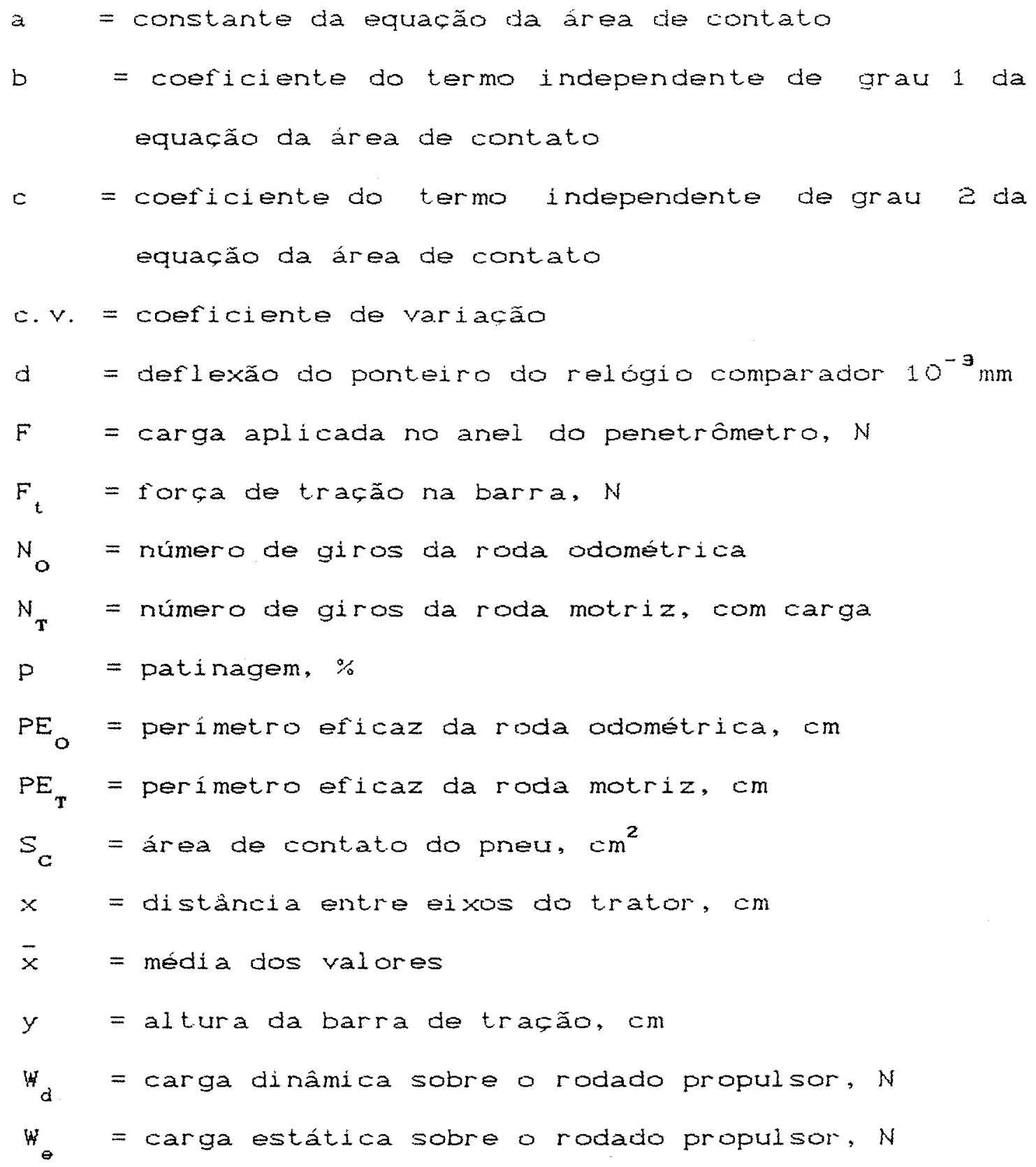




\title{
COMPACTAČÃO DO SOLO POR PATINAGEM DA RODA MOTRIZ \\ DE UM TRATOR AGRI COLA
}

\author{
Autor: JOSE VALDEMAR GONZALEZ MAZIERO \\ Orientador: Prof. Dr. LUIZ GERALDO MI ALHE
}

\section{RESUMO}

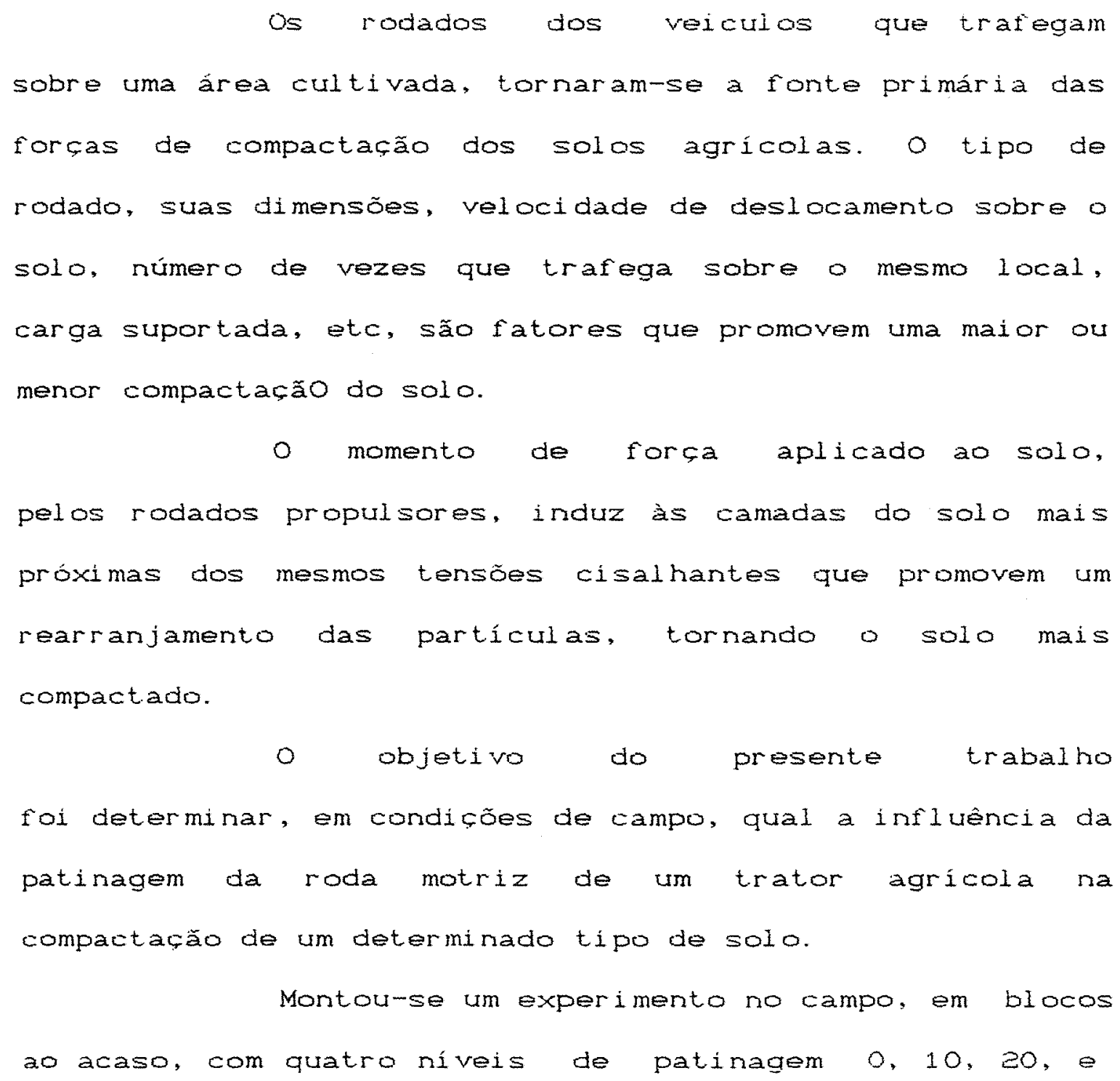


$30 \%$ e cinco repeticós, com delineamento estatistico em parcelas subdirididas.

$$
\text { A compactacăo foi avaliada através do }
$$
indice de cone, realizando-se quinze determinacöes na linha de centro do rasto da roda motriz e quinze ao 1 ado, em terreno não compactado pela roda. A cada determinação foram feitas leituras de indice de cone para seis profundidades: $2,5,5,0,7,5,10,0,12,5$ e $15,0 \mathrm{~cm}$.

Para minimizar a transferéncia de peso, para o eixo traseiro, um dispositivo especial foi adaptado a barra de tração para evitar alguma influencia sobre a compactação.

Constatou-se que a patinagem dos pneus tem influência sobre o grau de compactação do solo, até 5cm de profundidade, sob as condiçós do presente trabalho. Sendo o nivel de $30 \%$ de patinagem aquele que provocou diferencas significativas no grau de compactação do solo.

A patinagem provoca uma compactação maior mais próxima à superície, diminuindo em profundidade.

os aumentos percentuais dos valores Iiquidos de indice de cone em cada tratamento, comparado ao tratamento ACO\% foi de $16,7,20,9$ e $29 \%$ para os tratamentos $B(10 \%, C(20 \%) D(30 \%)$ respectivamente. 
SOIL COMPACTION FOR TRACTOR DRIVING WHEEL SLIP

Author: JOSE VALDEMAR GONZALEZ MAZIERO Adviser: Prof. Dr. LUIZ GERALDO MIALHE

\title{
SUMMARY
}

\begin{abstract}
Vehicles travelling over a crop field have become a primary source of forces compacting agricultural soils.

The type of tires used by those vehicles, their physical dimensions, their speed of displacement on the soil, the number of times their tires pass by the same place, and the load those tires support are some factors which cause higher or lower degree of soil compaction.

The force-moment applied to the soil by the driving wheels transfers stressing forces to the nearest soil layers modifying their particles arrangement turning the soil more compacted.

The objective of this study was to determine, under field conditions, the effect of slip of an agricultural tractor driving wheel upon the compaction of a specific type of soil.
\end{abstract}

A Randomized Complete Block design field 
experiment was carried out to analyse four different levels of slip $(0,10,20$, and $30 \%$ with five replications of sub-divided plots.

The degree of compaction was determined through the cone index of a soil penetrometer. Fifteen samples were taken from points along the center line of the driving wheel track, and another fifteen samples were taken from points along but outside the driving wheel track on soil band not compacted by the tires. Each sample was composed by readings from the penetrometer cone index at six different depths: $2,5,5,0,7,5,10,0,12,5$, and 15,0 $c m$.

In order to minimize the transference of weight to the rear shaft a special mechanical device was adapted to the drawbar to avoid any influence over the compaction.

It was found that slip had influence on degree of soil compaction up to $5 \mathrm{~cm}$ depth, under the conditions this study was carried out.

The $30 \%$ level of slip was the one that produced significant differences on soil compaction degree.

The slip produced higher compaction near the soil surface, decreasing with depth.

The percentile increases of readings for every treatment when compared to the treatment A C $0 \%$ were $16,7,20,9$ nd $29 \%$ to the treatments $B(10 \%, \quad C$ (20\%) and D (30\%) respectively. 


\title{
1. INTRODUCĀO
}

\begin{abstract}
S solo agricola, como um fator de producão e uma necessidade de subsistência. exige a manutenção e garantia de sua perenidade. Portanto, a indispensavel mecanizacăo das operacöes agricolas deve corresponder com as necessidades pedológicas e fitotécnicas.

Nos ultimos anos, tem-se observado um aumento no tamanho dos tratores, na potëncia de seus motores, no número de marchas, nas dimensóes e tipos de rodados. Tudo isso, aliado a modernos implementos e técnicas agricolas, săo capazes de criar uma condição de estrutura do solo favoravel ao crescimento das plantas, mesmo sob condicóes edáficas e climáticas desfavoraveis. No entanto, essa vantagem inicial poderá ser comprometida pela compactacão devida ao tráfego de equipamentos durante a fase de desenvolvimento, ou entăo no final do ciclo da cultura, quando pesadas máquinas são utilizadas na colheita e no transporte.
\end{abstract}

A compactaçăo do solo agricola, à primeira rista, parece ser uma propriedade do solo facilmente descrita e mensuravel e de conceito relativamente simples. Este não é o caso, ela está intimamente relacionada com 
propriedades fisicas, quimicas e biológicas que sem dúvida alguma säo importantes ao devenvolvimento das plantas. A compactaçăo do solo altera as relacóes entre ar, água e temperatura, influenciando na germinaçăo, na emergencia das plantulas, no crescimento radicular e, de fato, todas as fases do desenvolvimento.

Em vista disto, ha a necessidade de direcionar o projeto, selecăo e manejo dos equipamentos agricolas e sistemas de producăo, yisando obter niveis de compactacăo ao longo do perfil do solo que não sejam restritivo ao desenvolvimento da cultura.

Na melhor visualizacăo dos vários tatores que concorrem para os agravamentos do fenómeno, como é o caso da patinagem ${ }^{1}$ dos rodados, 0 entendimento dos processos pelos quais a compactacão do solo pode ser modificada e controlada e a forma de se determinar essa compactação, são elementos essencias para uma agricultura permanente.

objetivo desse trabalho é o de determinar. em condicóes de campo, qual a influência da patinagem da roda motriz de um trator agricola na compactacão de um determinado tipo de solo.

O trabalho parte da hipótese de que existe uma relaçao entre níveis de patinagem e grau de compactaçăo na região de contato pneu-solo em função dos esforcos que são aplicados pela banda de rodagem.

(1) A justificativa para o uso deste termo encontra-se no
APENDICE 1 


\section{REVISÃO BIBLIOGRAFICA}

\subsection{Processos de compactacão do solo}

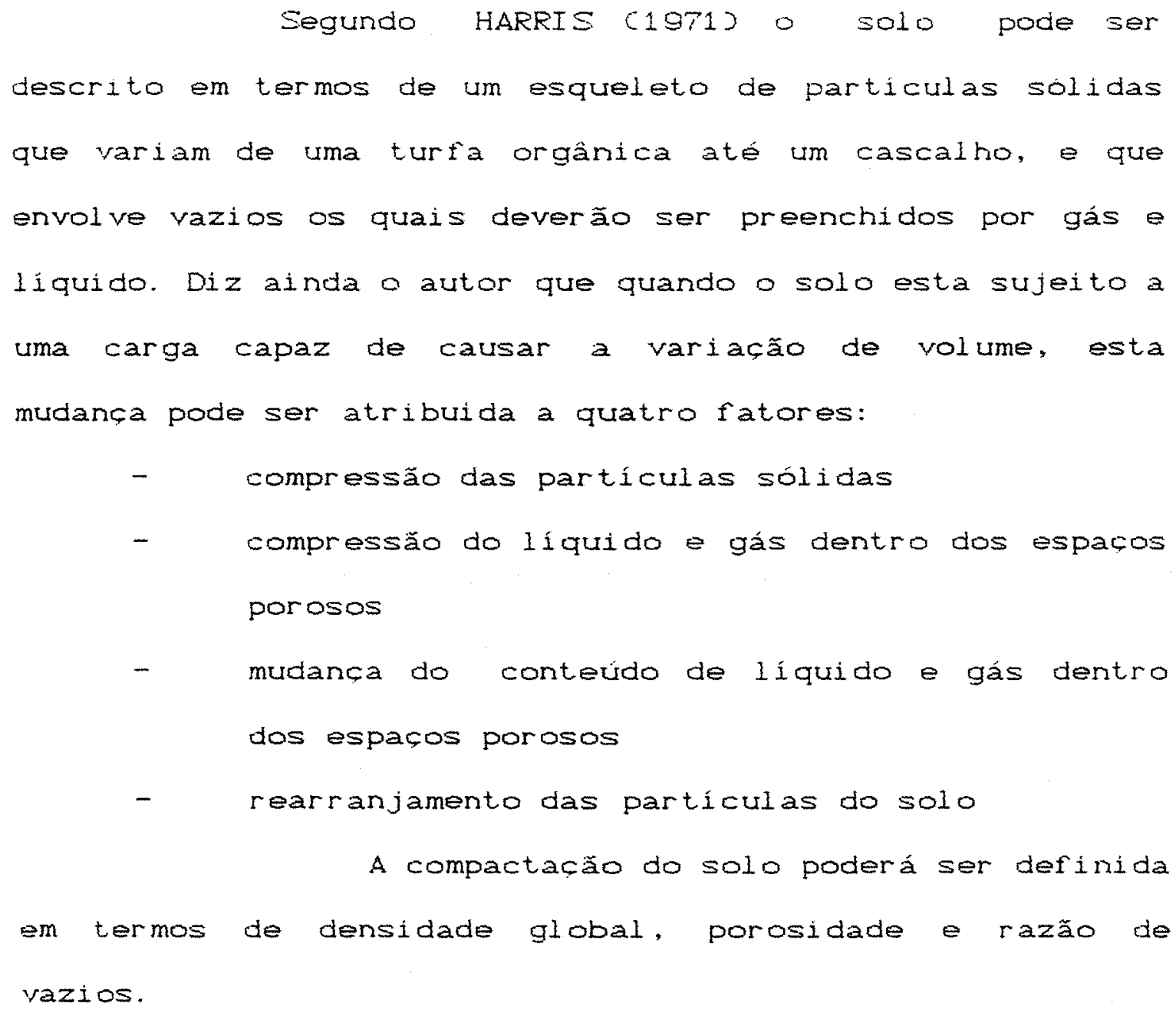




\title{
2.2. Forças que causam a compactaçăo
}

\begin{abstract}
A compactacáo de um solo e definida como a diminuição do volume de uma determinada massa desse solo, provocado pelo rearranjo de suas particulas. Essa mudanca do volume e causado por forcas que para COHRON (1971) podem ser classificadas em duas grandes categorias internas e externas. Internas são todas aquelas originarias dentro da massa do solo, tals como: congelamento e degelo, umidecimento e secamento. Externas săo aquelas que resultam da construçăo de edificios, tráfego de veiculos e ferramenta que atuam no solo. Segue ainda o autor dizendo que essas forcas conceitualmente são expressas como tensão. Assim sendo, não deveria ser dada nenhuma distinção entre elas pois provavelmente tenham a mesma ação no sistema.
\end{abstract}

\section{3 Compactaçáo sob pneus agricolas}

- tráfego de pneus em solos agrícolas difere radicalmente do tráfego em rodovias. Sómente em circunstancias excepcionais, 0 solo agricola apresenta resistencia à cargas aplicadas por pneus sem exceder o Iimite elástico e deformar-se permanentemente. A forma e a extensão dessas deformaçóes dependem sobretudo das 
propriedades fisicas do solo e do pneu

SOANE et al. C1981 citam que a pressão de inflaçăo, o tamanho do pneu e a resistencia da carcaça controlam a distribuicăo de força sobre a area de contato com o solo, que é influenciado primariamente pela resistência inicial do solo.

As forcas na interface pneu-solo a a resistencia inicial do solo controlam a magnitude e distributçăo das tensöes no solo abaixo do pneu.

De acördo com COHRON (1971) os veículos tornaram-se inquestionavelmente a fonte primária de forcas de compactação dos solos agricolas; o aumento do peso dos tratores fez com que houvesse um aumento do tamanho dos pneus num esfôrço de manter constante a pressâo normal de contato do pneu com o solo.

\subsubsection{Efeito da distribuiça de tensão sob a área de contato}

A determinação da pressão normal sobre o solo normalmente e feita determinando-se a área de contato do pneu ou esteira e distribuindo sobre essa área a carga aplicada. Esta simplificacăo năo fornece a distribuicăo real que ocorre sob o dispositivo de tracăo.

Outra maneira comumente usada para descrever a distribuicăo de tensão e atraves do conceito de pressão 
media de contato. Assim. toda vez que uma carga vertical fosse aplicada sobre um pneu, mantendo-se constante sua pressäo interna, êle se deformaria de tal maneira que o produto da pressão media e a área de contato seria igual a carga vertical aplicada. De outra maneira se a mesma carga rosse aplicada, mas diminuisse a pressão interna do pneu, ele se deformaria o suficiente para aumentar a área de contato, mantendo assim a pressão média de contato. Porém năo é bem assim que ocorre essa distribuicăo.

VANDEN BERG \&GILL (1962) trabalhando com

pneus lisos instrumentados com sensores, afim de determinar como ocorriam as tensões sob uma roda dinâmicamente carregada, obtiveram modelos de pressão em diversos tipos de solo. Os dados indicaram que os modelos de pressão, são influenciados pelas condicões dos solos assim como pelo pneu, e que a mudanca na pressão de inflaçăo, mudou consideravelmente o modêlo de distribuicăo de pressão sobre o solo. Foram medidas pressóes no solo de duas a cinco vezes a pressáo de inflacăo.

TRABBIC et al. (1959) instrumentaram um pneu de trator agricola com sensores eletricos afim de medir a pressăo na interface solo-pneu, na parte frontal, tópo, parte traseira da garra, e na carcaca entre as garras. O trabalho tambem mostrou uma distribuicão não uniforme da pressão sob a área de contato. 
2.3.2 Efeito das dimensốs do pneu e estrutura da carcaça

\begin{abstract}
Muitos estudos de compactaçăo por pneus de tratores foram realizados, dando-se especial atencão a três caracteristicas do pneu, as quais podem ser variadas independentemente dentro de certos limites, e que săo: carga nominal, dimensöes do pneu e pressăo de inflaçăo.
\end{abstract} Tabalhando nessas caracteristicas, uma a uma ou combinando-as, é possivel aumentar, diminuir ou manter constante a pressão media de contato.

\title{
KOLOBOV (1966) cita que alem dos fatores
} operacionais como, carga nominal, pressăo de inflação e propriedades mecanicas do solo em contato com o pneu, o valor e a distribuição da pressão de contato são também influenciadas pelas propriedades inerente a construção do pneu, como dureza da carcaca e tipo de banda de rodagem.

O trabalho de VANDEN BERG \& GILL (1962) citado anteriormente, mostra também que, a influencia da dureza dos flancos torna-se evidente à baixa pressão de infilação. Assim sendo, a influência dos fatores de projeto pode ser medido pela distribuição de tensão.

O aumento da largura ou diâmetro do pneu para um aumento de carga, não significa que deixará de haver um aumento da compactacão, para uma pressão de inflaçăo e pressäo média de contato constantes. BLACKWEEL \& 
SOANE (1981) estudando um metodo de predicão de mudanca na densidade global em solos agricolas, resultante do tráfego de veiculos, citam que muita enfase tem sido dada à reducão de pressão de contato com o solo. e que o modélo por êles encontrado revela iqual, senão maior, a importância de Je reduzir a carga na roda para controlar a compactacão do solo abaixo de $10 \mathrm{~cm}$ de profundidade. Eles recomendam que aumento do peso do veiculo não pode ser simplesmente compensado pelo aumento da area de contato.

Resultados pouco contraditorios a essas recomendacóes foram encontrados por CAMPBELL \& DICKSON (1984). Esses autores verificaram o efeito de compactaço em canteiros, causado por pneus frontais montados em um trator equipado com pneu traseiro desenvolvido especialmente para minimizar a compactaçäo. Irabalharam com quatro diferentes tipos de pneus: convencional 7.50-16. GPR, seçao larga diagonal 400-17.5, secăo larga radial $12.0-18$ e seçăo muito 1 arga baixa pressäo $38 \times$ 20.00-16.1 ("Terra Tire"), com e sem lastro frontal. A medida da compactaçăo foi obtida atraves do indice de cone e da densidade global. No ensaio com lastros frontais o pneu Terra Tire e o de secão 1 arga radial causaram um aumento de densidade menor que os outros dois. Para os mesmos pneus sem lastro, as diferencas foram muito pequenas.

RAGHAVAN et at. (1976) estudaram a 


\begin{abstract}
compactaça causada por pneus agricolas de tamanhos diferentes equipando um trator com massa de $4.670 \mathrm{~kg}$, utilizando pneus de dimensöes $46,7 \times 76,2 \mathrm{~cm}$ e pressão de inflacáo de $0,703 \mathrm{~kg} \cdot \mathrm{cm}^{-2}$ e um pulverizador com massa de $3.424 \mathrm{~kg}$, utilizando pneus de dimensöes $28.6 \times 61,0 \mathrm{~cm}$ pressão de inflacăo de $1,476 \mathrm{~kg} \cdot \mathrm{cm}^{-2}$

Devido a maior carga sobre a área de contato do pneu $28.6 \times 61.0$, o pulverizador causou considerável compactacăo comparando com a menor area de contato do pneu que equipava o trator. No caso do pneu do pulverizador, a máxima densidade foi de $0,24 \mathrm{~g} . \mathrm{cm}^{-3}$ entre 7 e $17 \mathrm{~cm}$ de profundidade. Para o pneu do trator, a máxima densidade observada foi de $0,16 \mathrm{~g} \cdot \mathrm{cm}^{-3}$, entre 17 e 20 cm de profundidade. Quando o autor comparou as linhas de pontos de mesma densidade, verificou-se que o pneu do pulverizador compactou maior volume de solo. Isto, segundo - autor, demonstra claramente a vantagem da utilizaçăo de pneus mais largos, afim de distribuir a carga sobre uma área maior, resultando em menor compactaçăo.
\end{abstract}

\title{
2. 3.3 Efeito do tipo de construçáo do pneu
}

Os pneus radiais devido a disposicão das lonas tornam os flancos mais flexiveis. Isto permite um aumento de área de contato maior que o pneu de construção 


\begin{abstract}
diagonal de mesmo tamanho e submetido a mesma carga.
ABEELS (1976) comparou a relação existente entre a carga aplicada e a área de contato efetiva, sobre superficies rigidas, de pneus com dimensöes 12.4 - 36 com 6 lonas de construcăo diagonal e radial. Para uma carga de 10 $k N$ a área de contato do pneu radial foi aproximadamente $40 \%$ maior que a área do pneu diagonal.

PLACKEIT (1984) determinando a pressão de contato de pneus agricolas submetidos a uma carga baixa e em superficies rígidas, verificou para os pneus de dimensões $16.9-34$ diagonal e radial, que a uma mesma carga e mesma pressão de inflação o pneu radial apresentou $15 \%$ de reducăo no valor de máxima pressão aplicado ao solo, em relação ao diagonal.
\end{abstract}

\title{
2.3.4 Efeito da pressáo de inflacăo
}

Segundo SOANE et al. (1981) para pneu tipo "balão", sem garras, existe uma relacăo direta entre a pressão de inflacão e a pressão de contato. Todavia, pneus de tratores com garras, não apresentam uma relaçăo clara entre pressão de inflacão e pressão de contato.

MCLEOD et ai. (1966) estudando características

de força de tração, eficiência de potência e compactaçăo do solo para pneus simples, duplos e baixa-pressão, 
verificaram que quando a pressão de inflacăo de um pneu de baixa pressäo carregando $10.8 \mathrm{kN}$ baixou de 41 para $27 \mathrm{kPa}$ houve uma reducão de $42 \%$ da área da seccăo transversal do sulco.

2.3.5 Efeito da intensidade de tráfego

Dependencio do teor de umidade e das condicões iniciais do solo tem-se maior ou menor influencia da segunda ou subsequentes passadas na compactação do solo. NOVAK et al (1989) estudaram o efeito do tráfego de trator em solos com dois níveis de umidade, verificando que para um mesmo teor de umidade, considerado alto para aquele solo, a medida que aumentou o número de passadas as isolinhas de pressão atingiram praticamente o dôbro da prof undidade

$$
\text { COLETI \& DEMATTE (1982) verificaram }
$$

a compactacão artificial em solos de plantio de cana-deaçúcar. A compactação artificial foi obtida utilizando um caminhão carregado com massa de $15 \mathrm{t}$. sendo realizados cinco niveis de passadas (1, $2,3,4$ e 103 . As passadas do caminhão foram repetidas periodicamente a $0,20,30,46$ e E8 horas após chuva simulada. Os autores concluiram que, estando o solo úmido, a tendência dos valores de densidade é de aumentar de acôrdo com o número de passadas, assim 
como de aumentar em profundidade. Aproximadamente 50 a $60 \%$ da compactaçăo do solo se manifestou com as primeiras passadas.

\title{
2.3.6 Efeito da velocidade de deslocamento
}

\begin{abstract}
STAFFORD \&MATTOS $(1981)$ estudando 0 efeito da velocidade de deslocamento na compactacäo do solo, verificaram que a compactacăo por rodas aumenta, dentro de uma faixa grande de teores de umidade com o decréscimo da velocidade. Esse efeito é atribuido, pelos autores a adição da compactação produzida pela deformação que é causada por cisalhamento devido a patinagem, sendo este efeito menor a altas velocidades.
\end{abstract}

\section{4 Patinagem tensâo de cisalhamento}

De acordo com GILL \& VANDEN BERG (1967),
a tensão de cisalhamento não se acha na interface de
contato solo - rodado, esim na superficie de ruptura csolo
- solo).
REECE (1967) considera que a formulacăo
de teoria simplificada sobre o fenómeno da tracão por
rodados deve partir do empuxo máximo que o rodado dos




\begin{abstract}
tratores tem condicões de exercerem quando apresenta-se com uma determinada area de contato e desenvolvendo uma patinagem. O autor cita ainda que, para uma área de contato plana, paralela à superficie do solo, o empuxo máximo equivale ao produto da área de contato pela máxima tensão de cisalhamento que o solo sob ela é capaz de suportar.
\end{abstract}

FLORES et ar.(1990), partindo de consideracóes teóricas, que o empuxo exercido pelo rodado é diretamente proporcional à tensão máxima de cisalhamento do solo, determinaram tensões de cisalhamento necessárias para proporcionar tração num determinado solo, yariando a umidade e patinagem provocada pelos esforcos tratórios impostos aos rodados durante os ensaios.

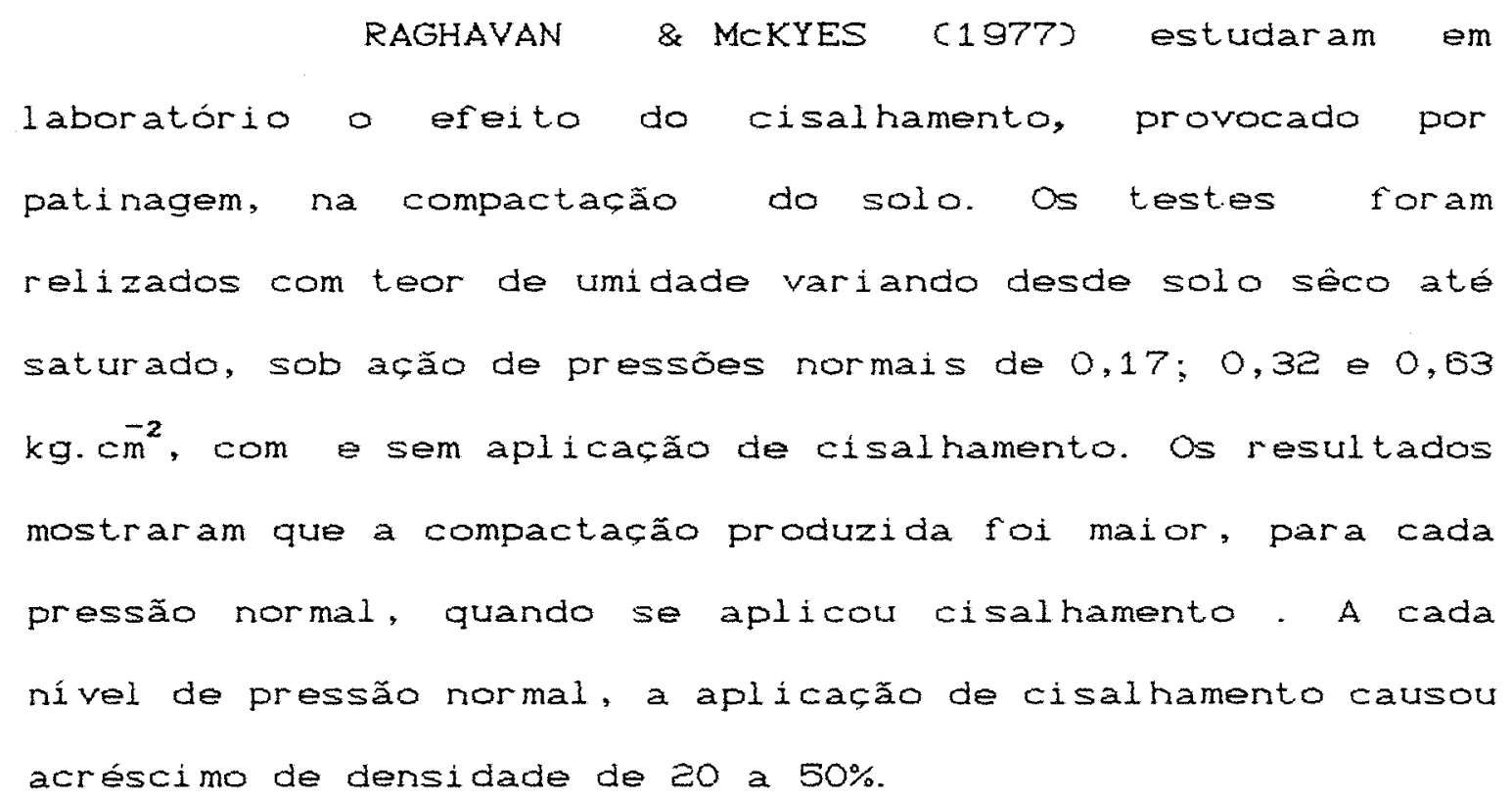

DAVIES et al. (1973) verificaram o efeito do peso do trator e patinagem como causas da compactacăo. Os 
autores trabalharam com dois tipos de solos, dois tratores com massas diferentes em cada solo e com niveis de patinagem de: $0,20,30 e 40 \%$. Em um dos solos houve um aumento de carga do ei xo traseiro para os dois tratores que ali trabalharam. Foram utilizadas cinco diferentes medidas para estimar a compactação a saber: profundidade do rasto, densidade e porosidade, resistencia ao cisalhamento, resistência a penetração do cone e taxa de infiltração. Os resultados permitiram concluir que a patinagem provou ser uma causa mais importante na compactacăo, do que a lastragem.

Segundo os autores, em situaçóes onde existe a necessidade de um melhor controle da compactação, atenção especial deverá ser dada a lastragem e a velocidade operacional, de maneira que se obtenha um mesmo desempenho com reduzida patinagem.

Estudando o efieito da patinagem na compactacăo do solo, RAGHAVAN et al. (1977) trabalharam com pneus de três tamanhos $42,9 \times 71,1 \mathrm{~cm} 46,7 \times 76,2 \mathrm{~cm} e$ $46,7 \times 86,4 \mathrm{~cm}$ a diferentes niveis de patinagem. Os dados de densidade foram coletados, com auxílio de uma sonda de neutron, transversalmente à passagem da roda. Paralelamente testes de cisalhamento de solo em laboratório foram realizados com três niveis de pressão normal.

Para o preu $42,9 \times 71,1$ em solos arenoso e argilo arenoso a máxima compactação ocorreu entre 20 e $25 \%$ 
de patinagem, todaria a compactacao se reduz abaixo de $10 \%$ e acima de 50\%. Para o pneu 46,7 776,2 operando em solo argilo arenoso a máxima compactaça ocorreu entre $10020 \%$ de patinagem. O preu $46,7 \times 86,4$ apresentou resultado semelhante ao primeiro.

Os autores concluiram que acréscimos de densidade de $0,129 \cdot \mathrm{cm}^{-3}$ e 0.25 g.cm for $\mathrm{m}^{3}$ obtidos devido a patinagem em teste de campo para solo arenoso e argilo arenoso respectivamente. A maxima compactacäo ocorreu entre 15 e $25 \%$ de patinagem, reduzindo a medida que houve aumento desta.

Os resultados de laboratório mostraram o efeito do cisalhamento sob a compactacão para très diferentes pressões normais e variação de umidade. A cada nível de pressão normal o cisalhamento causou um acrescimo de densidade global de até 45\%, dependendo do tipo e umidade do solo.

BLASZKIEWICZ (1985) realizou estudos para verificar a influencia da patinagem da roda motriz do trator, a diferentes velocidades, sobre a densidade os teores de água e ar em um solo leve. Os resultados mostraram que a patinagem teve uma considerável influência na densidade, no conteúdo de ar e água e na distribuicão do tamanho dos poros no solo; a natureza e extensão das variacões nestas caracteristicas são determinadas pela velocidade do trator. A minima variacão destavorável na 
densidade, teor de água e ar do solo foram obtidas com velocidade de $1.65 \mathrm{~m} / \mathrm{s}$ para valores de patinagem próximas de zero e maiores que $25 \%$

\section{5 Alguns efeitos da compactaçăo}

FONTAINE citado por ROSEMBERG (1964) aponta que a produtividade de solos compactados é afetada pelo aumento da resistência mecânica a penetração radicular, redução da aeraçấo, alteraçăo na disponibilidade e filuxo de água, calor resultante do aumento da densidade do solo e reducão dos espaços porosos.

Diz ainda o autor que, num determinado tempo e local um desses fatores poderá tornar-se importante para o desenvolvimento das plantas, porem isso depende do tipo de solo, condiçóes climáticas, espécie e desenvol vimento da planta, quando suas raízes encontrarem uma condição de solo compactado.

TRouse (1966) estudou a alteracão na
capacidade de infiltracăo e permeabilidade, causada por
tráfiego de veiculos em solos tropicais, utilizando um
veículo cuja pressão de contato com o solo era de 0,49
kg.cm². O autor constatou decréscimo de infiltracăo e
permeabilidade de $87 \%$ após a primeira passada e de $99.6 \%$
após a oitava passada, para um acréscimo de densidade de


13 e $17 \%$ respectivamente.

Para o caso de veiculos com pressăo de contato de $0,35 \mathrm{~kg} \cdot \mathrm{cm}^{2}$, o autor verificou pouca influencia sobre a permeabilidade hidraulica saturada de $58 \mathrm{~mm} . \mathrm{h}^{1}$ que foi reduzida a $48 \mathrm{~mm} . \vec{h}^{1}$ No entanto, para veiculo com pressão de contato de $0,93 \mathrm{~kg} \cdot \mathrm{cm}^{2}$, a reducăo de permeablidade foi de $58 \mathrm{~mm} \cdot \mathrm{h}^{-1}$ para $3 \mathrm{~mm} \cdot \mathrm{h}^{-1}$.

AKRAM \& KEMPER (1979) estudando cargas compactantes e teores de água nos solos, atraves de medidas da taxa de infiltracão, redução de volume e densidade global, verificaram que a máxima compactaçăo ocorre quando - solo está com seu teor de umidade próximo a capacidade de campo. Os autores encontraram que para cargas menores que $1 \mathrm{~kg} \cdot \mathrm{cm}^{2}$ a densidade global minima ocorreu quando o teor de umidade do solo estava uma vez e meia a capacidade de campo, indicando que a tensão superficial do filme de água no solo desempenhou um papel maior em termos de coesão e estabilização oposto a compactação. Cargas de compactação de $3,46 \mathrm{~kg} \cdot \mathrm{cm}^{2}$, em solo argilo arenoso e textura fina, na capacidade de campo, reduziu a taxa de infiltração para menos de $0.1 \%$ do valor obtidos para esses solos, quando compactados na condicão de seco ao ar.

Toda compactaça provoca, em grau menor ou maior, uma diminuicão do tamanho dos poros e isto certamente irá afetar o desenvolvimento das raizes.

Os dados encontrados por AUBERTIN \& KARDOS 
(1965) estudando o efeito do tamanho do poro e a rigidez deste no desenvol vimento de raizes de milho, observaram uma positiva influencia destes sobre o crescimento das raizes. Estas năo cresceram no sistema de poros rigidos, de diâmetro menor que aproximadamente $138 \mu$ e em sistemas rígidos menores que 412 i houve uma redução de crescimento das raízes.

HOPKINS \& PATRICK (1969) estudando o efeito combinado de teor de oxigennio e compactacăo do solo sobre a penetraçăo da raiz, obtiveram resultados que sugerem haver uma interação da compactação do solo e do conteúdo de oxigênio sobre a capacidade de penetração da raiz. Segundo os autores, a altos níveis de compactação ou a baixos teores de oxigenio, pequena ou nenhuma penetração ocorre. A um ótimo nível de um dos fatores, o aumento da penetração da raiz foi governado pelo outro fator.

TAYLOR \& RATLIFF (1969) estudando a taxa de alongamento radicular em plantas de amendoim e algodão, em função da resistência do solo, mostraram que a taxa de alongamento diminui com a resistência do solo em tôrno da raiz, e que, um acréscimo da resistência ao penetrômetro de - para $10 \mathrm{~kg} \cdot \mathrm{cm}^{2}$ reduziu a taxa de alongamento da raiz do algodão de 62\%, enquanto que para o amendoim foi de apenas $29 \%$ Para uma resistência do solo 5 e $30 \mathrm{~kg} \cdot \mathrm{cm}^{2}$, o alongamento da raiz de amendoim foi de 2,3 e 3,8 mm. $\vec{h}^{\mathbf{i}}$. respectivamente. 
TAYLOR \& GARDNER (1963) verificaram a

Influencia da densidade global, teor de umidade e resistencia do solo na penetração das raizes principais da planta de algodão. Os autores mostraram que existe uma relacão linear inversa altamente significativa entre percentagem de penetração da raiz e resistência do solo. Cerca de $70 \%$ das raizes principais penetraram em um solo cuja denstdade era de $10 \mathrm{~kg} \cdot \mathrm{cm}^{-2}$, mas somente $30 \%$ penetraram quando a resistencia toi de $20 \mathrm{~kg} \cdot \mathrm{cm}^{2}$.

\section{6 Custos e energia para descompactacão do solo}

As operacões de descompactação dos solos cultivados vem se tornando cada vez mais frequente, apesar dos custos e do dispêndio energético.

Segundo CHARLES (1984), entre 20 e $50 \%$ da energia transferida aos elementos de tração do trator é perdida. Esta energia não somente é perdida pelo rodado, mas também resulta em compactação. prejudicial à produtividade da cultura e que deverá ser corrigida também com dispêndio energético.

A subsolagem é uma prática de cultivo em profundidade que vem sendo utilizada com a finalidade de quebrar as camadas compactadas. Porém é uma operação de custo bastante elevado uma vez que exige elevado esforco 
tratorio à reiocidade de desiocamento relativamente baixa e pequena capacidade operacional. WOLF et al. (1981) trabalhando com quatro miveis de subsolagem concluíram que a profundidade teve um ếeito marcante na forca de tracăo e consequentemente na energia mecanlca requerida. A forca de tracăo por haste aumentou de $2,52 \mathrm{kN}$ para $6,20 \mathrm{kN}$ quando a profundidade aumentou de $0,28 \mathrm{~m}$ para $0,48 \mathrm{~m}$.

$$
\text { YOORHEES Et al. Il } 2 \text { LdOS por SOANE et ai. }
$$

619812 trabalhando em aracäo de um solo silte argiloso encontraram que a forca de tracáo aumentou em $92 \%$ como resuitado de uma compactaçăo pesada. A potencia requerida zumentou em grande proporcăo devido ao aumento da patinagem.

\section{Q.? Métodos para determinar a compactaçăo do solo}

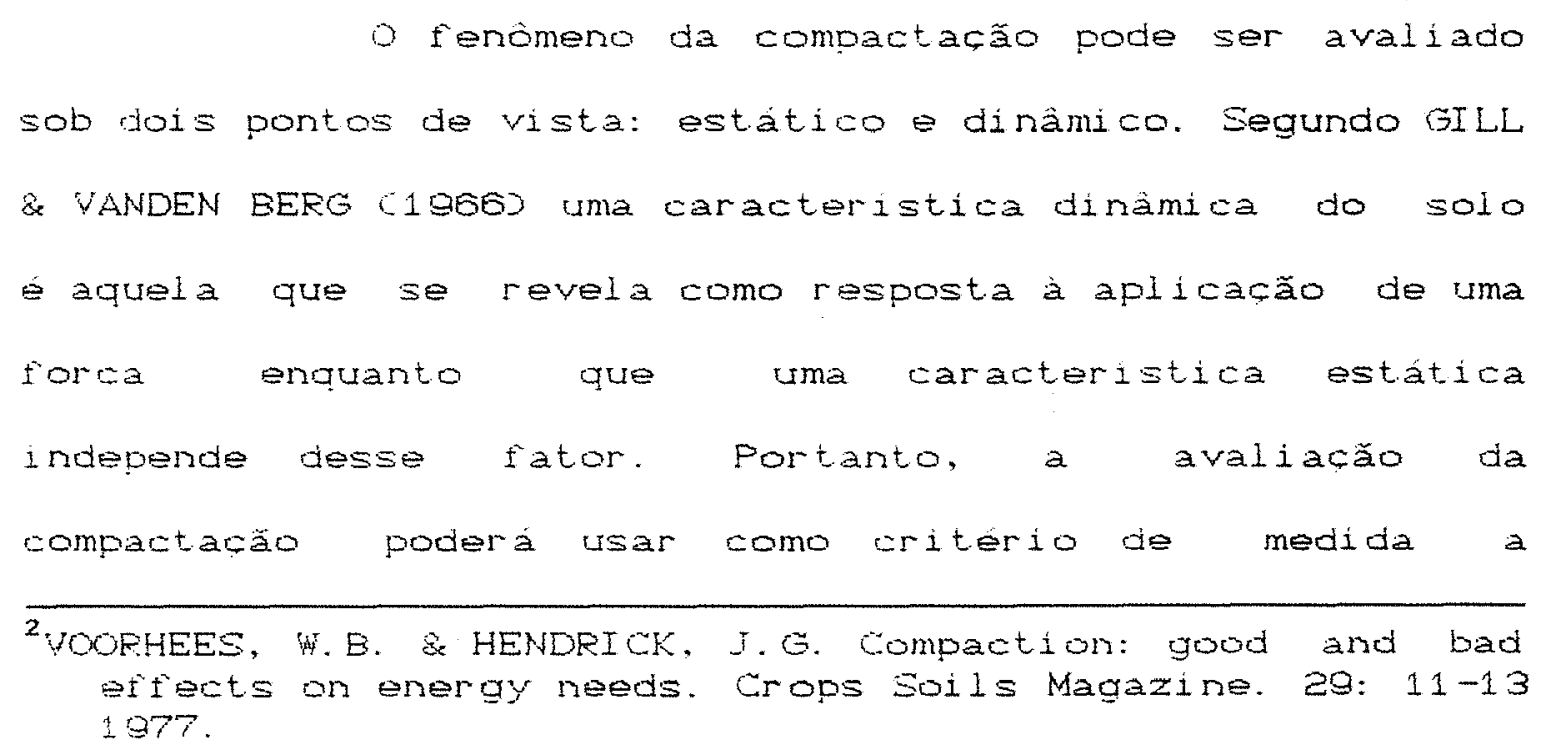


resistencia oferecida à penetracăo - como resposta à acăo de uma forca - ou, a relacăo entre massa e volume.

Segundo FREITAG 619713 ocorrem alteracốs

em très propriedades básicas do solo quando este e submetido a forfas de compactacăo: porosidade, distribuicáo e tamanho dos poros e textura. As mensuracóes das ateraços ocorridas nessas propriedades basicas são de grande valia no estudo da compactacăo e dos seus efeitos. O procedimento mais comum para obter cada uma dessas medidas é a determinação do volume e peso de uma amostra de solo. Outros métodos envolvem determinacão de : (a) condutividade para água, ar e radiação nuclear, (b) habilidade do solo em transmitir tensóes e Cc) a resistência do solo. Comenta ainda o autor que nenhuma dessas medidas podem ser aplicadas universalmente, e que cada uma tem suas vantagens e limitações.

O penetrômetro é um equipamento que indica a resistência do solo à penetraçăo de uma ponta cônica padrão. Ele representa um método simples, de determinaçóes relativamente rápidas e que podem ser feitas a consideráveis profundidades. Essa resistência é um parâmetro conhecido como indice de cone. A AMERICAN SOCIEIY OF AGRICULIURAL ENGINEERS (1987) especifica doIs padrões para a ponta cônica com ângulo de $30^{\circ}$, uma com diametros de base de 12,83 a outra com $20,27 \mathrm{~mm}$.

VOORHEES et al. (1978) estudando tráfego 
controlado em um solo barro limo argiloso, comparou as
técnicas da resistencia ao cone e densidade global
durante cinco anos. O autor considera que a resistência à
penetracăo é uma indicação mais sensivel da compactacão que
a densidade global. cita tambem que onde os valores de
densidade global tiveram um aumento de $20 \%$ ou menos devido
ao tráfego, os valores de resistencia ao penetrómetro aumentaram mais de $400 \%$

Um bom exempio de medidas relativas e dado por MCLEOD et al. (1966) no qual a largura e prof undidade de zonas compactadas de solo for am determinadas por várias intensidades de aplicacão de cargas. Neste caso a resistência ao penetrômetro também refletiram a relativa intensidade de pressăo de compactacăo aplicada.

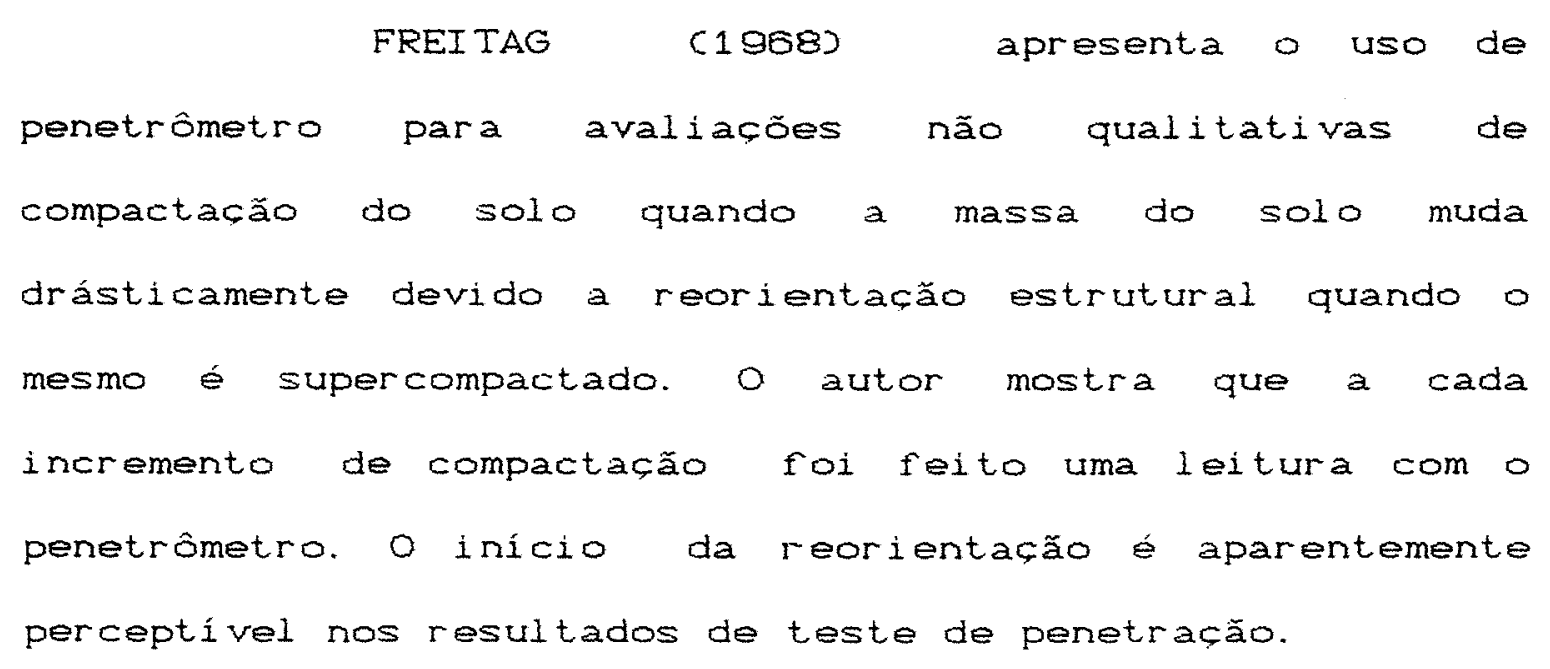




\section{MATERTAL E METODOS}

\subsection{Material}

\subsubsection{Tratores}

Como fonte de patinagem e compactação foi utilizado um trator Massey Ferguson modelo 275, devidamente instrumentado. Os pneus traseiros marca Pirelli com dimensöes 18.4 - 30, desenho de banda de rodagem $R 1$ e 10 lonas, foram inflados com pressão de $125 \mathrm{kpa}$.

Para simular as cargas na barra de tração foi utilizado um segundo trator, Massey Ferguson modelo 295 $4 \times 2$ TDA, acoplado ao primeiro trator por meio de um tirante de tração, com comprimento necessário para que o operador pudesse dirigílo segundo uma linha contida no plano médio vertical longitudinal do trator. 


\title{
3.1.2. Equi pamentos de mensuraçâo
}

\subsubsection{Mensuraçăo de força de traçáo}

\begin{abstract}
$\mathrm{Na}$ mensuração da força de tração fol utilizada uma célula de carga marca Alfa Instrumentos modelo $Q 10 T$ com capacidade máxima para $10 \mathrm{t}$. A célula de carga foi conectada elétricamente por um cabo ao indicador-registrador, marca Kratos modelo $\mathrm{Br} 103$. Este contém internamente um microprocessador, cuja programaçăo atraves de um teclado externo possibilita efetuar os comandos do indicador e da impressora, que, apresentam e registram respectivamente os valores da força de tração em kgf. A impressora ainda fornece a média dos valores obtidos durante cada determinação.

Os equipamentos de mensuração de força de tração săo al imentados com corrente al ternada e vol tagem de 110 v.. Para isso, foi acoplado na parte frontal do trator, local dos lastros, um motogerador de corrente alternada com capacidade de $2.500 \mathrm{w}$, marca Yanmar, modelo GMG 2500.
\end{abstract}




\title{
3.1.2. 2. Mensuracáo da patinagem
}

\begin{abstract}
Na mensuracăo da patinagem foi utilizado um equipamento, montado em uma caixa de aluminio anodizado, constituido de sete totalizadores eiétricos marca Veeder Rooter todos com visor em oristal liquido. A un dos totalizadores acoplou-se uma base de tempo transtormando-o em um cronometro elétrico. O acionamento dos totalizadores e do aronòmetro é feito simultaneamente atraves de interruptores, montados ra parte frontal da caixa e cuja finalidade e dar o inicio, parar e zerar os valores apresentados no visor.
\end{abstract}

Os totalizadores de pulsos recebiam sinais originados nas unidades geradoras de pulsos, constituidas de um suporte com engrenagem de 20 dentes e sensor indutivo marca Sense, que estavam acopladas às rodas de tracão do trator e a roda odométrica.

Toda vez que um dente passa defronte ao sensor, a consequente alteração do campo gerado nele emite um pulso que é indicado no visor do totalizador. o número de dentes da engrenagem determina o número de pulsos por volta.

A roda odométrica foi montada entre eixos do trator em um suporte que permitia que a mesma circulasse sobre o rasto deixado pela roda frontal. Ela tem por funcăo, como o própio nome indica, medir a distancia real 
percorrida pelo trator.

Consta de uma roda raiada com pneu ciclomotor ML $205,71 \times 43,2 \mathrm{~cm}$ inflado a pressão de $190,1 \mathrm{kpa} e$ permite um perímetro eficaz de $167 \mathrm{~cm}$. No cubo da roda, local da catraca, fol montado uma engrenagem de 20 dentes. A roda é fixada, através do seu eixo, no interior de uma estrutura em forma de "U" na qual encontra-se o sensor instalado em posição tal que a ponta sensora permaneca de topo para os dentes da engrenagem. A estrutura - fixada a um suporte preso ao trator por meio de mancals tubulares, vertical e horizontal permitindo que a roda tenha movimento livre nos dois planos.

$$
\text { No engate de três pontos fol montado um banco }
$$

para a pessoa que faz a anotação dos dados. Os equipamentos indicadores e registradores de forca, mais a caixa contendo os totalizadores e o cronómetro, foram afíixados a um suporte, montado sobre os paralamas, atrás do arco de segurança do operador. Montados dessa maneira, os equipamentos ficam voltados para a pessoa que faz as leituras.

- esquema da imposicăo de carga e a disposicão dos equipamentos instalados no trator são apresentados na Figura 1 . 


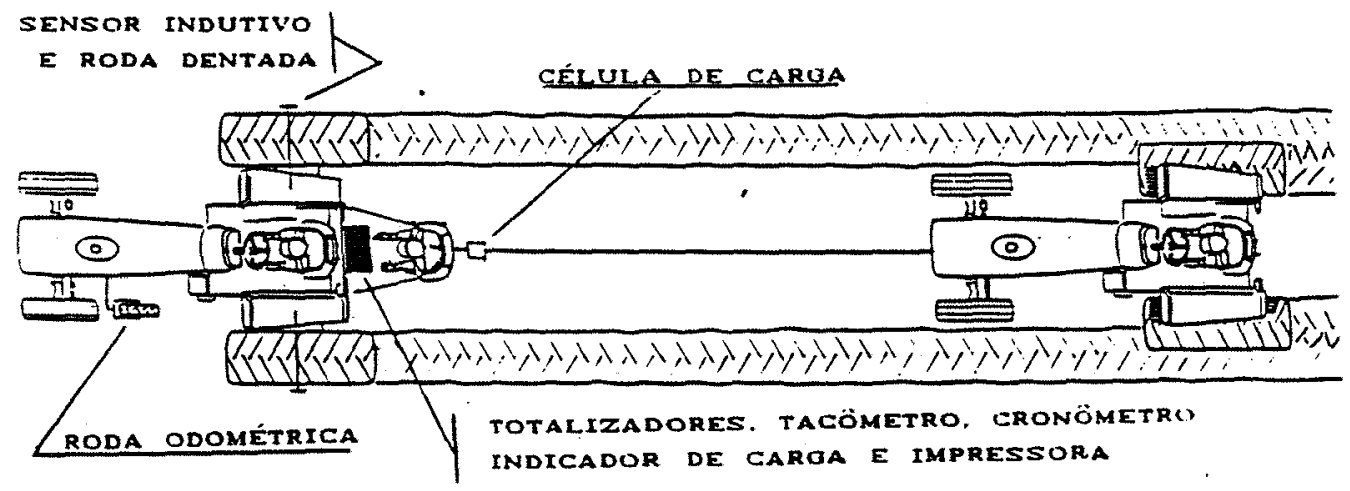

Figura 1. Esquema da disposicăo dos equipamentos instalados no trator

\title{
3.1.2.3 Resistência do solo à penetração
}

\begin{abstract}
Na mensuracão da resistencia do solo à penetração foi utilizado um penetrometro de anel marca Soloteste, referência S-210 equipado com relógio comparador marca Kafer com subdivisões de 0,001 mm. A calibracăo do penetrómetro é dada pela equacão:
\end{abstract}

$$
\begin{array}{r}
F=0.04018 \cdot d+0.3547 \\
r^{2}=0.9998
\end{array}
$$

onde

$$
\begin{aligned}
& F=\text { força aplicada no anel, } \mathrm{N} \\
& d=\text { deflexăo do ponteiro, } \mathrm{mm} \times 10^{-3}
\end{aligned}
$$


o equipamento utilizado possui haste com diâmetro de $15,9 \mathrm{~mm}$, base do cone com diâmetro de $20,27 \mathrm{~mm}$ e àngulo da ponta $30^{\circ}$ de acòrdo com especiticacão da AMERICAN SOCIETY OF AGRICULTURAL ENGINEERS 19873.

\subsubsection{Equipamentos para caracterizaça do solo}

\subsubsection{Densidade}

Para determinação da densidade global foram utilizados anéis volumétricos com $55,6 \mathrm{~mm}$ de diametro e volume de $100 \mathrm{~cm}^{3}$. recipientes de aluminio com tampa com capacidade de $180 \mathrm{~cm}^{3}$ para acondicionamento das amostras, martelo, castelo, enxadão, faca afiada para desbaste das amostras. No laboratório for am utilizados balanca marca Metler com precisão de $0,01 \mathrm{~g}$. , e estufa para secagem das amostras.

\subsubsection{Umidade}

Para retirada das amostras no campo foram utilizados: enxadão, vanga, recipientes de aluminio com tampa. No laboratorio for am utilizados os mesmos 
equipamentos citados no item anterior

\title{
3.1. 4 Campo de ensaio
}

O trabalho foi realizado nas dependências da Divisão de Engenharia Agricola, pertencente ao Instituto Agronomico de Campinas, situada no municipio de Jundiai,

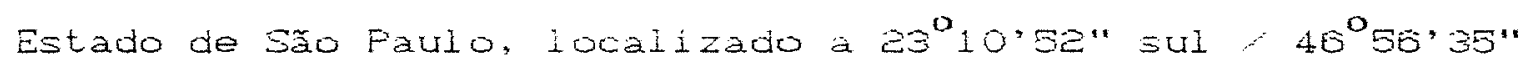
oeste, em area de aproximadamente 2 ha cparte interna da pista de ensaio de tratoress perfeitamente plana e em nivel. o solo onde realizou-se o trabalho é composto de $15 \%$ de argila, $35 \%$ de silte, $22 \%$ de areia fina e $28 \%$ de areia grossa o que caracteriza-o como um solo fRANCo de acordo com Servico de Conservacão de Solos do Departamento de Agricultura dos Estados Unidos conforme citado por OLIVEIRA (1992).

\begin{abstract}
Na ocasiäo do trabalho a cobertura regetal compunha-se de: capim carrapicho cenchrus echiratus $L$. picão preto Bidens pilosa L., tiririca Cyperus rotundusl., amor amarrado Desmodium carrum CGmel.) Sching et Theil, capim marmelada Brachiaria plantaginea (Link) Hitch, grama seda Cynodon dactylon (L.) Pers. grama batatais Paspalum notatum.
\end{abstract}

A Tabela Ae-1 do APENDICE 2 apresenta os valores médios de umidade e densidade das parcelas para 
cada tratamento, obtidos em tres profundidades 65,10 e 15 $c m$.

\subsubsection{Caracterizacáo da banda de rodagem}

Os equipamentos utilizados para caracterização da banda de rodagem dos pneus foram: trena em lâmina de aço com comprimento de $3 \mathrm{~m}$ marca starret, paquímetro marca Somet, transferidor marca Mytutoio e dispositivo medidor de altura de garras desenvolvido por MENEZES \& YANAI (1989).

o trator estava equipado com pneus traseiros marca Pirelii 18.4 - 30, com 10 lonas, construção diagonal. desenho de banda de rodagem $R 1$ com as seguintes dimensóes:
a) ângulo da garra $\ldots \ldots \ldots \ldots \ldots \ldots \ldots \ldots 5^{\circ}$
b) passo da garra ....................... 245. 0 mm
c) altura da garra ...................... $35.0 \mathrm{~mm}$
d) I argura da garra $\ldots \ldots \ldots \ldots \ldots \ldots \ldots \ldots .5 \mathrm{~mm}$
e) comprimento da garra .................. 300.0 mm
f) espaçamento da garra - perpendicular .......125. $0 \mathrm{~mm}$
g) espacamento da garra - ctrcunferencial....... 160.0 mm
O APENDICE 3 apresenta um diagrama da banda de rodagem com a localização das dimensốes aci ma citadas. 


\section{2 Método}

\subsubsection{Caracterizaçáo do pneu}

As caracteristicas de construcão de um pneumático tem marcante influência no seu desempenho.

Trabalhos de avaliação do desempenho de pneumáticos de tratores agricolas, segundo algumas caracteristicas de construção foram realizados por VASEY \& NAYLOR (1958), TAYLOR (1973 a), TAYLOR (1973 b), TAYLOR et al. (1976), BURT \& BAILEY (1982), respetivamente sobre: influência, ângul o e espacamento das garras; construção da carcaça (diagonal radial); pressão de inflaçáo e carga di nâmica sobre os pneus.

Como cada uma dessas caracteristicas mostrou diferente desempenho dos pneumáticos, procurou-se então caracterizar o pneu do trator utilizado no trabalho.

\subsubsection{Preparo da área do ensaio}

A área é totalmente plana e nivelada, e estava sem uso a pelo menos quatro anos. Apenas trator com rocadora circulou sobre a mesma para servico de 11 mpeza. Por 1sso, para tornar as condlcóes do solo as mais 
homogeneas possiveis, foram realizadas: uma aracăo, a mais ou menos $20 \mathrm{~cm}$ de profundidade, utilizando um arado com três discos de 26 polegadas e duas gradagens utilizando uma grade com 28 discos de 18 polegadas.

Realizou-se o ensalo sobre a área após um periodo de quatro meses de descanso da mesma.

\subsubsection{Avaliação da compactação}

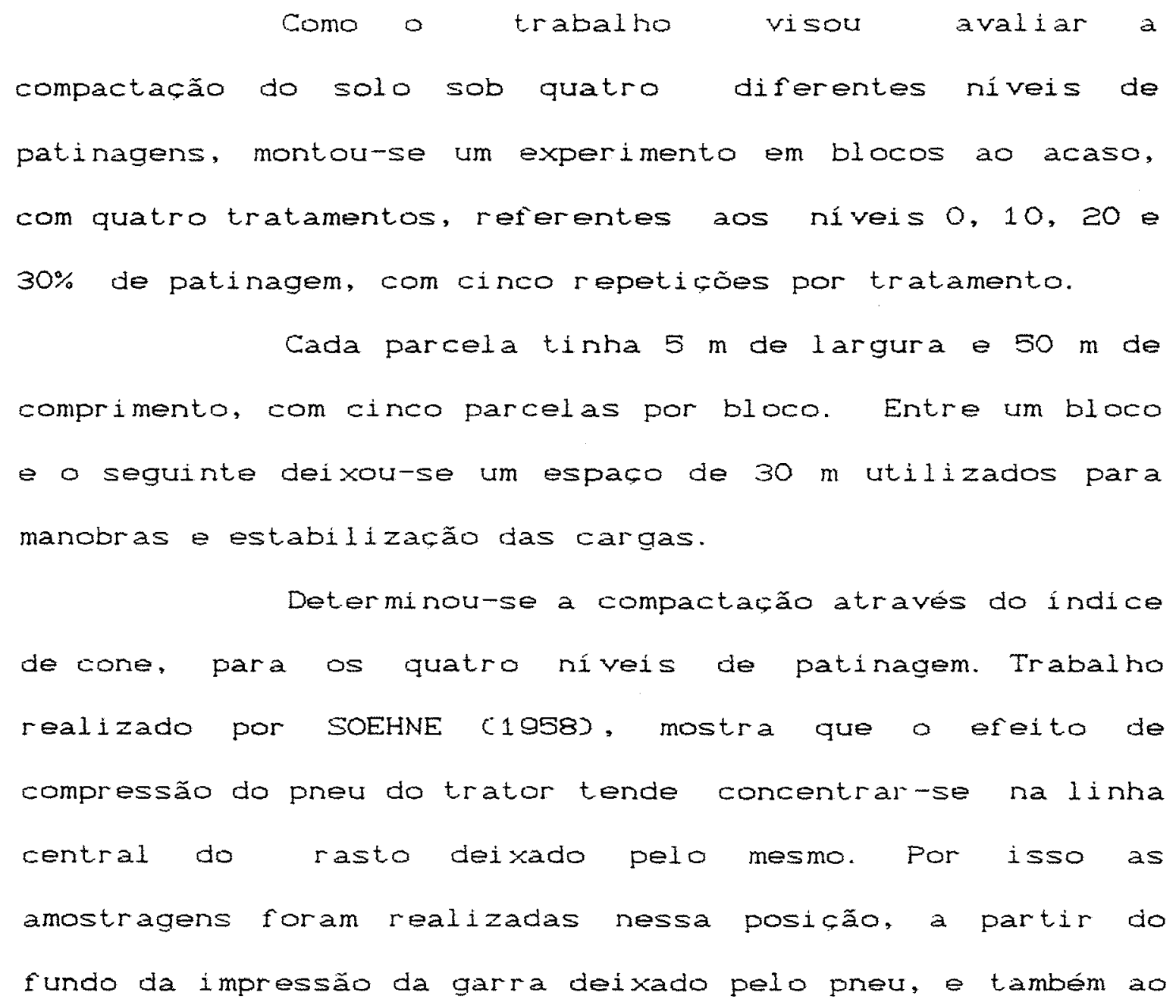


lado, afastado mais ou menos $0.8 \mathrm{~m}$ da 1 inha de centro do rasto do pneu, em terreno não compactado pela roda. Realizaram-se quinze amostragens em cada uma das posicóos. Fez-se para cada amostragem leituras de indice de cone a cada $2,5 \mathrm{~cm}$ de profundidade até $15 \mathrm{~cm}$. Comparou-se os valores do indice de cone obtidos no rasto do pneu com aqueles obtidos ao lado.

3.2. 4. Caracteristicas ponderais e dimensionais do trator

A pesagem foi feita com a finalidade de se saber qual a carga normal imposta ao solo pelo pneu traseiro. Pesou-se o trator, Ltilizando para isso os equipapamentos da Seção de Máquinas de Tracão e de Potencia composto de células de carga, indicadores digitais, plataformas de ferro e madeira e duas talhas manuais fixadas nos extremos de uma ponte rolante com capacidade para 196.000 N.

Determinou-se o peso total, e sobre os eixos traseiro e dianteiro.

o trator foi pesado nas condicões em que realizou os ensaios no campo, isto é, instrumentado, com dois operadores, lastros líquido e metálicos nas rodas traseiras, apresentando um peso total de $39.300 \mathrm{~N}$ sendo 
$10.738 \mathrm{~N}$ no eixo dianteiro e $28.568 \mathrm{~N}$ no eixo traseiro.

As dimensões de interesse dizem respeito somente a distancia entre eixos e altura da barra de tração em relaçăo do nivel do solo, que săo respectivamente 2.150 $\mathrm{mm} e 425 \mathrm{~mm}$.

\subsubsection{Bitola}

Com base no trabalho de DICKSON $(1980)^{3}$ citado por CLAVERIE et al.(199e) para evitar o efeito da pressão de contato da roda dianteira do trator na área trafegada pelo pneu traseiro em estudo, a bitola dianteira foi regulada para a posição minima, $1.420 \mathrm{~mm}$ enquanto a traseira foi regulada para a posição máxima $2.160 \mathrm{~mm}$.

\subsubsection{Barra de traçăo}

A barra de tração foi invertida e instalou-se um dispositivo, esquematizado na figura $e$, construído de chapa de aco SAE 1020 com $101,6 \mathrm{~mm}$ de 1 argura e 12, $7 \mathrm{~mm}$ de espessura, que fol acoplado no ponto de fixação da barra de tração ao trator juntamente com ela. Dessa maneira o ponto de engate da barra de tração passou a situar-se a $100 \mathrm{~mm}$

DICKSON, J.W. The relative compaction effects of a tractor front andrear wheel on asandy loam. Scot. Inst. Agric. Eng. Dept. note sin/es1, 9 p. 1988. 
do plano vertical que passa pelo centro do eixo traseiro.

Se o trator utilizado tivesse sido operado com a barra de tração na altura normal, à medida que fossem sendo impostas as cargas na barra de traçăo para conseguir as patinagens desejadas, maiores transferencias de peso também iriam ocorrer, o que poderia afetar os resultados ficando a dúvida se a compactaçăo teria sido devido a patinagem ou a uma maior pressão do pneu sobre o solo.

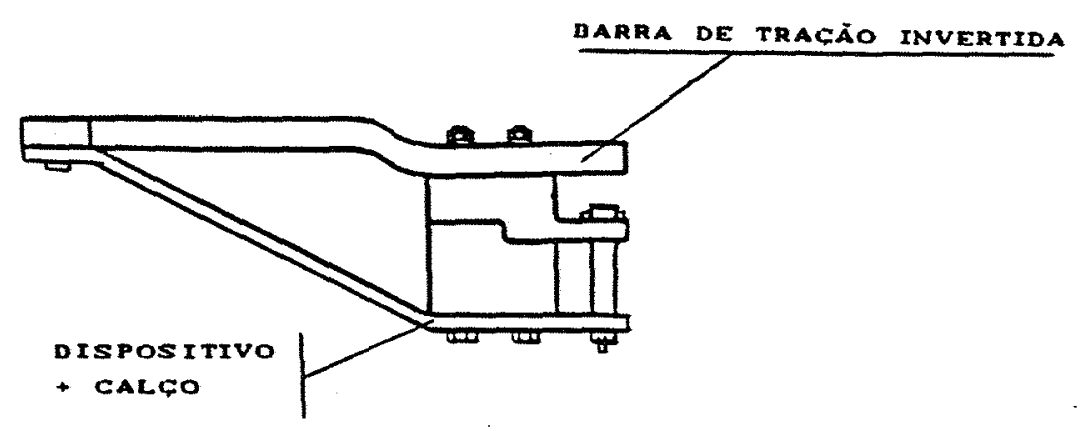

Figura 2. Esquema da barra invertida e dispositivo, com finalidade de diminuir altura de engate à barra 
3.2.7. Ensaios preliminares

3.2.7.1 Determinaçao das cargas para obtençáo dos ni veis de patinagem

\begin{abstract}
Para determinar os valores de forca a serem aplicados à barra de tracăo durante o ensaio, afim de proporcionar a patinagem desejada, realizou-se um trabalho preliminar em terreno localizado junto ao campo experimental. Nesse trabalho o trator que estava a reboque impos carga crescentes ao trator submetido ao ensaio. Para cada carga calculou-se a patinagem correspondente.

Com os dados obtidos determinou-se a equaçáo da patinagem em função da força de tração, cujo gráfico é apresentado na Figura 3. A partir desse gráfico foram estabelecidas as cargas aplicadas à barra de traçăo do trator, durante os ensaios definitivos, para obter os niveis definidos de patinagem em cada tratamento, com uma toleräncia de mais ou menos $1 \%$ no máximo, em torno do valor nomi nal.
\end{abstract}




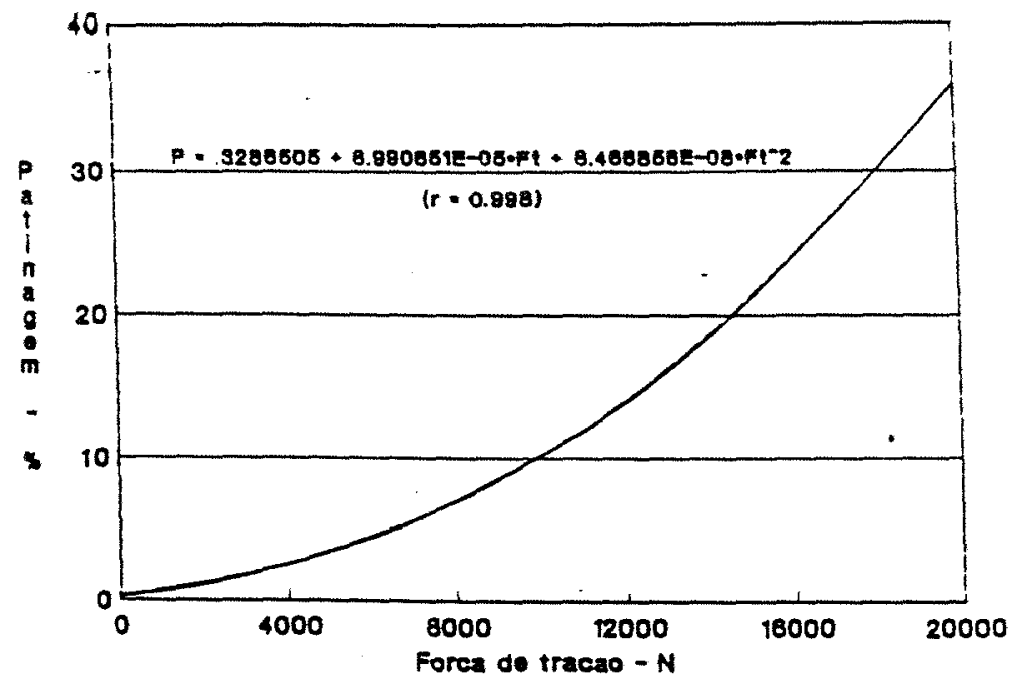

Figura 3. Relação patinagem - força de tração determínada preli mi narmente

Fez-se o cálculo da patinagem, utilizando a

equação:

$$
P=\frac{N_{T} \circ P E_{T}-N_{0} \circ P E_{O}}{N_{T} P E_{T}} \cdot 100
$$

onde:

$$
\begin{aligned}
& P=\text { patinagem, } \% \\
& N_{\mathbf{T}}=\text { número de giros da roda motriz com carga } \\
& N_{0}=\text { número de giros da roda odométrica } \\
& P E_{T}=\text { perímetro eficaz da roda motriz, cm } \\
& P E_{0}=\text { perimetro eficaz da roda odométrica, cm }
\end{aligned}
$$

Perimetro eficaz é o perimetro de uma roda equivalente à distância por ela percorrida em uma volta completa, com patinagem presumível igual a zero. 
motriz do trator e da roda odometrica, foram realizadas em pista de concreto, e considerada como condicäo zero a definida pela AMERIGAN SOCIETY OF AGRICULTURAL ENGINEERS (1986). Para isso o trator locomoveu-se jobre a pista. a velocidade de $e$ km/h: demarcaram-se os espacos percorridos por cinco voltas das rodas motriz 10 voltas da roda odométrica. Dividindo-se as distâncias pelo número de voltas respectivas de cada uma das rodas, obteve-se o perimetro eficaz das mesmas.

3.2.7.2 Avaliacáo da variacáo da área de contato do prieu

O interesse em determinar a área de contato, foi o de estimar qual a alteracão na pressão média nominal de contato, causada pela transferencia de peso decorrente do aumento da forca na barra de tracão, necessário à obtenção dos vários niveis de patinagens.

Nessa estimativa admitiu-se a área nominal de

contato pneu-solo plana e distribuicão uniforme de pressão, critérios julgados satisfatorios tendo em vista que o objetivo é apenas verificar, de forma comparativa, a provável variação na pressão média nominal.

A área de contato do pneu foi determinada em uma superfície rigida e em condicão estática, de acôrdo com metodologia utilizada por PLACKETI (1984), para varias 
cargas aplicadas sobre o pneu . A primeira carga, considerada foi aquela para qual o trator trấegou livre, sem estorco algum na barra de traçăo. Nessa condicâo admitiu-se que a tranferencia de peso devido a forca para vencer a resistència ao rolamento seja zero, então a carga aplicada seria a propria carga estatica. As cargas seguintes foram equivalentes às cargas dinàmicas, correspondentes a cada força aplicada na barra de tracão para obtencăo dos niveis de patinagem esperados, calculadas para trator $4 x \mathrm{e}$, sequndo MCKIBBEN (19e8) pela equação:

$$
w_{d}=w_{e}+\frac{y}{x} F_{t}
$$

onde:

$$
\begin{aligned}
& W_{d}=\text { carga dinámica sobre a rodado propulsor, N } \\
& W_{\theta}=\text { carga estatica sobre a rodado propulsor, } N \\
& y=\text { altura da barra de tração, mm } \\
& x=\text { distância entre eixos do trator, } \mathrm{mm} \\
& \mathrm{F}_{t}=\text { forca de tração na barra, } \mathrm{N}
\end{aligned}
$$

No APENDICE 4 são apresentados os valores das cargas aplicadas sobre os pneus e as respectivas áreas de contato.

Os valores das áreas de contato e as
correspondentes cargas aplicadas permitiram elaborar com o


auxilio do programa AJUST desenvolvido por Jurandir Zullo Junior CEPAGRI/UNICAMP e Flávio Bussmeyer Arruda SID/IAC, a equacão apresentada a seguir, que exprime essa relação, representada no gráfico da Fig. 4.

$$
\begin{gathered}
S_{c}=-a+b \cdot W d+c \circ w d^{2} \\
r=1.000
\end{gathered}
$$

onde:

$$
\begin{aligned}
& a=-3659.266 \\
& b=0.5727361 \\
& c=-1.650669 \mathrm{E}-05 \\
& S=\text { Area de contato de um pneu, } \mathrm{cm}^{2} \\
& w_{d}=\text { Carga dinâmica sobre o rodado propulsor, N }
\end{aligned}
$$

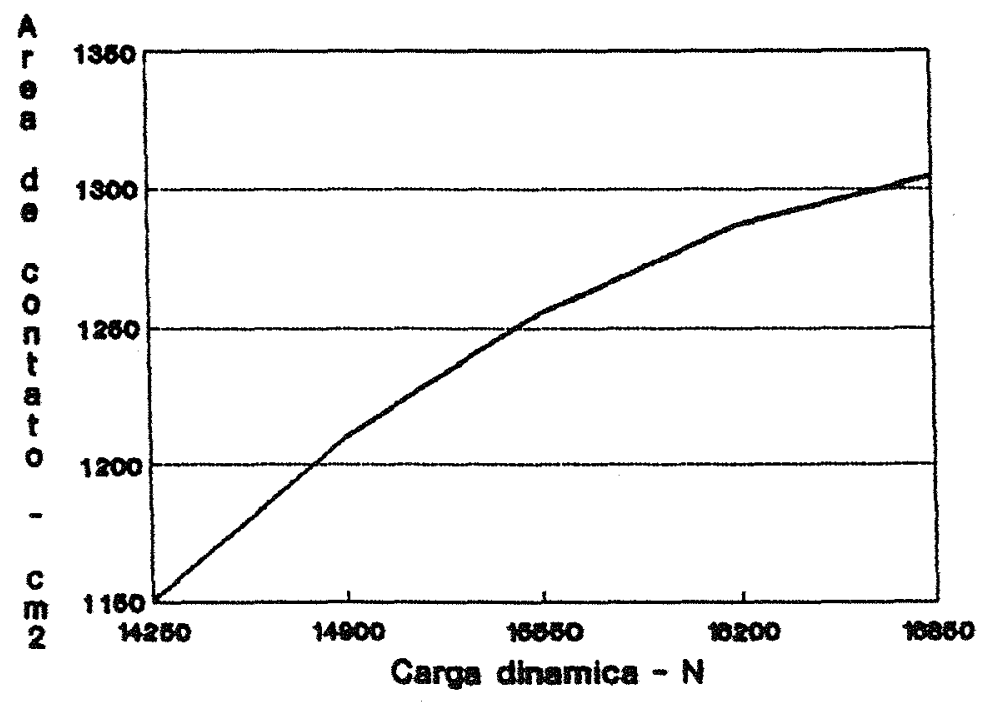

Figura 4 Representação gráfica da equação da área de contato em função da carga dinâmica sobre os pneus 


\title{
3. 2.8 Método de ensaio de campo
}

\begin{abstract}
As parcelas, no campo, for am dispostas em blocos ao acaso. Demarcou-se com letras de "A" até "D" representando respectivamente $0,10,20$ e $30 \%$ de patinagem, com indices de 1 a 5 , representando as repetiços.

Os trabalhos iniciaram-se pela parcela A $_{1}$ Cpatinagem zeros, com o trator operando em 4 marcha, que permite manter a mesma velocidade angular do motor mesmo com cargas erescentes, máxima aceleracão, e com bloqueio de diferencial acionado.
\end{abstract}

Após o trator ter trafegado sobre a parcela realizou-se as determinações de indice de cone, em quinze pontos na linha de centro do rasto deixado pelo pneu da roda motriz e mais quinze ao lado, conforme esquema na Figura 5. A cada determinação fez-se leituras para seis prof undi dades.

Para determinacăo da umidade do solo, em cada parcela retirou-se amostra de solo em três profundidades: $\quad 0-5, \quad 5-10$ e $10-15 \mathrm{~cm}$ com três repeticóes ao longo da parcela, a intervalos regulares.

A determinação da densidade também foi realizada em três profundidades e com três repetiçóes utilizando anel volumét.rico com volume de $100 \mathrm{~cm}^{3}$.

No caso dos tratamentos $B, C$ e a patinagem 
foi induzida por intermédio de um segundo trator que impunha cargas crescentes previamente estabelecidas as quais produziam as patinagens esperadas.

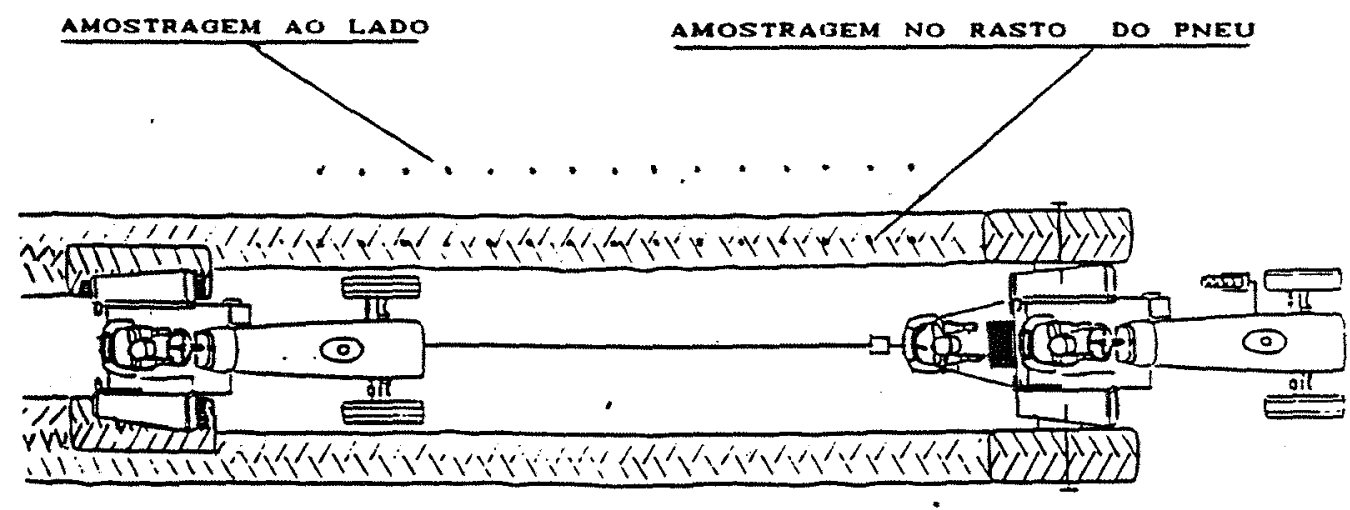

Figura 5. Esquema das amostragens dos valores de índice de cone em uma parcela.

3.2. 9 Análise estatistica

- delineamento experimental adotado foi o de blocos ao acaso em parcelas subdivididas, com cinco repeticões. Os niveis de patinagens constituiram as parcelas e nas subparcelas foram colocadas as 
prof undidades.

Foram executadas tres series de analise de variância e nos casos de significância ao nivel de $5 \%$ do teste "F" efetuou-se a comparacão multipia das medias através do teste de Tukey, ao nivel de $5 \%$ de probabilidade, utilizando o programa estatistico SANEST desenvolvido por ZONTA $P$ MACHADO (1990)

A primeira serie de análise de variância realizou-se com os dados médios de indice de cone de cada tratamento obtidos ao lado do rasto do pneu, para cada profundidade e para cada parcela. Objetivou-se com isso verificar a condicão inicial do perfil do solo, partindo-se do pressuposto de que, sendo o terreno homogêneo, ela representa a condicäo antes da passagem do pneu.

A segunda série de analise de variância tól realizada com os dados médios de indice de cone de cada tratamento obtidos na linha de centro do rasto do pneu, para cada profundidade e tratamento. o objetivo foi verificar a influência de cada nivel de patinagem na compactação do solo, nas várias prof undidades estudadas.

Essas análises foram efetuadas a partir de um arquivo com os dados médios de cada parcela, para as duas condiç̃es. Conforme se denota pelo APENDICE 5 , no arquivo săo considerados quatro fatores, a saber:

- Fator A : compactacáoj com dois niveis, o primeiro 
denominado SEM representa os valores de indice de cone obtidos ao lado do rasto do pneu, o segundo denominado COM representa os valores obtidos no rasto do pneu.

- Fator B : Cpatinagem com quatro niveis, 0, 10, 20 e 30\%;

- Fator C: Cprofundidades com seis niveis, 2,5, 5,0,7,5, $10,0,12.5,15,0 \mathrm{~cm}$

- Fator D : Cblocosa composto pelas repeticóes.

A terceira serie de análise de variancia foi aplicada nas médias das diferencas entre os valores de indice de cone obtidos na linha de centro do pneu e ao lado, para cada tratamento e para cada profundidade, nas cinco repeticóes. Essa análise, efetuada sobre os dados líquidos de indice de cone, constitui-se numa maneira de avaliar o efeito compactante da patinagem, de forma independente do nivel inicial de compactação do solo.

Montou-se para isso um segundo arquivo apresentado no APENDICE $\sigma$, onde o fator A é composto pelos niveis de patinagens e o fator $B$ pelos niveis de prof undidades. 


\title{
4. RESULTADOS E DISCUSSÃO
}

\subsection{Força de traçåo e patinagem}

\begin{abstract}
A Tabela 1 apresenta os dados de forca imposta à barra de tração e os respectivos valores das patinagens, obtidas em cada parcela. Os valores de força de tração dentro de cada bloco podem ser considerados homogêneos, em função do baixo coeficiente de variação. O mesmo ocorre com a patinagem, permanecendo dentro da tolerância de mais ou menos $1 \%$ do valor nominal de cada nivel, conforme previsto no subtitulo 3.2 .7 .1$.
\end{abstract}

4. Z Área de contato e pressáo média sobre o solo

A Tabela A7-1 do APENDICE 7 apresenta os
valores de forca de tracão, para cada tratamento,
determinados durante o ensaio e que permitiram atraves das
Equaçóes 2 e 3 estimar as cargas dinâmicas e as respectivas
areas de contato e com isso calcular a pressão medias sobre


o solo. Esses valores permitiram elaborar os gráficos da Fig. 6.

Tabela 1. Valores de forca de tração e patinagem de cada parcela, obtidos durante o trabalho

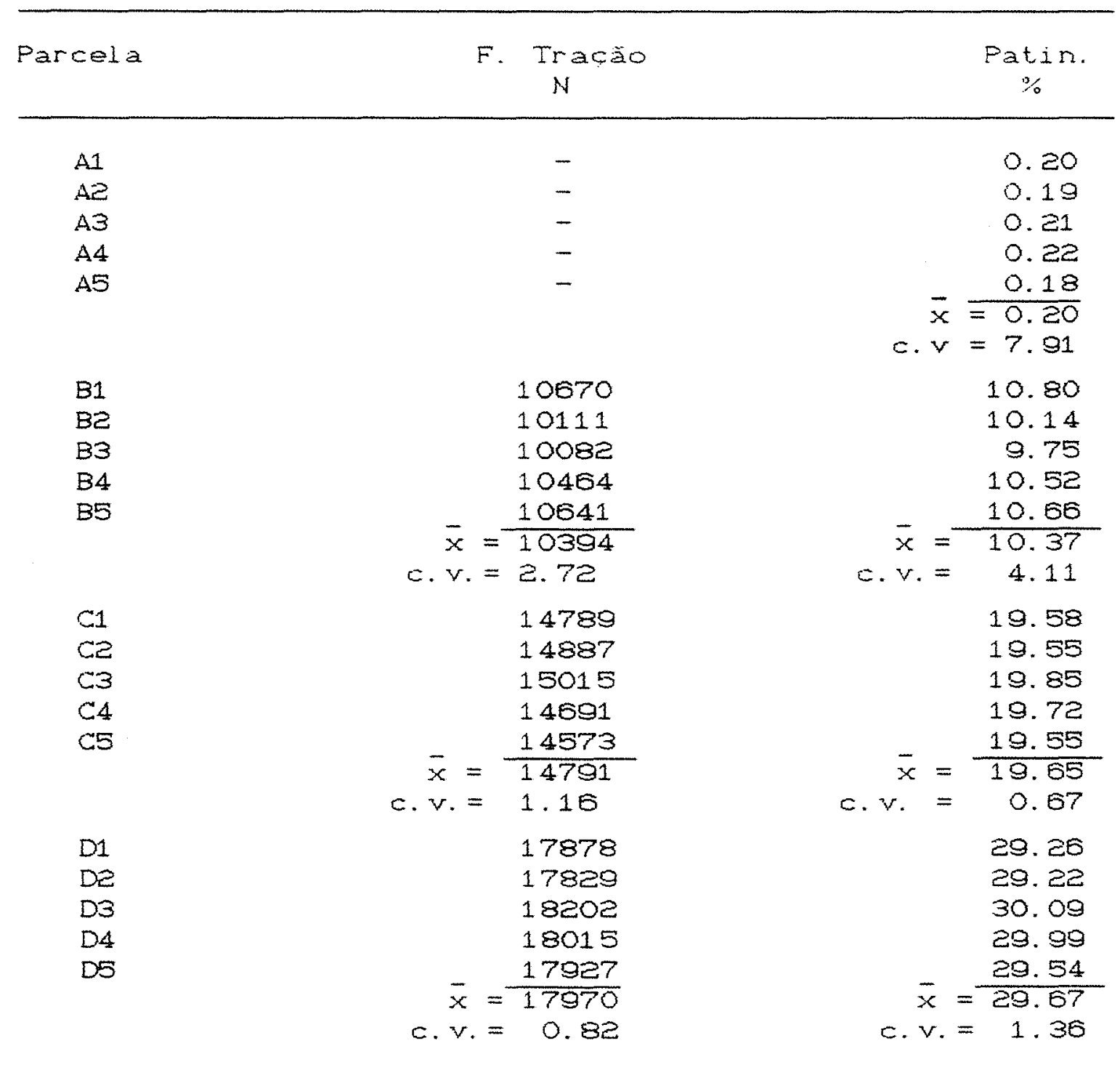



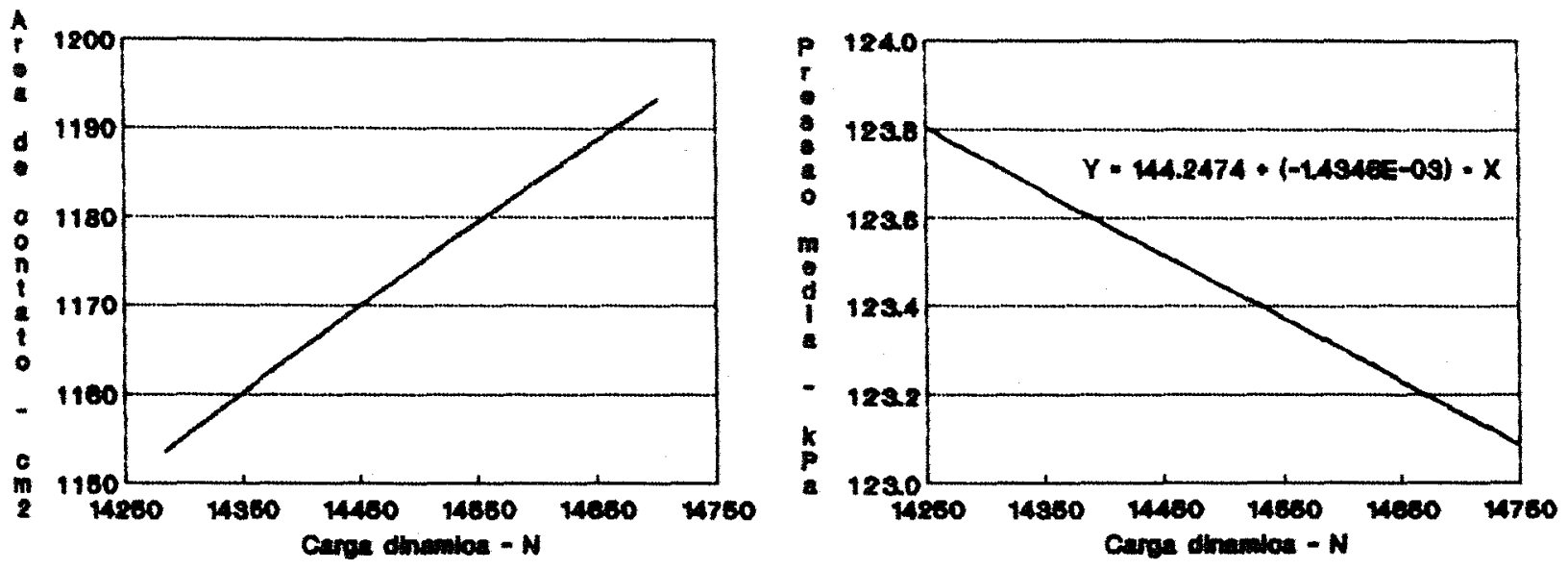

Figura 6 - Area de contato e pressão média em função da carga dinâmica, estimadas a partir dos valores das forças de tração na barra, para cada tratamento

Conforme denota-se a área de contato para a faixa de carga dinâmica aplicada aumenta proporcionalmente com o aumento desta. No entanto, observa-se que a pressão média diminui em função do aumento da área de contato. Dessa maneira, pode-se considerar que será desprezível o possível acréscimo de efeito compactante decorrente da ação de acréscimo na pressão exercida pelo pneu, face a transferência de peso. Assim, é de se esperar que as diferencas de compactação que se encontrar entre os tratamentos serão devidas tão somente aos diferentes níveis de patinagens. 


\section{3 Valores de Indice de cone}

As Tabelas A8-1 ate A8-es, do APENDICE 8
apresentam os valores de indice de cone, para cada
parcela, determinados na i inha de centro do rasto da roda
de tracão e ao lado da passagem da roda, para seis
profundidades, em quinze repeticóes.

Os resultados médios de indice de cone das

parcelas referentes a cada tratamento, em funcão da profundidade, permitiram traçar as curvas mostradas no gráfico da Figura 7. Observa-se que os pontos correspondentes à condição II C mensurações realizadas ao lado do rasto do pnew apresentam tendencias uniforme de incremento de índice de cone com a profundidade.

Para a condicão I C mensurações realizadas na Iinha de centro do rasto do pneu $>$ parece haver diferencas entre tratamentos, de acordo com a profundidade.

Observa-se para o tratamento A Cpatinagem zeros na qual o trator apenas deslocou-se sobre o terreno sem nenhum esforço de tração, que os valores de indice de cone mantiveram-se praticamente constantes desde a superficie até a profundidade de $15 \mathrm{~cm}$.

Para o tratamento B (10\% de patinagem parece haver um efeito compactante maior até a prof undidade de 7,5 cm, após o qual iguala-se ao efeito do tratamento A. Os tratamentos $C \Leftrightarrow D$ foram os que apresentaram maior efeito 
compactante" inicial, todavia igualando-se ao tratamento A na profundidade de $12.5 \mathrm{~cm}$.

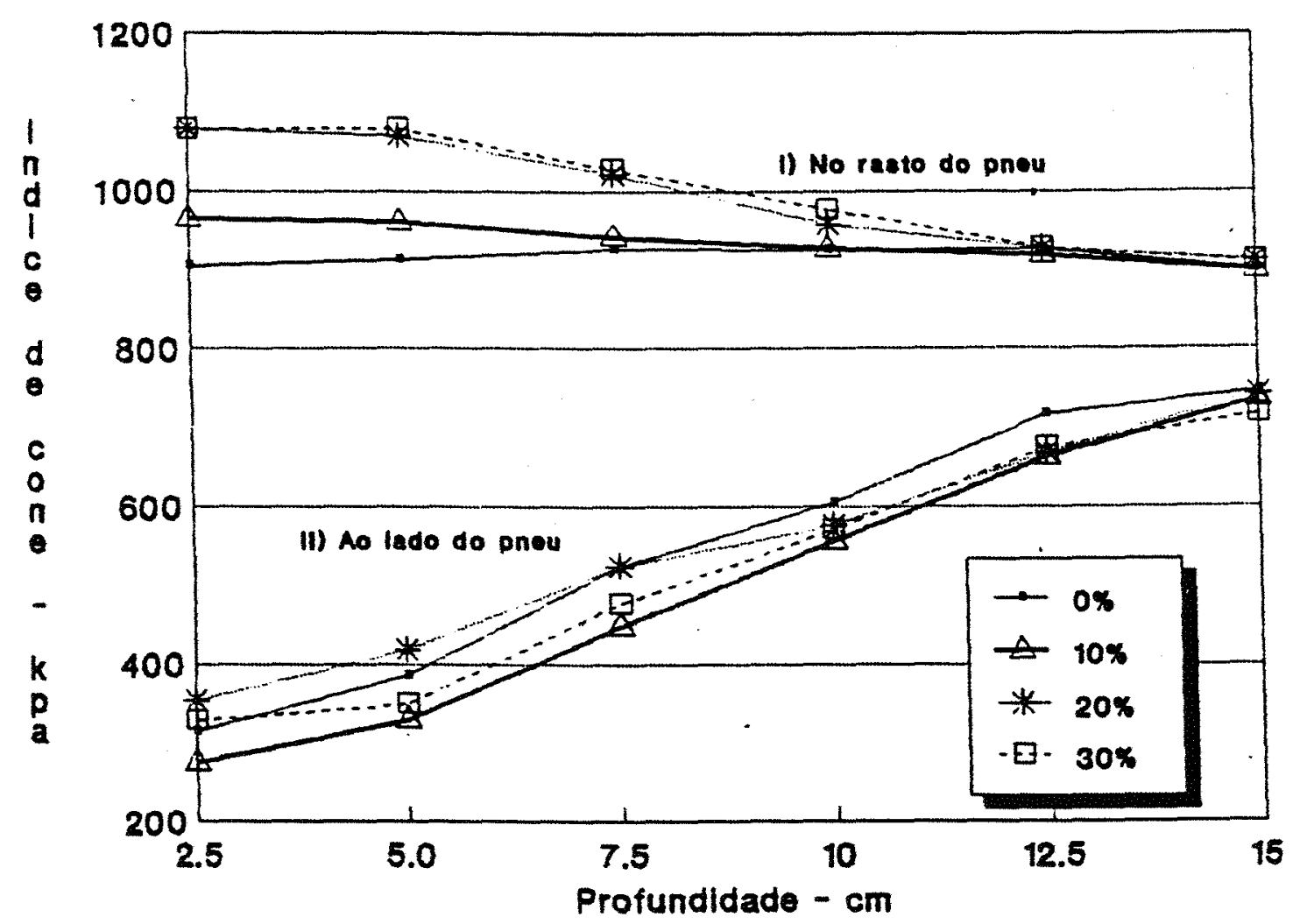

Figura 7. Variações nos valores médios de indice de cone em função da profundidade, para os diferentes niveis de patinagem, no rasto do preu e ao 1 ado

No gráfico da Figura 8, são mostradas as Iinhas que representam as diferencas, para cada tratamento, entre os valores médios de indice de cone, obtidos na linha 
de centro do rasto do pneu e ao lado, nas diversas prof undi dades.

Dessa maneira, pode-se observar a contribuicão de cada tratamento no efeito compactante, uma vez que a compactação inicial do solo foi colocada no mesmo nivel de referência. Tomando-se a média das diferenças de indice de cone, para cada tratamento, ao longo de toda profundidade e comparando-as com o tratamento A Cpatinagem O\% verificam-se aumentos nos valores do indice de cone de $16.7 \%$ para o tratamento B, $20.5 \%$ para o tratamento C e $29.0 \%$ para o tratamento D.

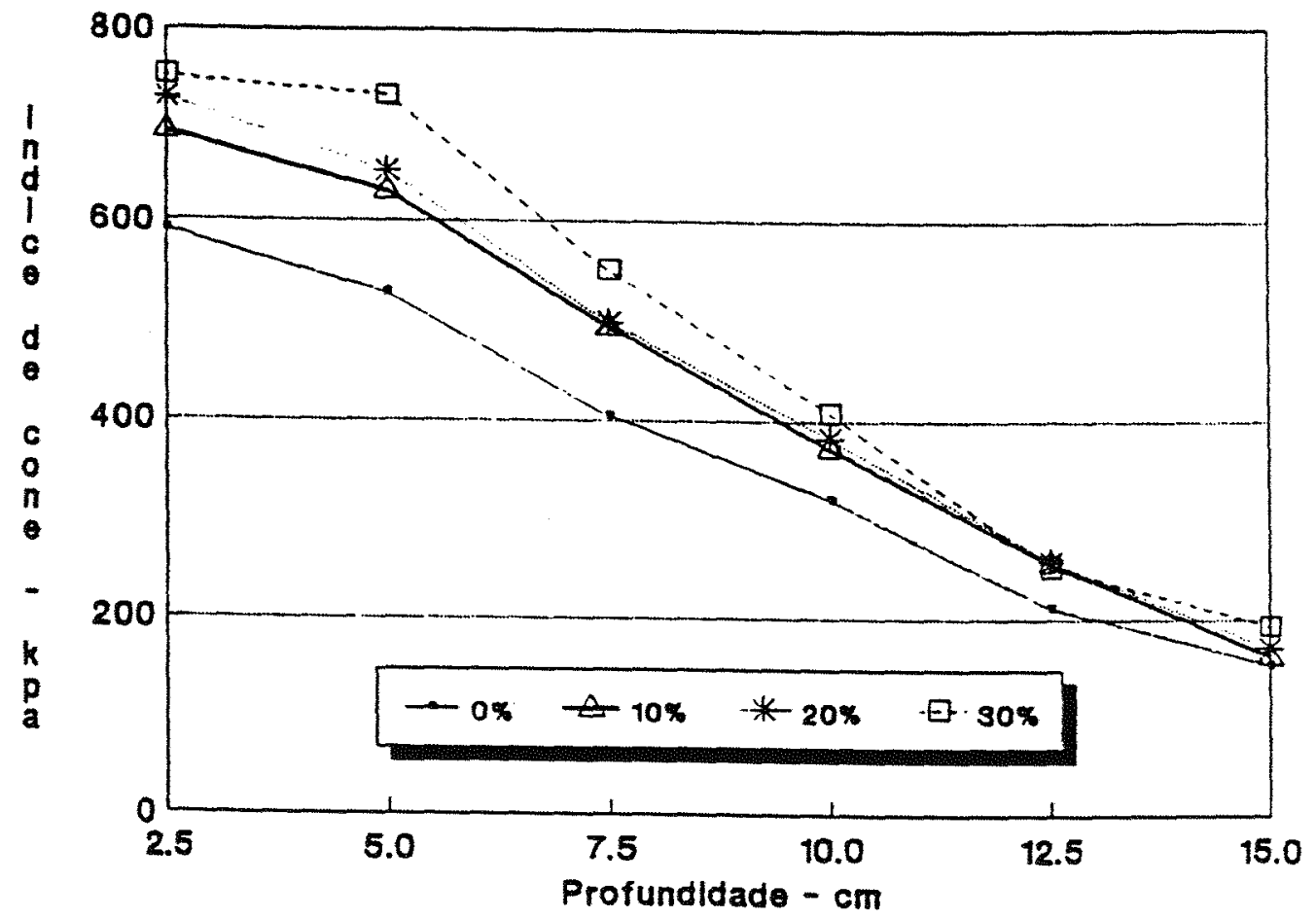

Figura 8. Médias das diferenças de indice de cone obtidos no rasto do pneu e ao 1 ado. 


\begin{abstract}
Esses resultados acham-se em concordância com os trabalhos de RAGHAVAN et. al (1977), uma vez que para uma mesma pressăo normal o cisalhamento devido a patinagem, promoveu uma maior compactação.
\end{abstract}

\title{
4. 4 Análise estatistica dos dados
}

Na análise estatistica dos dados obtidos
levou-se em conta tres enfoques, conforme descrito anteriormente no subtitulo 3.2.9. o primeiro enfoque analisa os dados relativos às determinaçóes do indice de cone efetuados ao lado do rasto da roda do trator, enquanto - segundo abrange os dados levantados diretamente sobre o rasto, ambos considerando os dados primártos, como obtidos "In situ". Sob o terceiro enfoque, é feita análise dos dados Iiquidos do índice de cone.

\section{4.1 Analise estatistica dos dados obtidos ao lado do rasto do pneu}

Utilizando os dados do arquivo constante do APENDICE 5, realizou-se a análise de variância fixando-se - nivel SEM do fator compactacão. O resultado consta da Tabela 2 , onde veriflca-se, que para a causa de vartacao 
"Patinag" (Fator B) não apresentou diferença significativa ao nivel de 5\% entre os tratamentos, isto é, as médilas de indice de cone referentes às parcelas de cada tratamento não diferiram estatísticamente. Isto está sugerindo uma uniformidade do estado de resistencia do solo à penetracáo. em todas as parcelas.

Para a causa de variação "Profund" (Fator CD as diferenças apresentaram-se significativas ao nível de $5 \%$ Para a comparacão múltipla das médias de todos os tratamentos em cada profundidade, utilizou-se do teste de Tukey, cujos valores encontram-se no APENDTCE 9.

Tabela 2. Análise de variancia fixando o nível SEM do fator A C compactação ?

\begin{tabular}{|c|c|c|c|c|}
\hline C. Varia. & G. L. & S. Q. & Q.M. & Valor $F$ \\
\hline Blocos & 4 & 424413.6997080 & & \\
\hline Patinag. & 3 & 46725.2758531 & 15575.09195 & 0.2044 \\
\hline Residuo (B) & 12 & 914377.5991994 & 76198.13326 & \\
\hline Subparcel as & 19 & 1385516.5747585 & & \\
\hline Prof und. . & 5 & 2778580.5115783 & 555716.12231 & $56.3486 *$ \\
\hline Pat $*$ Prof & 15 & 30714.4579510 & 2047.63053 & 0.2076 \\
\hline ResiduocCo & 80 & 788968.8963564 & 9862.11120 & \\
\hline Total & 119 & 4983780.5406442 & & \\
\hline
\end{tabular}

Média Geral $=529.195010 \mathrm{kpa}$

Coeftciente de Vartação $(A)=21.295 \%$

Coeficiente de Variação $(B)=18.766 \%$

(*) signiflcativo ao nivel de $5 \%$ de probabilidade 


\begin{abstract}
Observando-se as médias de profundidade. verifica-se um aumento de indice de cone com o aumento da profundidade. Nota-se que não ocorre diferença significativa entre as proíndidades 2,5 e 5.0,7,5e $10,0,12,5$ e $15,0 \mathrm{~cm}$, indicando que o efeito é sensivel para intervalos iguais ou superior a $5 \mathrm{~cm}$ na profundidade.

Assim observa-se que, em funcao do preparo da área conforme descrito no subtitulo 3.2 .2 , houve um natural efeito adensador em profundidade nesse tipo de solo.
\end{abstract}

\title{
4.4. 2 Análise estatistica dos dados obtidos no rasto do pneu
}

\begin{abstract}
A Tabela 3 apresenta os resultados da análise de variância dos dados do arquivo constante no APENDICE 5 , fixando-se o nível CoM Cdados obtidos na linha de centro rasto do preul do fator compactação.

Felos valores do teste "F" observa-se que não houve diferenca significativa entre as médias de indice de cone dos tratamentos $@$ da interaça patinagem versus profundidade. No entanto, os tratamentos diferiram entre si com relação a profundidade, com significância ao nivel de $5 \%$ de probabilidade.
\end{abstract}


Tabela 3. Análise de variancia fixando o nível CoM do fator compactação

\begin{tabular}{|c|c|c|c|c|}
\hline c. Varia. & G. L. & S. Q. & Q.M. & Valor $F$ \\
\hline Blacos & 4 & 918984.8494327 & & \\
\hline Patinag. & 3 & 161489.1479838 & 53829.71598 & 1.1008 \\
\hline Residuo (B) & 12 & 586825.9046494 & 48902.158720 & \\
\hline Subparcelas & 19 & 1667299.9020659 & & \\
\hline Prof und. & 5 & 180208.8673151 & 36041.77346 & 5. $4605 x$ \\
\hline Pat *Prof & 15 & 104621.6592311 & 6974.77728 & 1.0567 \\
\hline Rest duo(C) & 80 & 529036.7438853 & 6600.45929 & \\
\hline Total & 119 & 2480167.1724972 & & \\
\hline
\end{tabular}

Médi a Geral $=961.373350$

Coeficiente de Variação $(A)=9.391 \%$

Coeficlente de $\operatorname{Variação~}(B)=8.451 \%$

(*) significativo ao nível de $5 \%$ de probabilidade

No APENDICE 10 são apresentadas os valores referentes aos testes de Tukey para as médias de patinagens. Verifica-se que as diferenças entre as médias para os tratamentos 0 e $10 \%$ não são significativas, ocorrendo o mesmo entre as médias do tratamentos 20 30\%. No entanto, os dois grupos diferem entre si.

No mesmo apéndice são apresentados as tabel as de valores do teste de Tukey para as médias de patinagens dentro dos seis niveis do fator profundidade. Nota-se que para as profundidades de 2,5 e $5 \mathrm{~cm}$ ocorrem diferenças significativas para patinagem acima de 20\%. Patinagem ao 
nivel de $10 \%$ provocou um incremento no indice de cone que estatisticamente, năo difere dos demais niveis.

Ou seja, até $5,0 \mathrm{~cm}$ de profundidade só fol significativo o efeito compactante da patinagem no contraste entre os niveis de $0 \%$ e $20-30 \%$ de patinagens. Para os demais níveis de profundidades, não observou-se efeito compactante da patinagem. Alnda nesse mesmo apêndice são apresentadas os valores do teste de Tukey efetuado para as médias de profundidade, verificando-se um aumento do indice de cone para as camadas mais próximas da superfície. Observa-se também que os valores médios obtidos nas profundidades 2,5 e $5.0 \mathrm{~cm}$ diferem significativamente daquela encontrada na profundidade 12.5 e $15.0 \mathrm{~cm}$.

Também săo apresentados nesse apêndice os valores de teste de Tukey das médias de profundidade dentro de cada nivel do fator patinagem. Verifica-se que não ocorreram diferencas entre os níveis de profundidade para o tratamento $0 \%$ de patinagem. Nota-se, para o mesmo, que em razăo da ausência da patinagem não ocorreu um aumento dos valores do indice de cone para as camadas mais próximas da superficie, como nos demais tratamento. Esses resultados acham-se em concordância com o trabalho de DAVIES et al. (1973), que também encontraram valores de índice de cone menores para patinagem zero. Os valores do indice de cone para os tratamentos 20 e $30 \%$ decresceram com a profundidade ocorrendo alem disso diferencas entre nivels de 
prof und dade.

Através do gráfico da Figura 9, el aborado com as médias dos valores de índice de cone, contidos no APENDICE 5 nível COM, para cada profundidade dentro dos diversos tratamentos, observa-se que a medida que aumenta o nível de patinagem ocorre um aumento do índice de cone para todas as profundidades, com maior expressão para as profundidades 2,5 e $5,0 \mathrm{~cm}$. Nota-se também que quanto mais próximo da superficie maiores são os valores de índice de cone para os tratamentos estudados.

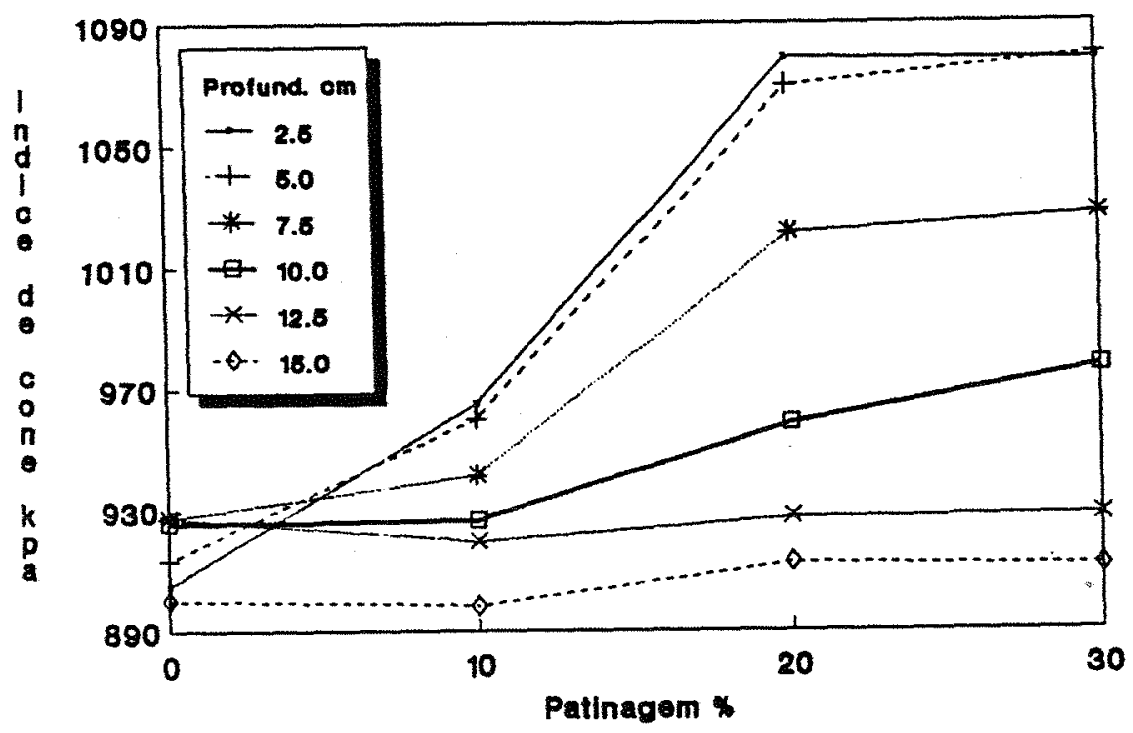

Figura 9 Valores de indice de cone em funça dos nivels de patinagens, para as profundidades estudadas

4. 4.3 Analise estatistica dos dados 11 quidos do Indlce de cone 
Com os dados do arquivo constante do APENDICE 6. realizou-se a análise de variancia apresentada na Tabela 4. Verifica-se que o teste "F" para patinagem e profundidade apresentou-se significativo ao nível de $5 \%$ de probabilidade

Tabela 4 Análise de variância da diferença de média entre os dados obtidos na linha de centro da roda e ao I ado

\begin{tabular}{lrrrrr}
\hline C. Varia. & G.L. & S. Q. & Q.M. & Valor F \\
Patinag. & 3 & 203081.7074898 & 67693.90249 & $3.1274 *$ \\
Profund. & 5 & 4530651.9970535 & 906130.39941 & $41.8626 *$ \\
Residuo & 111 & 2402630.6233726 & 421645.3209 & \\
\hline Total & 119 & 7136364.3279059 & & & \\
\hline
\end{tabular}

Média Geral $=426.393340 \mathrm{kpa}$

Coeficiente de Variação $(A)=34.504 \%$

Coeficiente de Variação $(B)=8.451 \%$

(*) significativo ao nível de $5 \%$ de probabilidade

O APENDICE 11 apresenta o teste de Tukey para as médias de patinagem, nota-se que os valores de indice de cone são malores para níveis de patinagens mais altos, diferindo significativamente em apenas dols niveis 0 e $30 \%$ de patinagem. Dentro de cada nível do fator profundidade não houve diferença entre as médias.

Analisando-se as médias de profundidade e estas dentro de cada nível de patinagem, observa-se que o valor do indice de cone decresce com a profundidade, para todos os níveis de patinagens. 


\section{CONCLUSÃO}

- Os resultados obtidos comprovam a hipótese formulada, de que existe uma relação entre niveis de patinagens e grau de compactaçăo.

- Constatou-se que a patinagem dos pneus tem influencia sobre o grau de compactaçăo do solo, até $5 \mathrm{~cm}$ de prof undidade, sob as condiçóes do presente trabalho.

- O nivel de $30 \%$ de patinagem foi o que provocou diferencas significativas no grau de compactacão do solo. O teste de Tukey indica significancia para os niveis de $30 \%$, quando comparado a $0 \%$ de patinagem.

- Colocando-se a compactacão inicial do solo como nivel de referencia, e fazendo-se a comparação dos incrementos relativos observados no indice de cone, verifica-se um aumento progressivo do efeito compactante com o aumento da patinagem.

- O aumento de carga no rodado propulsor em razăo do aumento de carga na barra de tracăo aparentemente não influenciou na compactacăo causada pelos diversos tratamentos, visto que teóricamente a pressão causada sobre o solo manteve-se praticamente iqual entre eles. 


\section{REFERENCIAS BIBLIOGRAFICAS}

ABEELS, P.F.J. Tire deflection and contact studies. Iournal of Terramechanics, Hanover, 13(3): 183-96, 1976.

AKRAM, M. \& KEMPER, W.D. Infiltration of soils as affected by the pressure and water content at the time of compaction. Soil Science Society American Journal. Los Angeles $43(6): 1080-86.1979$

AMERICAN SOCIETY OF AGRICULTURAL ENGINEERS. Uniform terminology for traction agricultural tractor, self-propeled implements, and other traction and transport devices. S 296: e St. Joseph, 1986

AMERICAN SOCIETY OF AGRICULTURAL ENGINEERS. Standard cone soil penetrometer 5 312: 2. St. Joseph, 1987

AUBERTIN, G.M.; KARDOS, L.I. Root growth through pores media under controlled conditions: 1 Effect of pore size 
and rigidity. Soil Sciency Society American Proceedings Col umbus, $\underline{\underline{9}}(3)$ : $290-93,1965$.

BLACKWELL, P.S.; SOANE, B.D. A method of predicting density changes in field soils resulting from compaction by agricultural traffic. Journal of Soil Science, London, $32: 51-65,1981$

BURT, E. C.; BAILEY, A. G. Load and intiation pressure effects on tires. Iransactions of the ASAE, St. Joseph, Michigan. 25 (04): $881-884$. $198 \widehat{2}$.

CAMPBELL, D.J.; DICKSON.J.W. Effect of four alternative fronte tyres seedbed compaction by a tractor fitted with a rear wheel designed to minimize compaction. Journal of Agricultural Engineering Research, Bedfordshire, 29:83-91 1984.

CHARLES, S.M. Effects of ballast and inflation pressure on tractor tire performance. Agricultural Engineering, St. Joseph, SSC2): $11-3,1984$.

CLAVERIE, J.A.; HILBERT, J.A.; BALBUENA, R.H. Efect del diseno del tractor sobre la compactacion del suelo. In CONGRESSO BRASILEIRO DE ENGENHARIA AGRICOLA, 21, Pelotas 1992. Anais, Pelotas, Sociedade Brasileira de Engenharia 
Agricola 1992. p. 1586-92.

COHRON, G.T. The causing soil compaction. In: BARNES, K. K. Compaction of agricultural soil. St. Joseph, American Society Agricultural Engineers, 1971 . cap. 4. p.106-24.

COLETI, J.T.; DEMATTE, J.L.I. Compactaçăo artificial em solos. Experiência e dados informativos. Alcool \& Acucar São Faulo, C6): 34-9, setemoro-outubro $198 \mathrm{e}$.

DAVIES, D.B.; FINNEY, J.B.; RICHARDSON, S.J. Relative effectes of tractor weight and wheel-slip in causing soil compaction. Journal of Soil Science, London, 24(3) $399-$ 409. 1973.

FERREIRA, A. B. de H. Novo Dicionário Brasileiro da Lingua Portuguesa. $e^{a}$ ed., Rio de Janeiro, Nova Fronteira, 1980.

FLORES, I. A. ; VON BARGEN, K.; GRISSO, R. D. SOIl moisture criteria for estimating workdays. St. Joseph, ASAE, 1990. 2OP C ASAE Paper, 90-1083)

FREITAG, D.R. Penetration tests for soil measurements Iransactions of the ASAE, St. Joseph, 11(6):750-3, nov' dec 1968. 
FREITAG, D.R. Methods of measuring soil compaction. In: BARNES, K.K. Compaction of Agricultural Soils. St Joseph American Society Agricultural Englneers, 1971 . cap. 3 p. $47-103$.

GILL, W. R.; VANDEN BERG, G.E. Soil dynamics in tillage and traction. Washington. USDA, 1967. $511 \mathrm{p}$ CUSDA Agricultural Handbook. 316$)$

HARRIS, W. L. The soil compaction process. In: EARNES,K.K., Compaction of Agricultural Soils. St. Joseph American Society Agricultural Engineers, 1971 . cap.a p. 9-43.

HOPKINS, R.M.; PATRIC, W.H. Combined effect of oxygen content and soil compaction on root penetration. Soil Science, Baltimore, 108(6): 408-13. 1969

KOLOBOV, G.G. Soil mesurements beneath tractor tyres. Journal of Trramechanics. Hanover, 364):9-15, 1966.

LAROUSSE CULTURAL. Grande Enciclopédia Larousse Cultural. Rio de Janeiro, Circulo do Livro, 1988.

MENEZES, J.F. de; YANAI, K. Medidor de altura de garra de pneus de tratores. Campinas, Instituto Agronômico, Boletim Técnico 127. 10 p. 1989. 
MCKIBBEN. E. G. Effect of drawbar puIl upon the effetive weight on front and rear wheels o farm tractors. Agricultural Engineering, St. Joseph, Michigan, EUA. 9 (8): $243-245.1928$.

MCLEOD, H.E.; REED, I.F.; JOHNSON, W.H.; GILL, W.R. Draft, power efficiency, and soil-compaction characteristics of single, duai and low-pressure tires. Iransactions of the ASAE. St Joseph, $9612: 41-4,1966$.

NOVAK, L.R.; MARTYN, P.J.; MANTOVANI, E.C.; FERNANDES, B. Efeito do tráfego de trator e da pressão de contato preu-solo na compactacão de um latossolo vermelho-escuro alico, em dois níveis de umidade. In: Congresso Brasileiro de Engenharia Agrícola, 18. Recife, 1989. Anais Recife Sociedade Brasileira de Engenharia Agrícola 1989. p. $520-35$

OLIVEIRA, J. B. de; JACOMINE, P. K. T.; CAMARGO, M. N. Classes gerais de solos do Brasil: guia para seu reconhecimento. Jaboticabal. FUNEP 1992, $201 \mathrm{p}$.

PLACKETT, C.W. The ground pressure of some agricultural tyres at lou and with zero sinkage. Journal Agricultural Engineering Research, Bedfordshire, 29: 159-56, 1984. 
RAGHAVAN, G.S.V.; MCKYES. E. Laboratory study to determine the effect of slip-generat shear on soil compaction. Canadian Agricultural Engineering, Otawa, 19(1) 40-4e, 1977.

RAGHAVAN, G.S. V.; MCKYES, E. ; CHASSE, M. Effect of wheel slip on soil compaction. Journal Agricultural Engineering Research, Bedfordshire, 르: 79-83, 1977.

RAGHAVAN, G.S. V.; MCKYES, E.; CHASSE, M.; MERIENEAU. F. Development of compaction patterns due to machinery operation in orchad soil. Canadian Journal Plant Science. Ste. Anne de Bellevue, 56:505-9, 1976.

REECE, A. R. Tractor design and tractive performance In: AGRICULTURAL ENGINEERING SYMPOSIUN OF THE INSTITUTION OF AGRI CULTURAL ENGINEERS, Silsoe, 1967. (Paper, $3 / 4 / 2,343$

ROSEMBERG, N.J. Response of plants to the physical effects of soil compaction. Advances in Agronomy, Nebraska 16: $181-96,1964$

SOANE, B.D.; BLACKWELL, P.S.; DICKSON, J.W.; PAINTER, D. I. Compaction by agricultural vehicles: A review II. Compaction under tyres and other running gear. Soil \& Tillage Research, Amsterdam, 1: 373-400, 1981. 
SOANE, B. D.; DICKSON, I. W. CAMPBELL. D.J. Compaction by agricultural vehicies: A review III. Incidence and control of compaction in crop production. Soil \& Tillage Research, Amsterdam, 2 : $3-36,1982$.

SOEHNE, w. Fundamentals of preassure distribution and soil compaction under tractor tires. Agricultural Engineering St. Joseph, 278-90, 1958.

STAFFORD, J.V.; MATTOS, P.C. de The effect of forward speedon whell-induced soil compaction: Laboratory simulation and field experiments. Journal Agricultural Engineering Research, Bedfordshire, 르: 333-47, 1981.

TAYLOR, J.H. Lug angle effect on traction performance of pneumatic tractor tire. Iransaction of the ASAE. St. Joseph. Michigan, 16(1):16-18, 1973 a.

TAYLOR, J.H. Effect of lug spacing on tractive performance of pneumatic tractor tires. ASAE Techinical Paper $N$ 은 136. American Society of Agricultural Engineering, St. Joseph, Michigan. 8 p. 1973 b.

TAYLOR, J. H.; BURT, E. C.; BAILlEY, A. E. Radial tire performance in firm and soft soils. Iransactions of the 
ASAE. St. Joseph. Michigan, 19 CE): 1062-1084, 1976.

IAYLOR, H.M. \& GARDNER, H.R. Penetration of cotton seedling toproots as influenced by bulk density, moisture content, and strenght or soll. Soil science. Baltimore, 9603$): 153-56,1963$.

TAYLOR, H.M.; RATLICC. L.F. Root elongation rates of cotton and peanuts as a function of strenght and soil water content. Soil Science, Baltimore, $108 \mathrm{C} 2 \mathrm{l}: 113-19,1969$.

IRABBIC, G.W.; LASK, K.V.; BUCHELE, W.F. Measurement of soil-tire interface preassures. Agricultural Egineering St. Joseph, 40:678-81, 1959.

TROUSE, A.C. Alteration of the infiltration permeability capacity of tropical soil by vehicular traffic. In: Congresso Pan Americano de Conservação de Solo 1, São Paulo. 1966, p. $1103-09$

VANDEN BERG, G.E.; GILL,W.R. Pressure distribution between a smooth tire and the soil. Transactions of the ASAE, St. Joseph, 5: 105-7, 1962.

VASEY, G.H. E NAYLOR, I.T. Field tests on 14-30 tractor tyres. Journal of Agricultural Engineering Research. 
Bedfordshire, $3: 1-8.1958$.

YOORHEES, W. B.; SENST, C.E.; NELSON, W. W. Compaction and soil structure modification by traffic in the northen corn belt. Soil Science Society Americam Journal, Los Angeles, $42(4): 344-49,1978$.

WOLF, D.; GARNER, T.H.; DAVIES, J. H. Tillage mechanical energy imput and soli-crop response. Iransaction of the ASAE, St. Joseph, 24C6):1412-19-21, nov/dec 1981.

ZONTA, E. P. \& MACHADO, A. A. Sanest - Sistema de análise estatistica. Pelotas, 1990. 
APENDICES 
- APENDICE 1 :

\author{
Definicão de patinagem \\ - Novo Dicionário CAurélios da Língua
} Portuguesa, FERREIRA (1986) define:

a) Patinagem ${ }^{(1)}$ : Ato ou exercicio de patinar ${ }^{(1)}$

b) Fatinagemi's): Acto ou efeito de patinar ${ }^{2)}$

c) Patinar ${ }^{1}$ : Deslizar sobre patins

d) Patinar : Recobrir de patina

e) Patinhagem: Acdo ou efeito de patinhar

f) Patinhar:...3. moverem-se as rodas de

(veiculo, automovel) girando sem imprimir desiocamento ao velculo, por faita de aderencia: o carro atolou-se e ficou patinhando. EVar., nesta acepc.: patinar. I

A Grande Enciclopédia Larousse Cultural, LARROUSE CULTURAL (1988) def'ine:

Patinagem: - 1. Ato de patinar ${ }^{(1)}$; patinacao. - 2. Rotacao, sem impulsionar as rodas motrizes de um veicuio, em consequecia de ader noia insuficiente.

$$
\text { Patinar }{ }^{(1)}:-i \text {. Desizar sobre patins. }
$$

- 2. Tratando-se de uma roda, girar sem avancar, por falta de aderencia; patinhar. - 3. Tratando-se de uma emoreagem, ter suas superficies de atrito desizando una contra 2 outra sem produeir arrasto. 


\begin{abstract}
Patinhar: ...3. Vo caso das rodas de un velculo de trcalo mecânica, girar em wa, por falta de aderencia, impedirdo o novimento do veiculo: patirar.

Optou-se pelo termo patinagem por parecer mais assimilável entre o público usual.
\end{abstract}

- APENDICE Z:

Tabela AZ-1 Valores médios de umidade e densidade do solo no campo experimental

\begin{tabular}{|c|c|c|c|c|c|}
\hline Irat. & $\begin{array}{l}\text { Prof } \\
(\mathrm{cm})\end{array}$ & $\begin{array}{l}\text { Umi dade } \\
\text { médias }\end{array}$ & $\begin{array}{l}\% \\
c . v .\end{array}$ & $\begin{array}{l}\text { Densidade } \\
\text { médias }\end{array}$ & $\begin{array}{l}\mathrm{kg} / \mathrm{m}^{3} \\
\mathrm{c.} \cdot \vee .\end{array}$ \\
\hline$A$ & $\begin{array}{r}5.0 \\
10.0 \\
15.0\end{array}$ & $\begin{array}{l}21.80 \\
23.16 \\
24.03\end{array}$ & $\begin{array}{l}6.60 \\
7.25 \\
6.57\end{array}$ & $\begin{array}{l}1458 \\
1570 \\
1620\end{array}$ & $\begin{array}{l}3.61 \\
1.86 \\
2.15\end{array}$ \\
\hline B & $\begin{array}{r}5.0 \\
10.0 \\
15.0\end{array}$ & $\begin{array}{l}20.13 \\
21.58 \\
22.89\end{array}$ & $\begin{array}{l}\text { 6. } 86 \\
6.12 \\
\text { 6. } 66\end{array}$ & $\begin{array}{l}1464 \\
1544 \\
1624\end{array}$ & $\begin{array}{l}3.63 \\
3.82 \\
1.77\end{array}$ \\
\hline $\mathrm{c}$ & $\begin{array}{r}5.0 \\
10.0 \\
15.0\end{array}$ & $\begin{array}{l}20.84 \\
22.56 \\
23.44\end{array}$ & $\begin{array}{l}7.73 \\
6.77 \\
5.56\end{array}$ & $\begin{array}{l}1454 \\
1516 \\
1588\end{array}$ & $\begin{array}{l}1.34 \\
1.37 \\
\text { 2. } 61\end{array}$ \\
\hline$D$ & $\begin{array}{r}5.0 \\
10.0 \\
15.0\end{array}$ & $\begin{array}{l}20.93 \\
23.33 \\
23.77\end{array}$ & $\begin{array}{l}7.63 \\
6.63 \\
5.58\end{array}$ & $\begin{array}{l}1440 \\
1530 \\
1604\end{array}$ & $\begin{array}{l}3.57 \\
2.49 \\
3.02\end{array}$ \\
\hline
\end{tabular}


Diagrama da banda de rodagem de um pneu

agrícola.

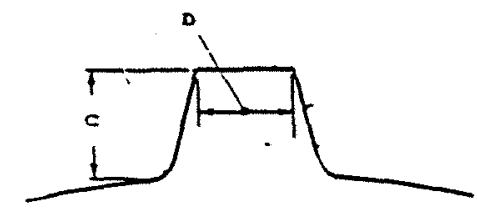

corte A-A

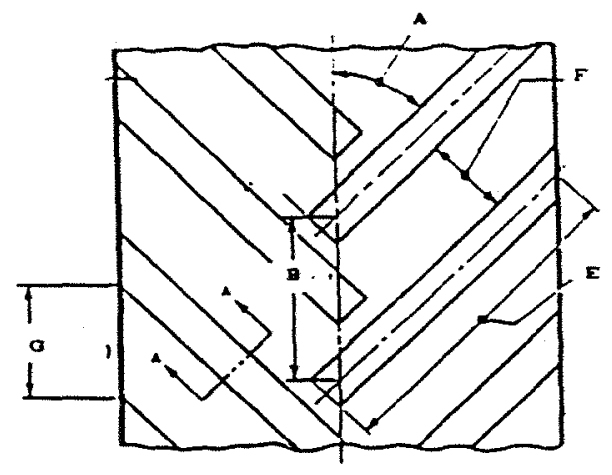

A - ângulo da garra B - passo da garra C - altura da garra

D - largura da garra E - comprimento da garra

F - espacramento da garra - perpendicular

G - espacamento da garra - circunferénctal

\section{- APENDICE 4:}

Valores das cargas aplicadas sobre o pneu e as áreas correspondentes, obtidas durante o ensaio preliminar de verificacão da variação da área de contato em função da carga.

Cargas

N

14279

15260

16201

16888
Áreas

$$
\mathrm{cm}^{2}
$$

1153.6

1236.1

1287.6

1305. 2 
- APENDTCE 5 :

Arquivo de dados contendo o fator $C A$ compactacão, com dois niveis denominados SEM e COM; o fator (B) patinagem composto por quatro niveis $0,10,20$ e $30 \%$; 0 fator (C) profundidade composto por seis niveis $2,5,5,0$, $7,5,10,0,12,5$ e $15,0 \mathrm{~cm} \otimes$ o fator CDD blocos composto pelas repetiçóes. 


\begin{tabular}{|c|c|c|c|c|c|c|c|}
\hline $\begin{array}{c}\text { FATOR A } \\
\text { COMPACTACAO } \\
\end{array}$ & $\begin{array}{c}\text { FATOR B } \\
\text { PATINAMENTO } \\
\end{array}$ & $\begin{array}{c}\text { FATOR C } \\
\text { PROFUNDIDADE }\end{array}$ & & Bro & $\begin{array}{l}\text { FATOR D } \\
\text { OSS - REP } \\
\end{array}$ & ICAO) & \\
\hline SEM & $10 \%$ & $\begin{array}{l}2.5 \\
5.0 \\
7.5 \\
10.0 \\
12.5 \\
15.0 \\
\\
2.5 \\
5.0 \\
7.5 \\
10.0 \\
12.5 \\
15.0 \\
\\
2.5 \\
5.0 \\
7.5 \\
10.0 \\
12.5 \\
15.0 \\
2.5 \\
5.0 \\
7.5 \\
10.0 \\
12.5 \\
15.0\end{array}$ & $\begin{array}{l}391.3 \\
565.9 \\
671.8 \\
707.1 \\
884.6 \\
916.0 \\
238.3 \\
291.6 \\
376.3 \\
488.6 \\
676.7 \\
882.2 \\
311.2 \\
340.6 \\
113.7 \\
518.8 \\
616.4 \\
663.2 \\
244.4 \\
267.2 \\
347.0 \\
428.1 \\
552.1 \\
561.9\end{array}$ & $\begin{array}{l}349.4 \\
358.4 \\
575.7 \\
739.4 \\
795.3 \\
807.7 \\
\\
269.7 \\
326.6 \\
140.6 \\
539.1 \\
609.1 \\
662.0 \\
479.7 \\
513.1 \\
627.0 \\
685.2 \\
664.5 \\
647.4 \\
228.9 \\
254.2 \\
369.4 \\
447.9 \\
561.0 \\
669.8\end{array}$ & $\begin{array}{l}315.2 \\
362.5 \\
416.2 \\
456.9 \\
466.8 \\
447.2 \\
\\
384.4 \\
411.7 \\
443.0 \\
482.9 \\
511.1 \\
566.0 \\
468.3 \\
611.6 \\
698.3 \\
730.8 \\
702.7 \\
672.6 \\
\\
672.7 \\
491.9 \\
605.1 \\
650.2 \\
658.0 \\
659.0\end{array}$ & $\begin{array}{l}259.9 \\
338.0 \\
473.7 \\
502.1 \\
609.0 \\
678.6 \\
\\
242.8 \\
277.0 \\
343.2 \\
462.9 \\
553.8 \\
603.4 \\
207.8 \\
311.2 \\
493.3 \\
501.3 \\
645.3 \\
804.5 \\
192.3 \\
204.5 \\
278.6 \\
366.5 \\
577.6 \\
659.0\end{array}$ & $\begin{array}{l}255 . \\
307 . \\
476 . \\
623 . \\
826.7 \\
883 . \\
\\
239.5 \\
342.3 \\
639 . \\
802.5 \\
964.0 \\
968.1 \\
\\
299.0 \\
316.1 \\
383.6 \\
442.3 \\
712.0 \\
925.8 \\
303.8 \\
534.2 \\
783.3 \\
958.3 \\
1030.0 \\
1039.5\end{array}$ \\
\hline $\cos$ & $0 \%$ & $\begin{array}{l}2.5 \\
5.0 \\
7.5 \\
10.0 \\
12.5 \\
15.0 \\
\\
2.5 \\
5.0 \\
7.5 \\
10.0 \\
12.5 \\
15.0 \\
\\
2.5 \\
5.0 \\
7.5 \\
10.0 \\
12.5 \\
15.0 \\
2.5 \\
5.0 \\
7.5 \\
10.0 \\
12.5 \\
15.0\end{array}$ & $\begin{array}{r}933.6 \\
1004.2 \\
1074.8 \\
1110.2 \\
1056.2 \\
1011.1 \\
956.2 \\
1062.5 \\
1123.2 \\
1140.4 \\
1165.1 \\
1154.3 \\
999.0 \\
1086.3 \\
1043.4 \\
1078.0 \\
1136.6 \\
1170.4 \\
905.2 \\
888.3 \\
929.9 \\
939.6 \\
927.0 \\
903.8\end{array}$ & $\begin{array}{r}1027.5 \\
1062.5 \\
1020.2 \\
942.9 \\
904.6 \\
886.6 \\
1021.8 \\
982.0 \\
922.5 \\
873.7 \\
869.9 \\
831.6 \\
1202.6 \\
1128.5 \\
990.1 \\
920.1 \\
865.5 \\
874.8 \\
1122.9 \\
1132.6 \\
1082.1 \\
1046.3 \\
985.2 \\
964.0\end{array}$ & $\begin{array}{r}776.0 \\
684.4 \\
658.4 \\
601.0 \\
614.0 \\
626.7 \\
1073.1 \\
868.8 \\
760.0 \\
732.0 \\
720.8 \\
674.7 \\
1079.6 \\
1018.6 \\
927.7 \\
792.3 \\
716.6 \\
648.2 \\
1201.4 \\
1209.9 \\
1069.0 \\
995.8 \\
944.5 \\
1006.2\end{array}$ & $\begin{array}{l}835.4 \\
817.9 \\
825.7 \\
862.3 \\
899.3 \\
907.1 \\
960.7 \\
837.9 \\
814.0 \\
801.2 \\
796.3 \\
797.3 \\
958.3 \\
990.1 \\
978.7 \\
916.0 \\
868.8 \\
849.3 \\
959.1 \\
953.5 \\
928.7 \\
854.1 \\
798.8 \\
774.8\end{array}$ & $\begin{array}{r}951.8 \\
998.2 \\
1057.2 \\
1112.2 \\
1163.5 \\
1069.0 \\
1013.7 \\
1049.5 \\
1087.6 \\
1078.0 \\
1045 . \\
1034.6 \\
1157.8 \\
1124 . \\
1166.1 \\
1086.2 \\
1048.7 \\
1019.9 \\
1202.3 \\
1212.3 \\
1127.8 \\
1050.3 \\
984.4 \\
907.1\end{array}$ \\
\hline
\end{tabular}


- APENDICE 0 :

Arqui vo contendo as medias das diferencas entre os valores de indice de cone obtidos no rasto do pneu e ao lado, para cada tratamento e cada prof undidade. Para a análise denominou-se de fator $A$ a patinagem e fator $B$ a profundidade.

\begin{tabular}{|c|c|c|c|c|c|c|}
\hline \multirow{2}{*}{$\begin{array}{l}\text { Fator A } \\
\text { Patinagem }\end{array}$} & \multirow{2}{*}{$\begin{array}{l}\begin{array}{l}\text { Fator B } \\
\text { Profund. }\end{array} \\
2.5\end{array}$} & \multicolumn{5}{|c|}{ Repeticões } \\
\hline & & 542.3 & 678.1 & 460.8 & 575.5 & 690.8 \\
\hline \multirow{7}{*}{$0 \%$} & 5.0 & 438.4 & 704.2 & 322.0 & 479.9 & 690.3 \\
\hline & 7.5 & 403.1 & 444.5 & 242.3 & 351.1 & 580.6 \\
\hline & 10.0 & 291.3 & 203.4 & 144.1 & 306.2 & 488.5 \\
\hline & 12.5 & 171.6 & 109.3 & 147.2 & 290.3 & 336.8 \\
\hline & 15.0 & 95.1 & 78.8 & 179.5 & 228.5 & 185.4 \\
\hline & 2.5 & 617.9 & 752.2 & 688.7 & 617.9 & 774.2 \\
\hline & 5.0 & 770.9 & 655.3 & 475.1 & 560.9 & 707.4 \\
\hline \multirow[t]{6}{*}{$10 \%$} & 7.5 & 746.9 & 481.9 & 317.0 & 470.7 & 549.3 \\
\hline & 10.0 & 659.8 & 334.6 & 249.1 & 338.3 & 275.2 \\
\hline & 12.5 & 488.4 & 260.8 & 209.4 & 242.6 & 81.4 \\
\hline & 15.0 & 272.1 & 169.9 & 108.8 & 193.9 & 66.5 \\
\hline & 2.5 & 687.9 & $7 \geq 2.9$ & 611.4 & 750.6 & 858.8 \\
\hline & 5.0 & 744.9 & 615.4 & 407.0 & 678.9 & 808.4 \\
\hline \multirow[t]{6}{*}{$20 \%$} & 7.5 & 629.7 & 363.1 & 229.5 & 485.4 & 782.4 \\
\hline & 10.0 & 559.3 & 227.1 & 36.2 & 207.9 & 569.0 \\
\hline & 12.5 & 520.3 & 201.1 & 13.8 & 77.3 & 270.3 \\
\hline & 15.0 & 509.2 & 227.4 & -24.4 & 44.7 & 94.1 \\
\hline & 2.5 & 660.8 & 894.0 & 531.6 & 759.0 & 900.5 \\
\hline & 5.0 & 621.1 & 878.4 & 718.0 & 748.9 & 678.1 \\
\hline \multirow[t]{4}{*}{$30 \%$} & 7.5 & 582.9 & 712.7 & 463.9 & 650.1 & 344.5 \\
\hline & 10.0 & 511.2 & 598.3 & 345.6 & 487.6 & 92.0 \\
\hline & 12.5 & 374.9 & 424.2 & 286.5 & 221.2 & -45.6 \\
\hline & 15.0 & 341.9 & 294.2 & 347.2 & 143.2 & -158.9 \\
\hline
\end{tabular}


APENDICE 7 :

Tabela AP-1 Valores de patinagem, carga dinámica, área de contato e pressäo media, em funcăo da forca de tração

\begin{tabular}{|c|c|c|c|c|c|}
\hline Parc. & $\begin{array}{c}\text { F. Trac. } \\
N\end{array}$ & $\begin{array}{l}\text { Patin. } \\
\because\end{array}$ & $\begin{array}{c}\text { C. Din. } \\
N\end{array}$ & $\begin{array}{c}\text { Area } C \\
\mathrm{~cm}^{2}\end{array}$ & $\begin{array}{c}\text { Press. Med. } \\
\text { kpa }\end{array}$ \\
\hline A1 & - & 0.20 & 14284 & 1153.79 & 123.80 \\
\hline $\mathrm{AZ}$ & - & 0.19 & 14284 & 1153.79 & 123.80 \\
\hline$A 3$ & - & 0.21 & 14284 & 1153.79 & 123.80 \\
\hline$A 4$ & - & 0.22 & 14284 & 1153.79 & 123.80 \\
\hline$A 5$ & - & 0.18 & 14284 & 1153.79 & 123.80 \\
\hline B1 & 10670 & 10.80 & 14532 & 1177.87 & 123.37 \\
\hline $\mathrm{Be}$ & 10111 & 10.14 & 14519 & 1176.66 & 123.39 \\
\hline $\mathrm{B3}$ & 10082 & 9.75 & 14518 & 1176.56 & 123.39 \\
\hline B4 & 10464 & 10.52 & 14527 & 1177.40 & 123.38 \\
\hline 35 & 10641 & 10.60 & 14531 & 1177.77 & 123.37 \\
\hline 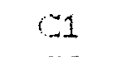 & 14789 & 19.58 & 14628 & 1186.64 & 123.27 \\
\hline 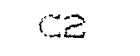 & 14887 & 19.55 & 14630 & 1186.82 & 123.27 \\
\hline 63 & 15015 & 19.85 & 14633 & 1187.09 & 123.26 \\
\hline 4 & 14691 & 19.72 & 14025 & 1186.37 & 123.27 \\
\hline 5 & 14573 & 19.55 & 14623 & 1186.19 & 123.27 \\
\hline$D 1$ & 17878 & 29.20 & 14590 & 1192.94 & 123.22 \\
\hline De & 17829 & 29.22 & 14608 & 1192.85 & 123.22 \\
\hline$D 3$ & 18202 & 30.00 & 14707 & 1193.64 & 123.21 \\
\hline 04 & 18015 & 29.90 & 14703 & 1193.29 & 123.22 \\
\hline$D S$ & 17927 & 29.54 & 14701 & 1193.10 & $123.2 \mathrm{e}$ \\
\hline
\end{tabular}


- APENDICE 8:

Tabelas A8-1 até A8-20 contendo os dados

de indice de cone, para cada parcela, na linha de centro do rasto do pneu e ao 1 ado. 


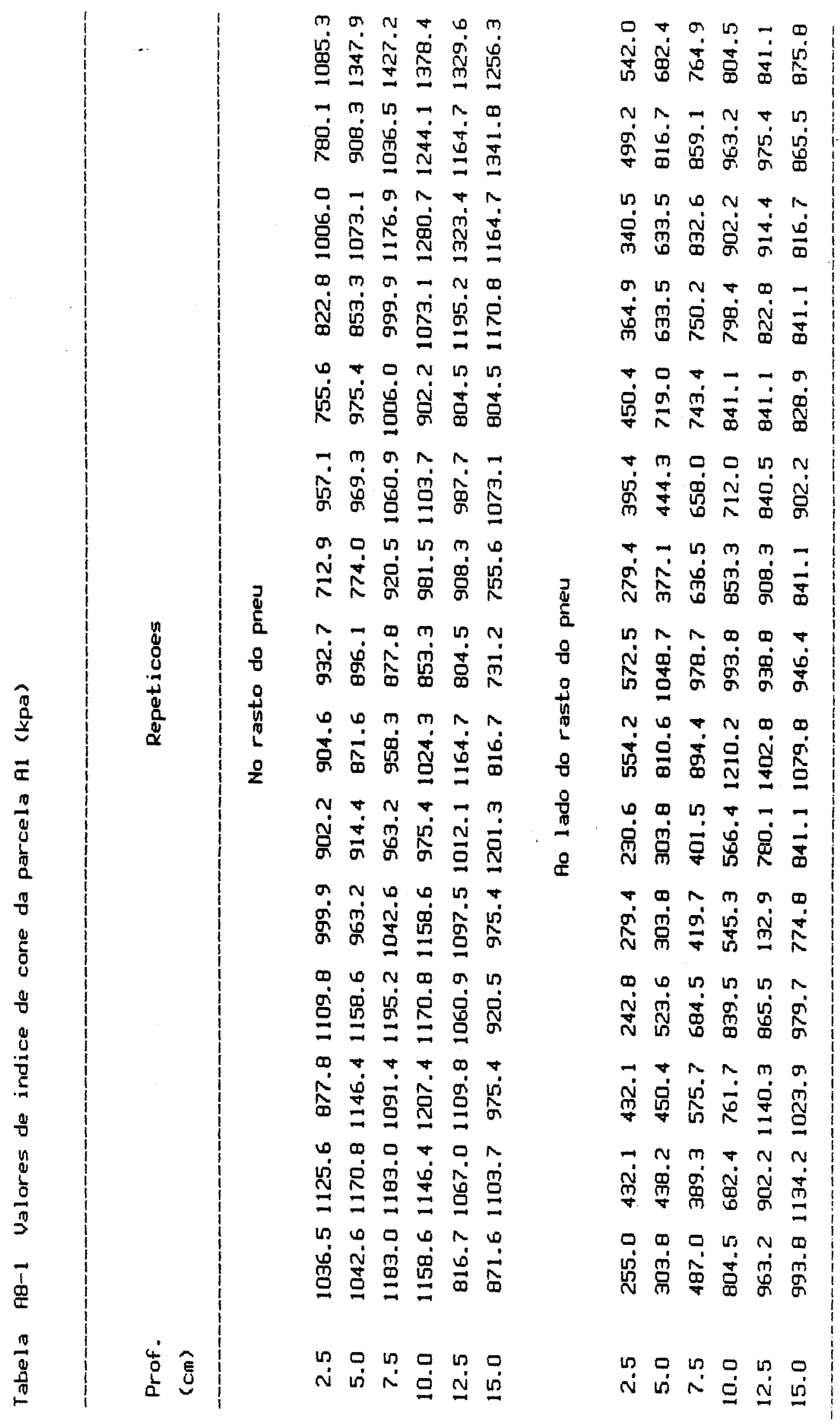




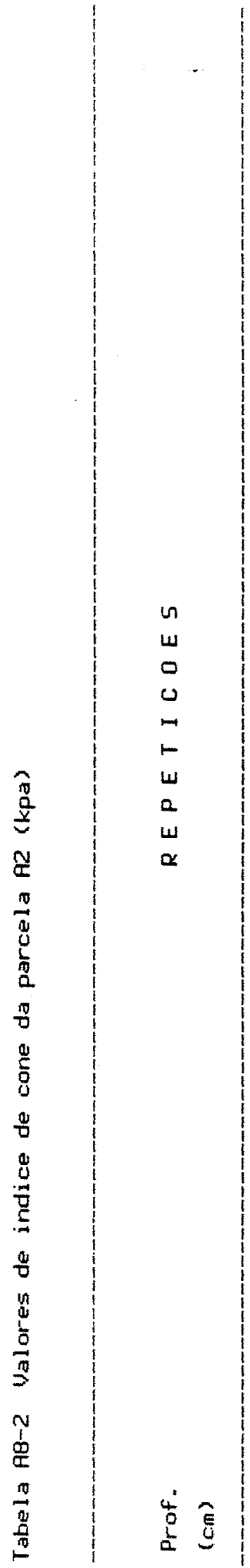

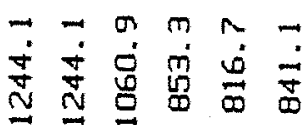

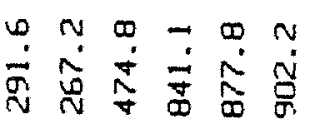

(n) $m$ or 0 us a

官兽 の̆

$\sigma \sigma-\pi \sigma \sigma$

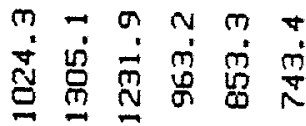

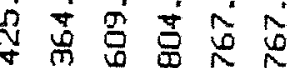

$\infty 0 \rightarrow \infty \omega$

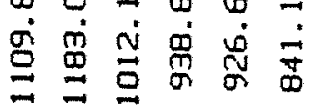

$\infty 0 \div-\sigma$

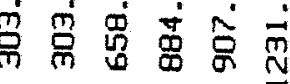

u $\sim m m$ -

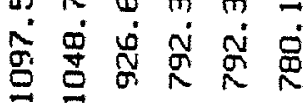

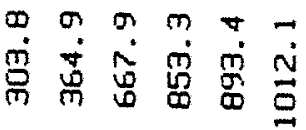

$\infty$ D N O a -

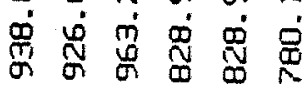

$\pi$ m $n$ U $N$

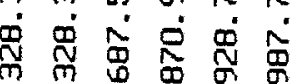

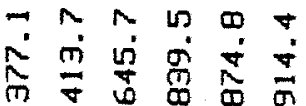

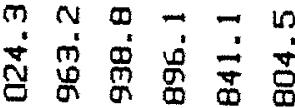

胥

a $\quad 200 \mathrm{mom}$

में

o $\div \infty \div$

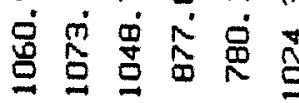

$\checkmark N \wedge N-\overline{0}$

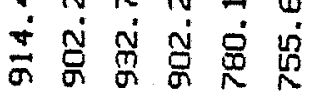

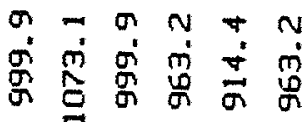

$\sim m \rightarrow \forall 0$

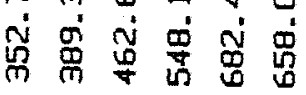

$+0=\infty m$

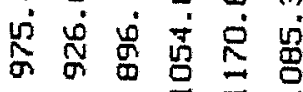

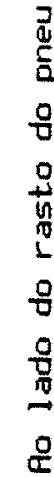

is $\pi N$ o $N$.

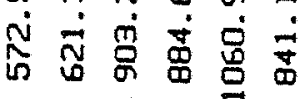

$\nabla$ u $m+n$

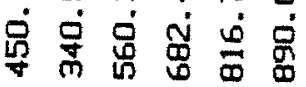

บ $\%$

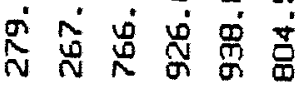

or 0 or $N$

$\sigma \rightarrow 0$ ○

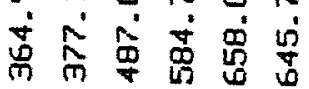

总密离

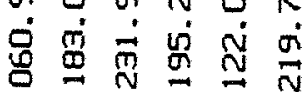

$0 m N \sim 0 N$

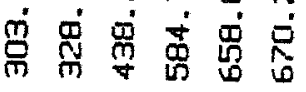

$0 \rightarrow-$ n on $N$

$m \wedge$ is $\infty-\pi$

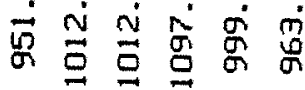

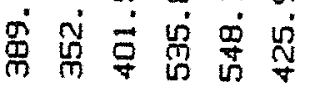

a $m-m$

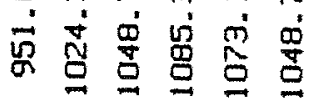

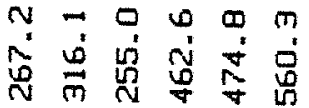

凹

n⿺辶一 


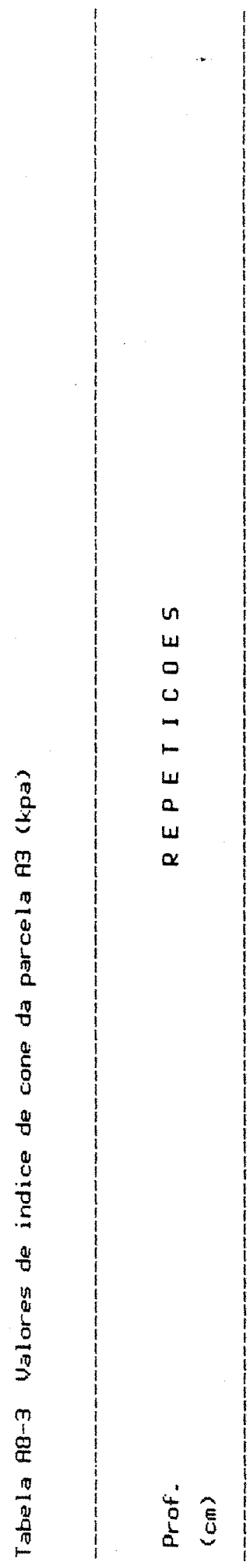

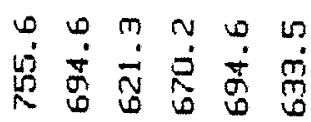

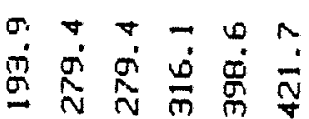

$\sim 0 \sigma$ n $\nabla$.

官

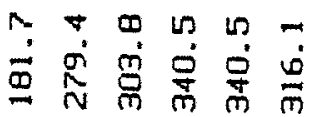

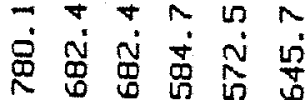

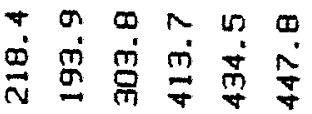

$\nabla$\begin{tabular}{lllll}
\hline & 0 & 0 & 0 & 0
\end{tabular}

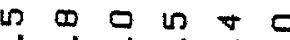

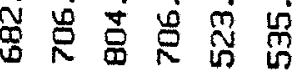

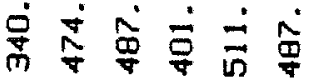

$n+n \infty n$

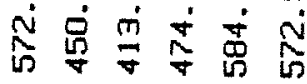

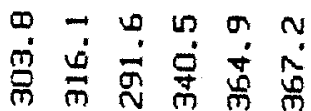

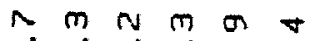

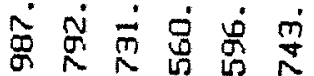

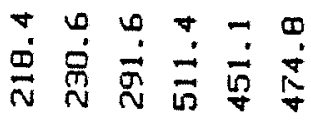

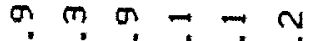

बूँ

$\infty N-N$ n $\infty$

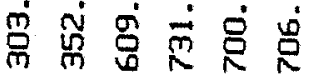

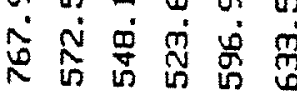

$\sim=\sim \operatorname{son}$

$\circ \infty m-r=\frac{\pi}{n}$

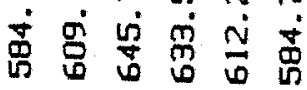

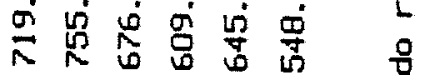

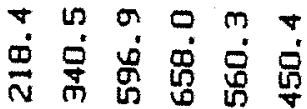

ம்

$\because ก \cong \sim \sigma \sigma$

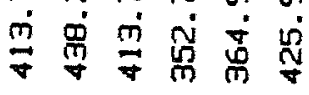

$m 0=0$ in

ณ

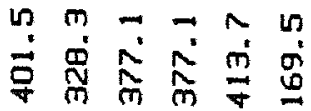

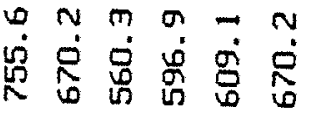

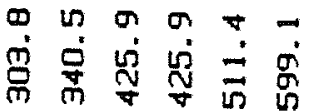

$\Rightarrow \forall \omega \nabla 0 m$

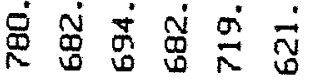

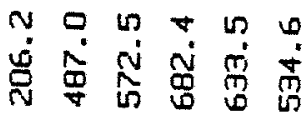

0 - $0 \mathrm{~m}$

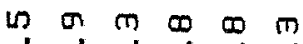

灾 官

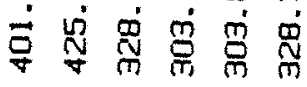

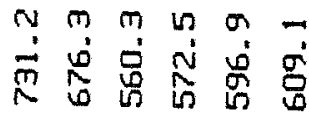

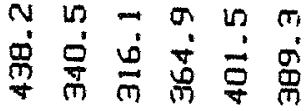

$\begin{array}{llll}4 & 10 & 0 & 0\end{array}$

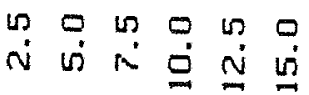




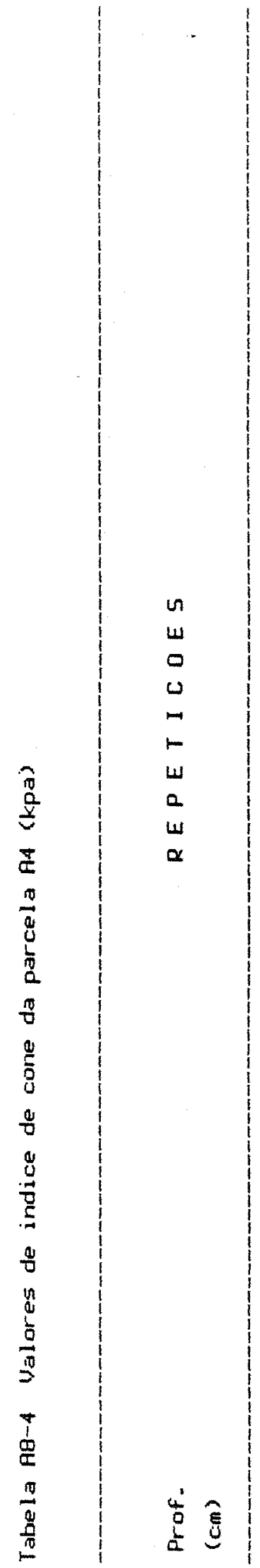

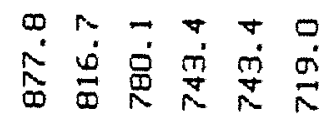

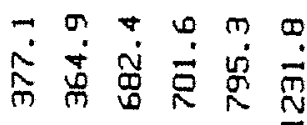

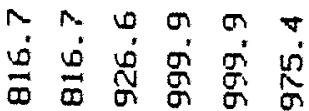

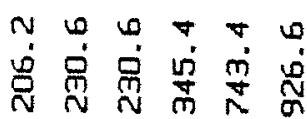

๒

O no 0 is us

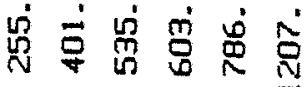

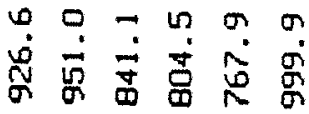

N $\nabla-\infty \mathrm{m}$

兽

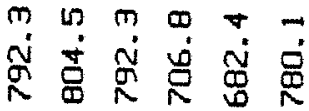

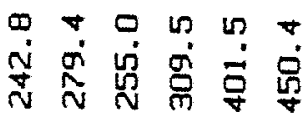

n $\pi \square m$

ல்

$m-\infty \quad \pi N$

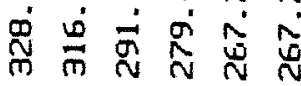

01000

ڤั

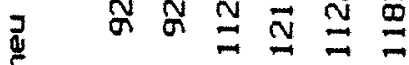

立

$\infty$ n $N$ un - N

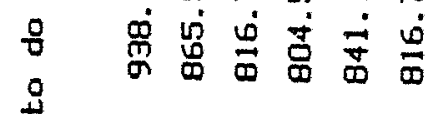

m

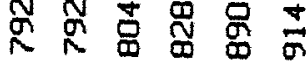

$0 \quad 00 N N$

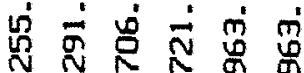

ब N $N$ 品

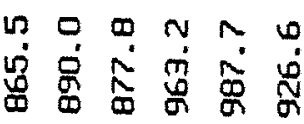

$\begin{array}{llllll}0 & 0 & 0 & 0 & 0 & N\end{array}$

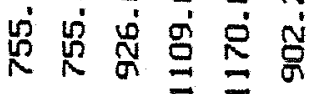

음

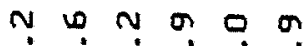

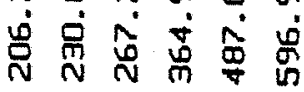

m. $0 \approx n m$

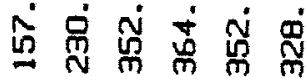

$\frac{0}{\frac{\pi}{0}}$

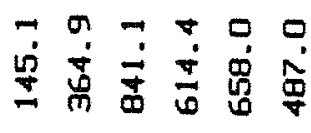

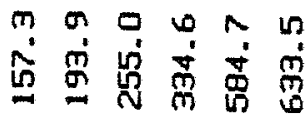

D N $D$ o N N

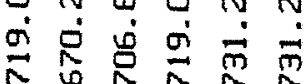

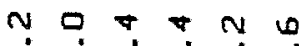

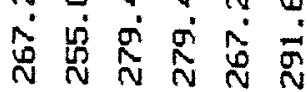

$m$ \& $\sigma$ o

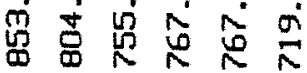

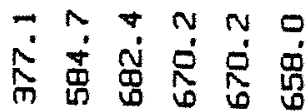

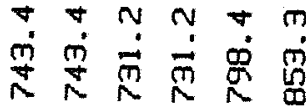

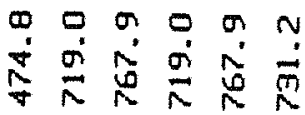

$\pi 0-\pi \sigma$

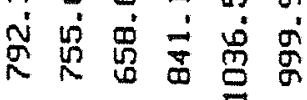

苛离

药

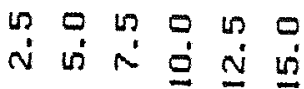




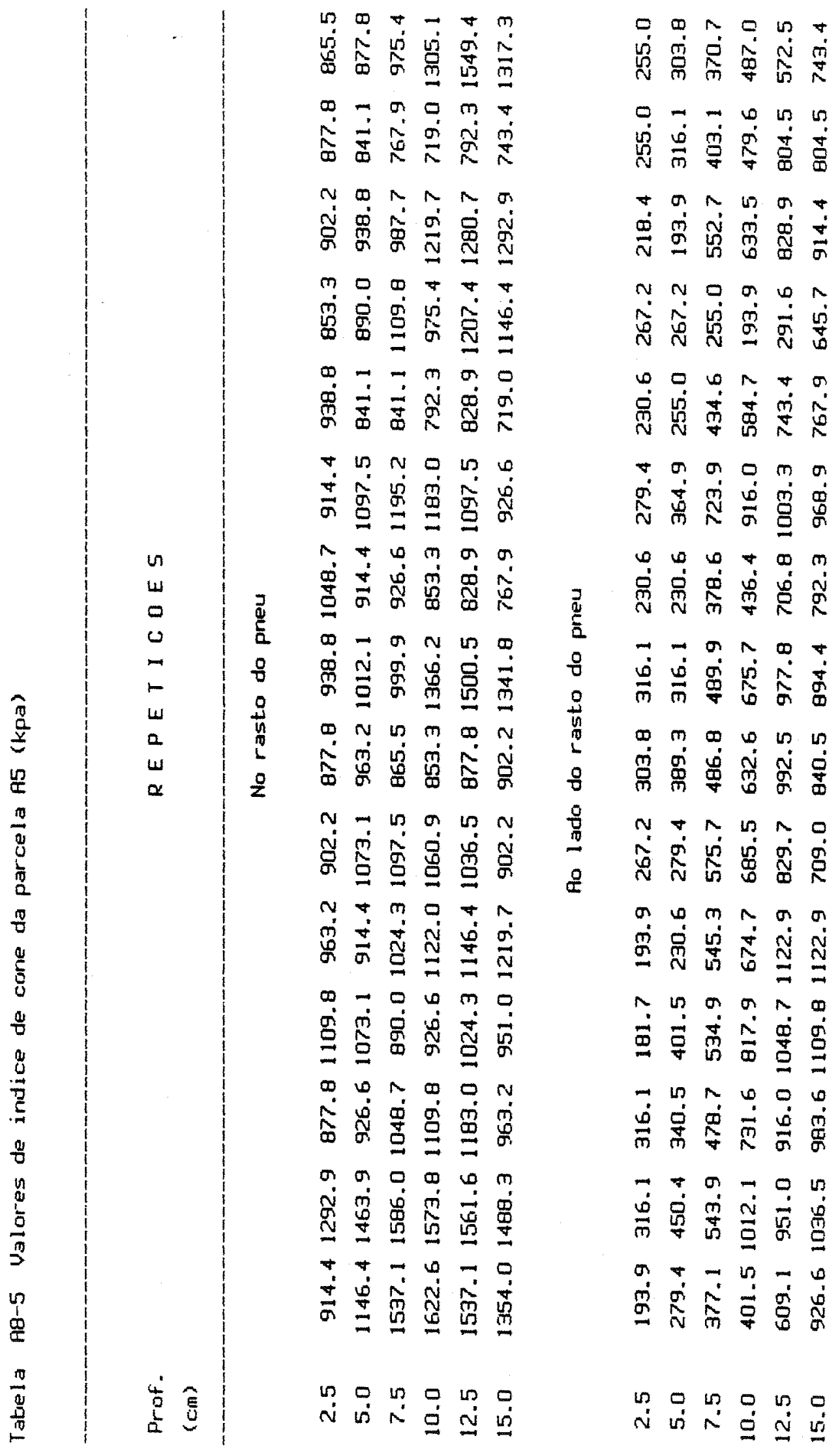




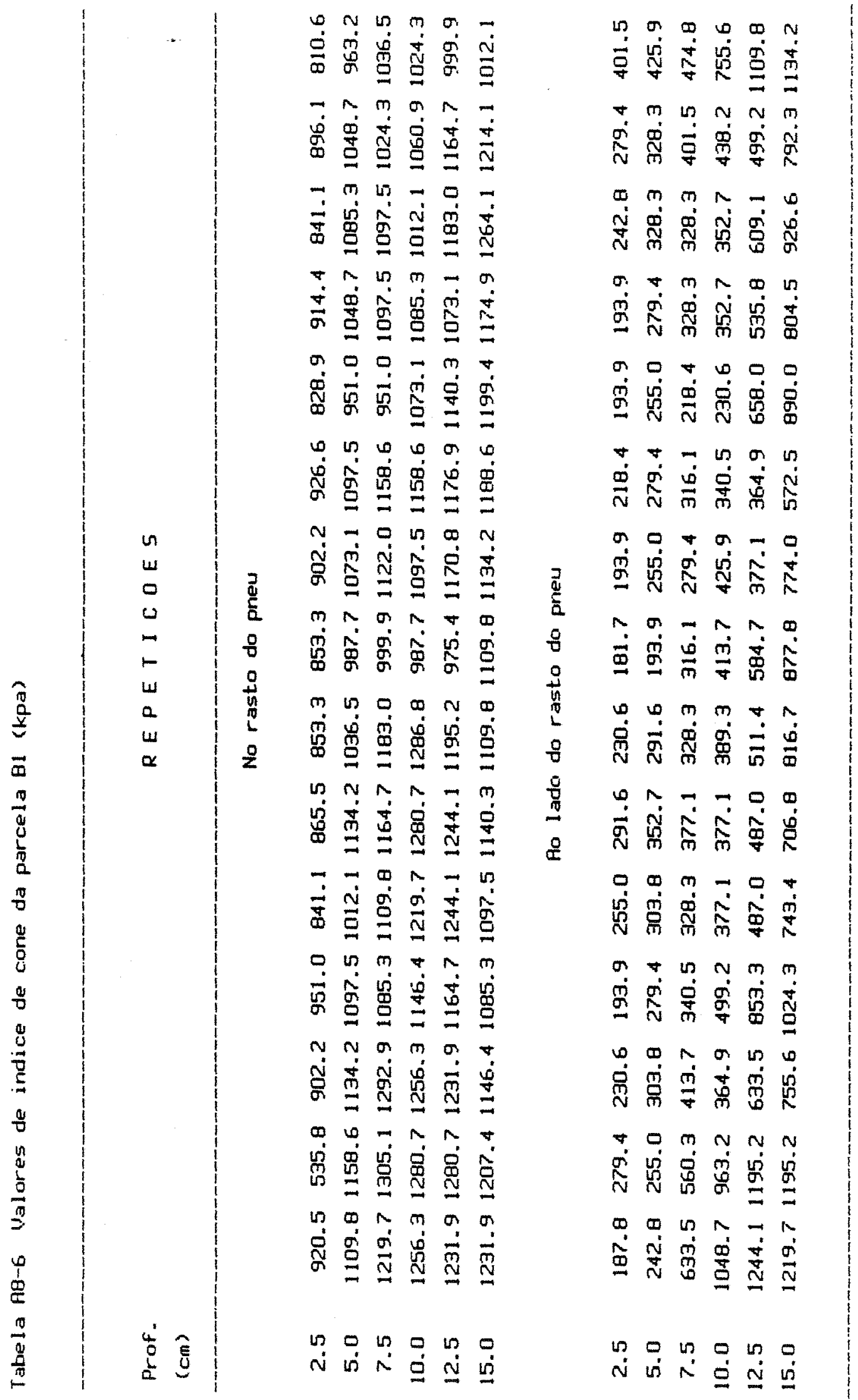




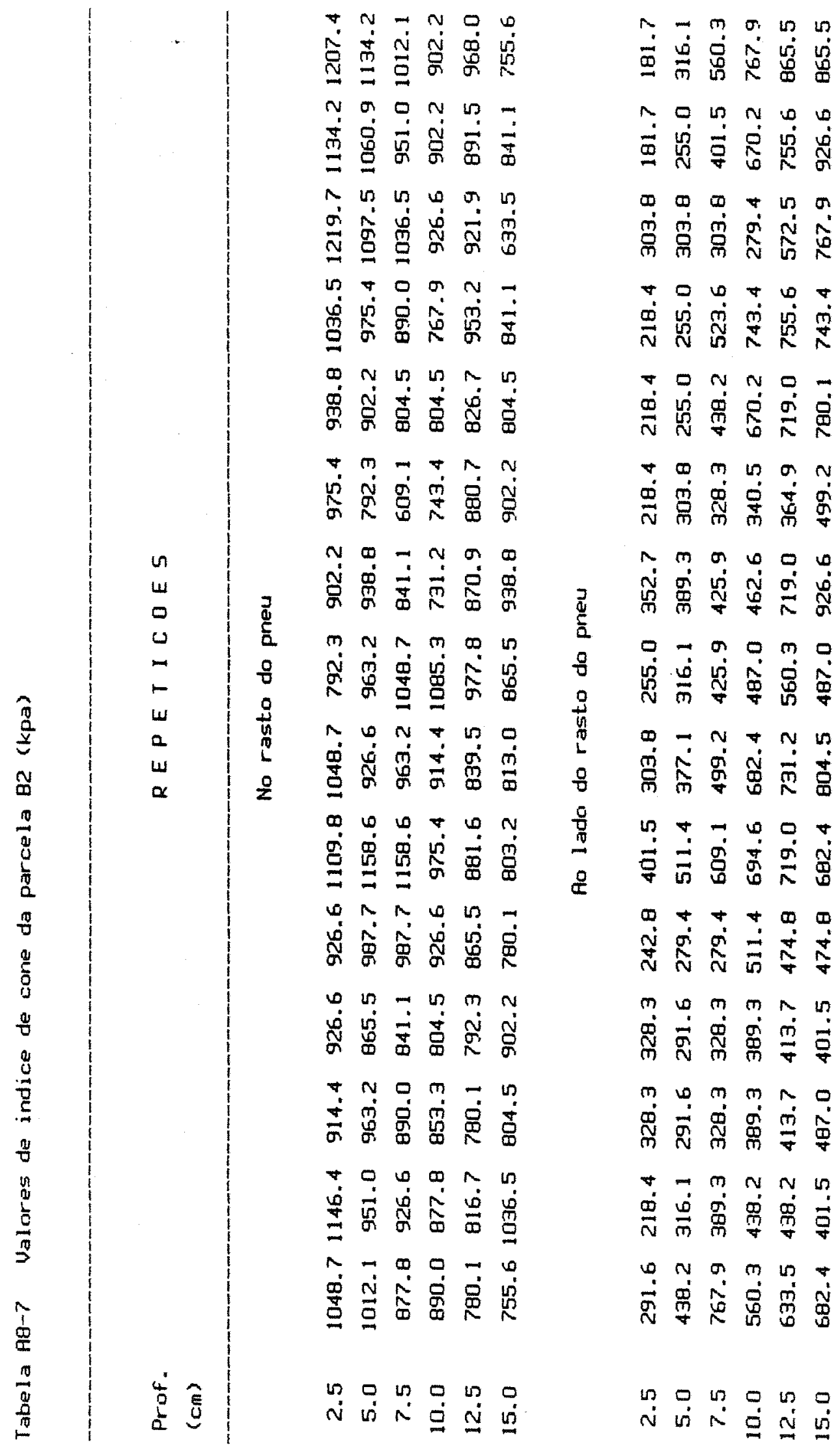




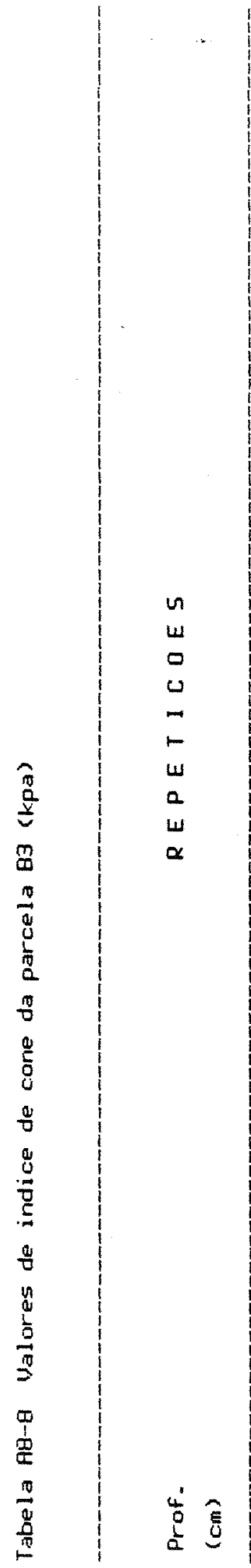

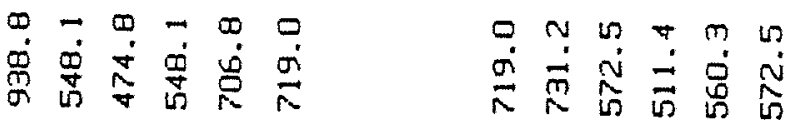

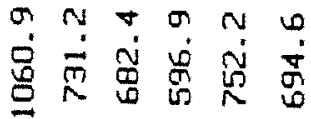

苞

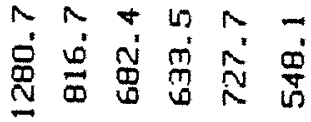

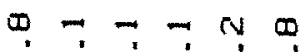

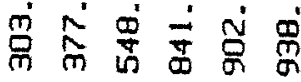

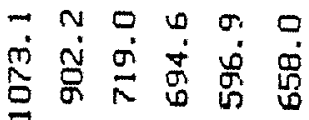

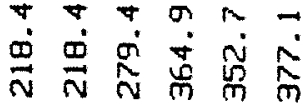

$0 \sigma \nabla-\infty n$

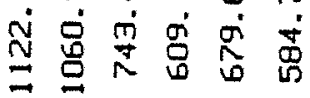

$\sigma-a N-$

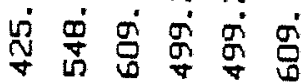

N $00 m \circ m$

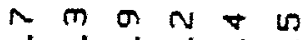

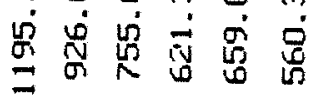

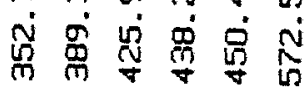

ก $\bullet \sim \sigma \rightarrow$

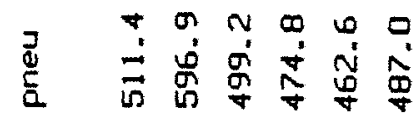

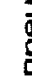

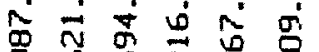

$\sim \sim m$ n $n$

m $m \propto n$ 웅

กิ่

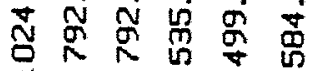

列

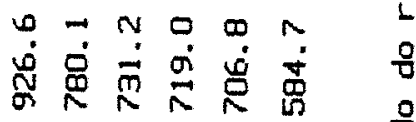

m $\bar{m}$ m

第

$m$ m $m$ o $\sigma \sigma$

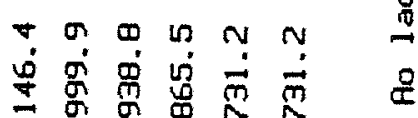

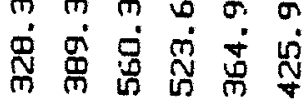

$0 \div 10=0$

$=\pi R$

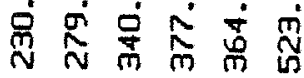

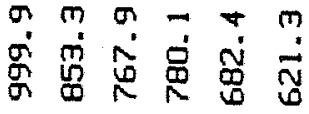

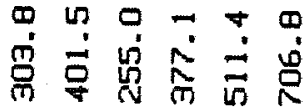

$\infty$ in $\infty$ o $n=$

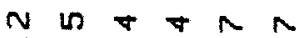

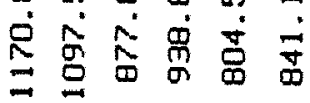

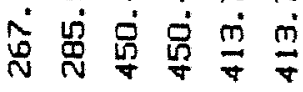

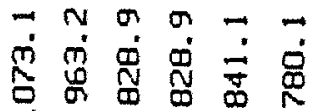

m

$\infty$ is o o n

$0 \pi N \infty$ แ

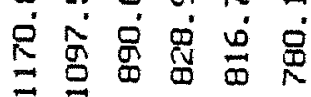

昜房界苦

$\omega=\sigma \quad \sigma=\sigma$

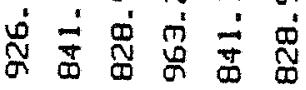

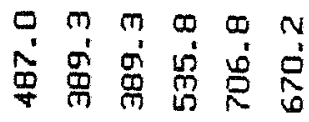

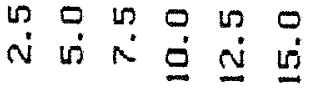

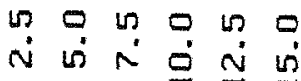




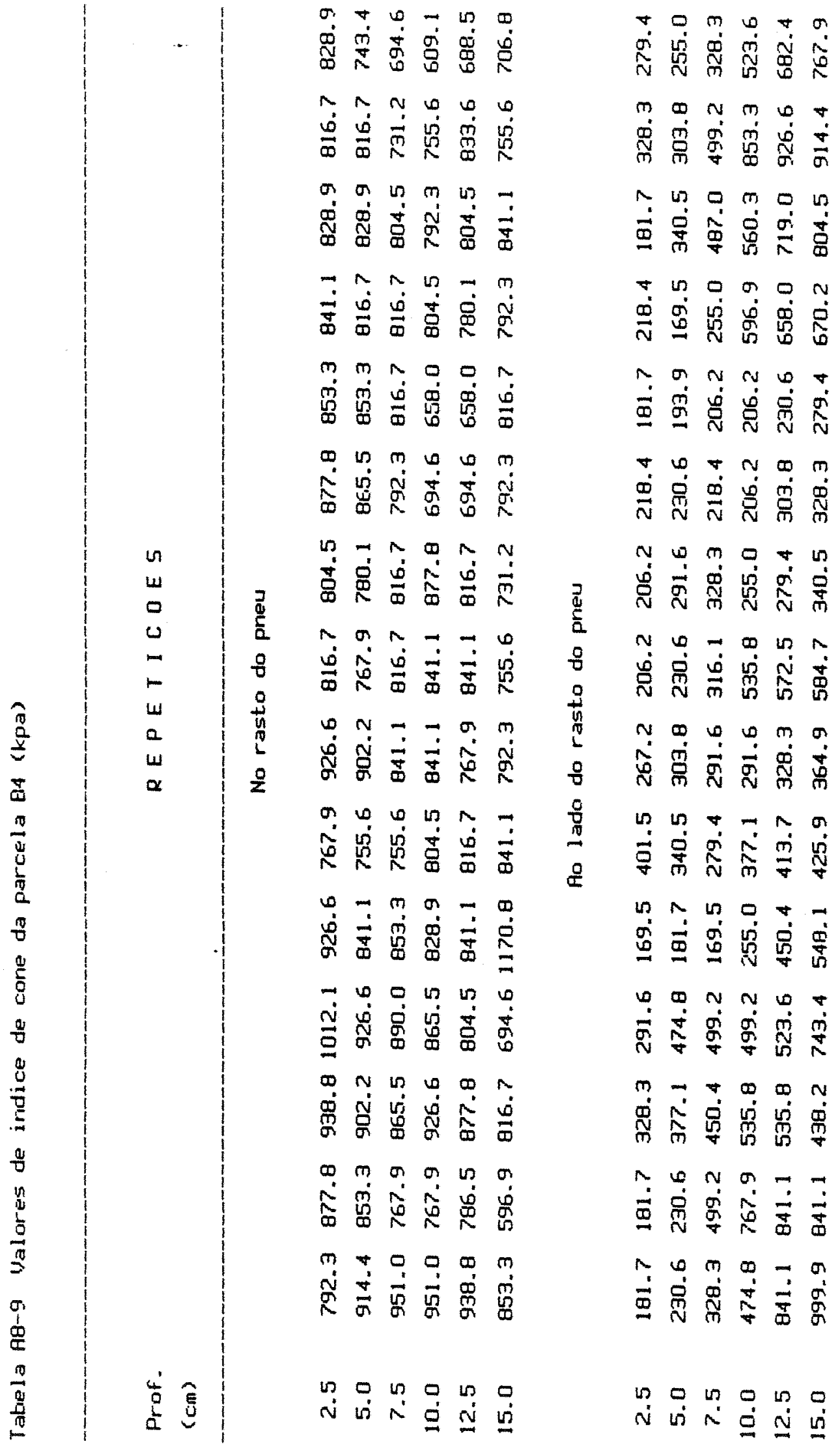




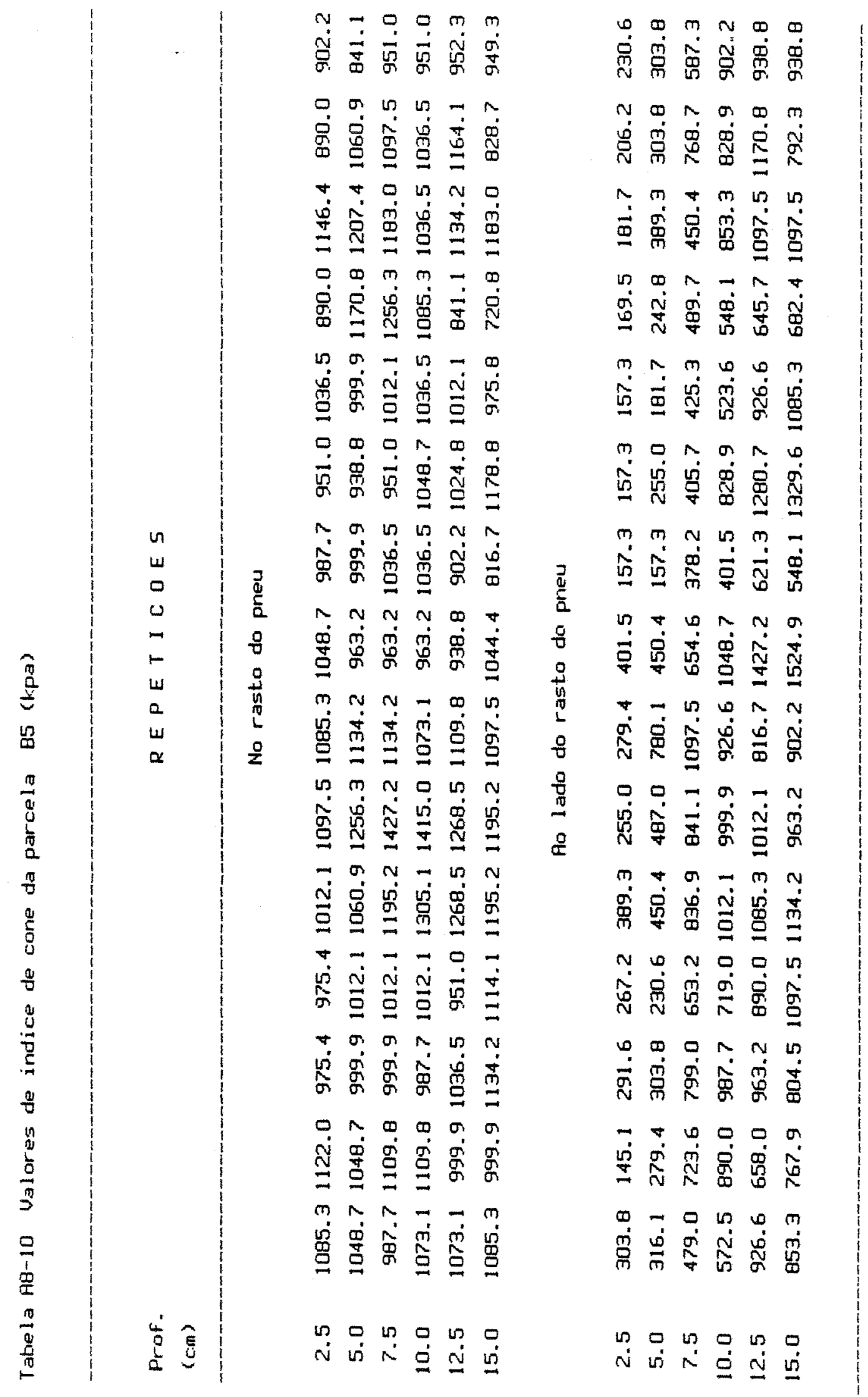




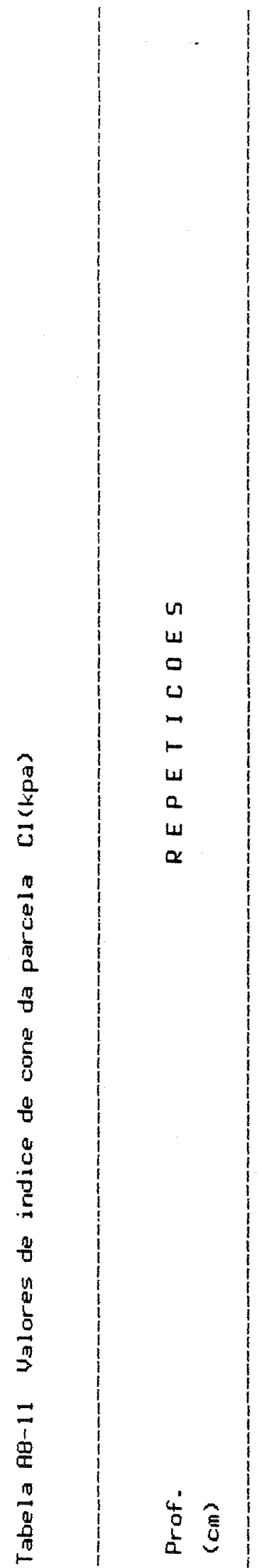

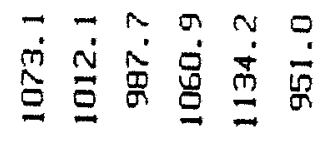

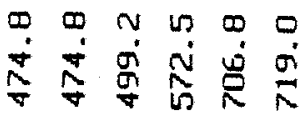

$\because \infty$ \% o $\sigma$ \%

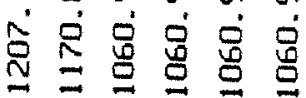

o $\infty=-N \Phi$

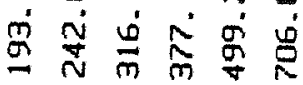

$\cap \sigma=0$ N

$\infty \quad 0 \quad 0$ 几

家完市恋等

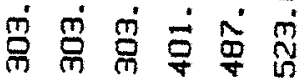

u $\rightarrow \square$ व 0

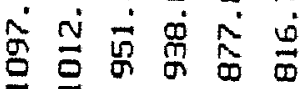

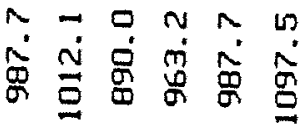

$0 \omega-\infty N N$

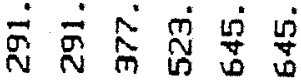

$-\ln n-N$ N

- in 00 u

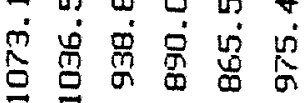

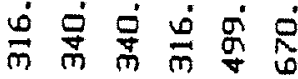

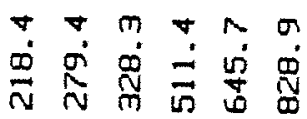

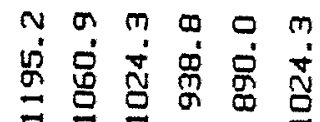

2

$m \sim$ un un

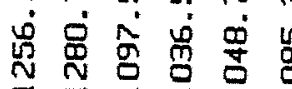

$-1=$

$0 \omega m+v$

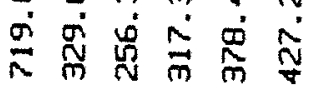

I $I$ 严

$\hat{n} \overrightarrow{\dot{v}} \hat{m} \dot{0}$

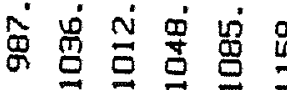

n is $\mathrm{NO}$ or $\mathrm{m}$

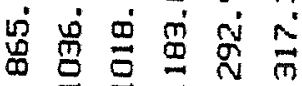

$\nabla \nabla r$

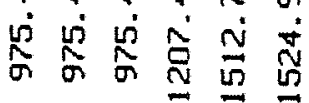

$\sim * N$ N $N$

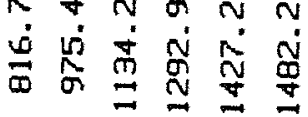

- In D $\sim \sim 0$

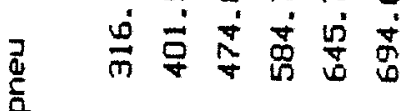

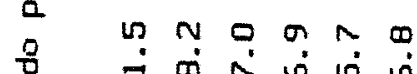

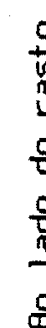

Nan u $n-N$

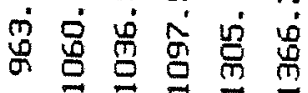

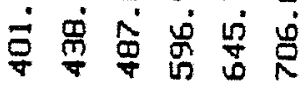

เ

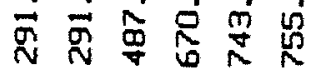

$0 N \infty-N N$

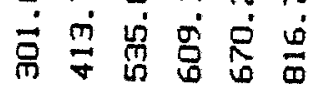

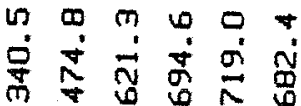

-

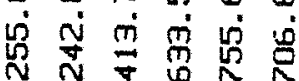

or $N$ un $N$ D

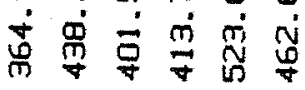

- $v m$ a n

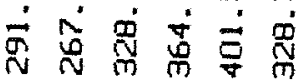

- $\infty$ us 0 a $N$

$\sigma N \omega+0 N$

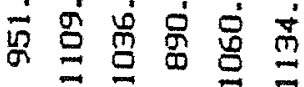

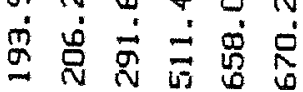

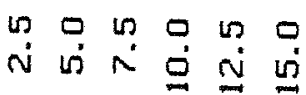

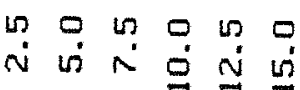




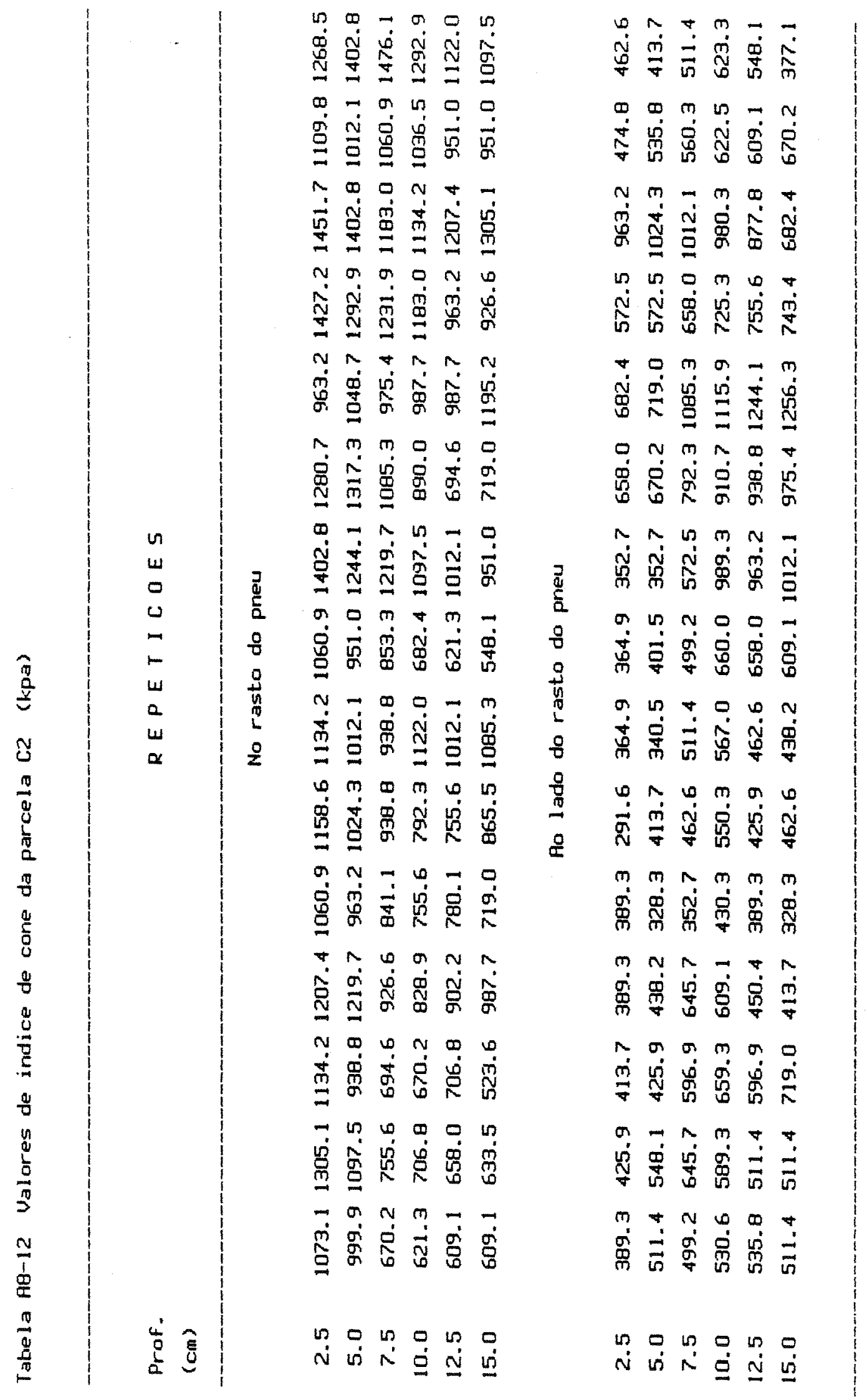




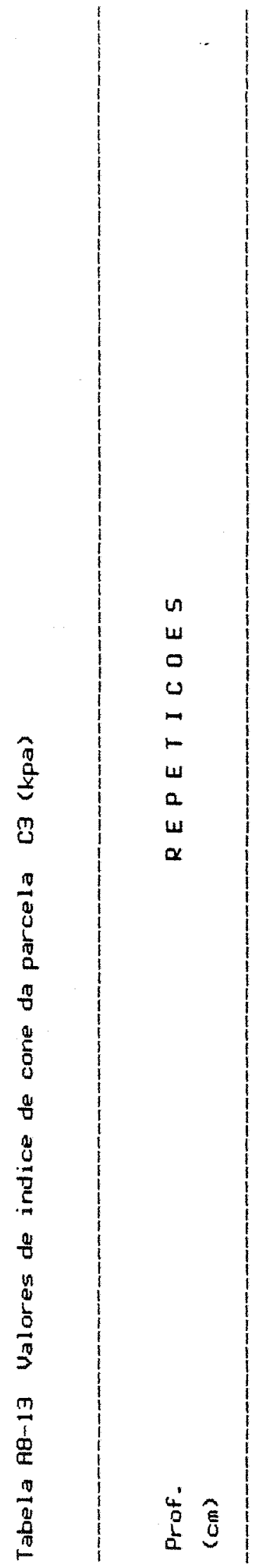

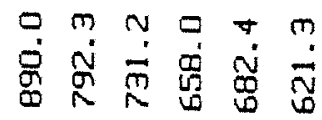

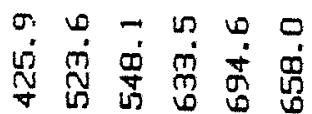

$0 N \div \nabla \infty 0$

0 or $\pi 00$ in

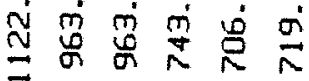

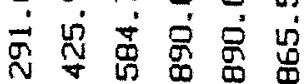

$\because 000$

$\because \because \ddot{n} \because \stackrel{n}{n}$

売罢虽志思

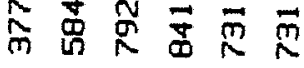

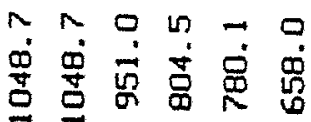

$-\omega N--0$

$\because+\infty \rightarrow 0 n$

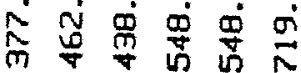

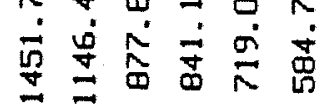

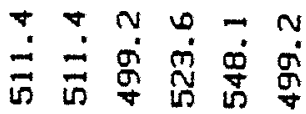

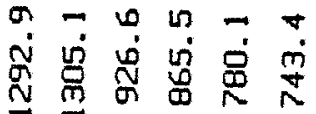

ก ?

- a - on n

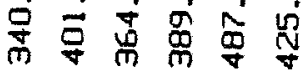

㐫怘㐫

$\frac{\vec{g}}{2}$

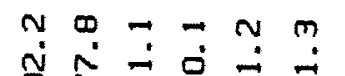

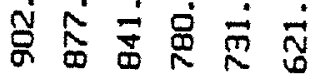

ษ

$=0$ or

ஸी น

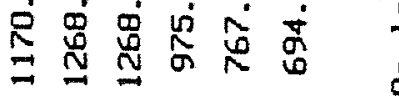

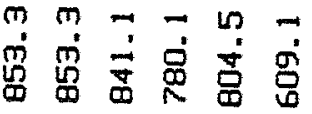

ก

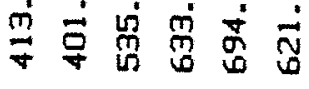

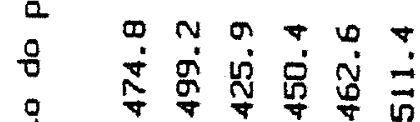

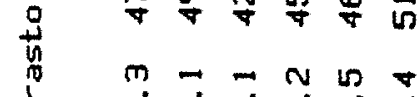

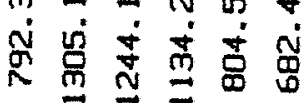

?

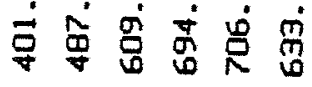

D $\omega-\nabla \omega$

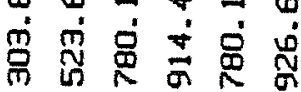

ğ

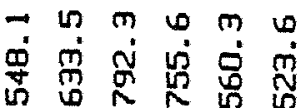

ก) ? 0 ก

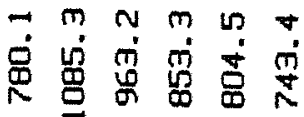

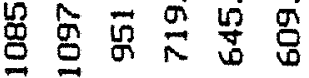

$\omega 0+\infty+n$

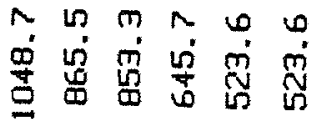

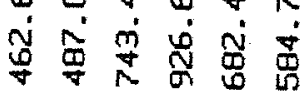

is on 0 a 0 or

$0 \div+\div+\frac{1}{1}$

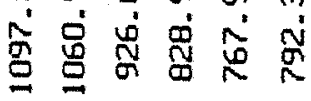

तु่

幺

ง 


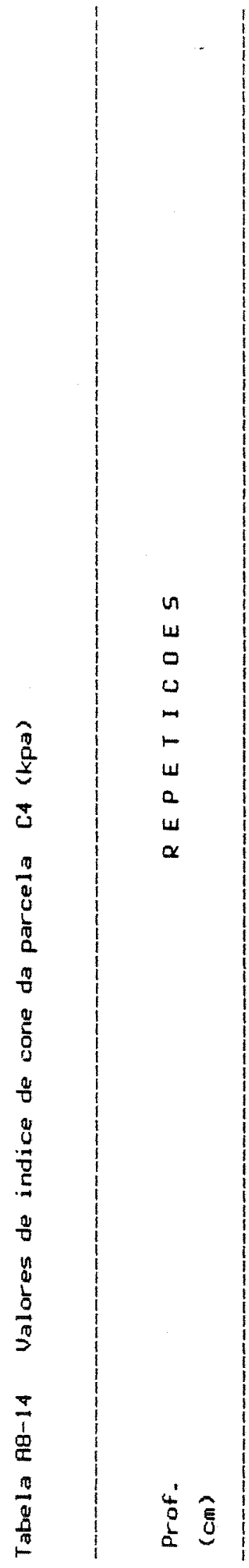

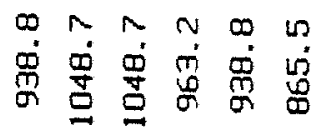

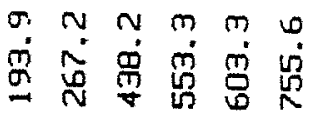

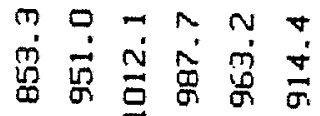

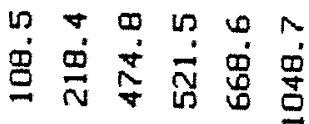

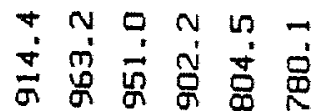

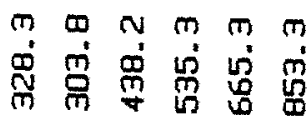

- $\backsim 0$ u

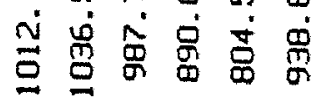

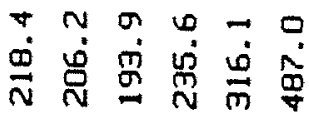

ก $\nabla 0 \infty \infty$

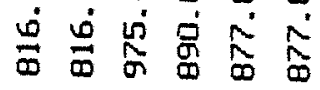

NoN $0 N+$

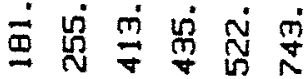

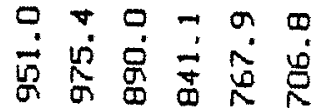

n $v m+m-$

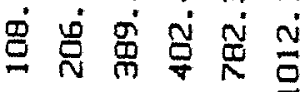

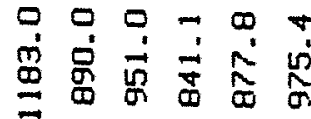

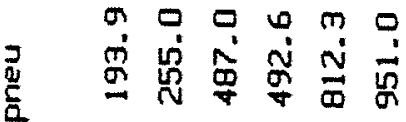

政

$\ln \sim \infty \sim N$

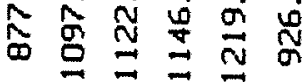

$\frac{9}{n+\frac{\pi}{0}}$

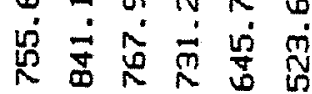

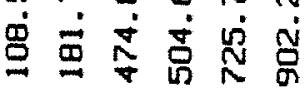

$\because \forall 0 \div$ in

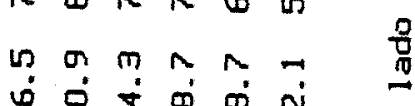

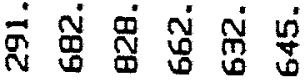

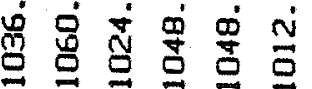

$\infty m+m+\infty$

$\stackrel{0}{a}$

b $\rightarrow$ 几

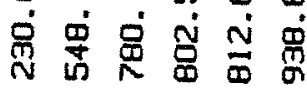

总票宁

$N N$ un un m

$\forall-N-N$

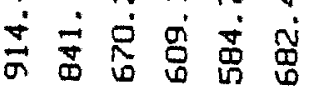

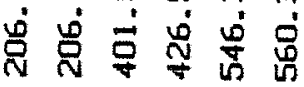

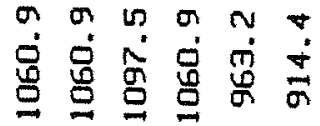

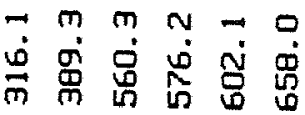

ก ก

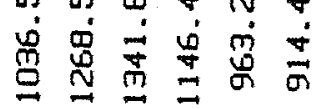

$m+\infty 0 \sigma 0$

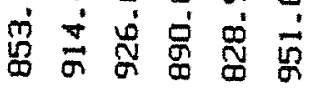

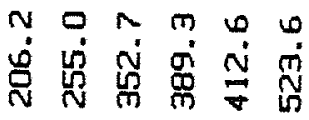

$N \nabla N \div N m$

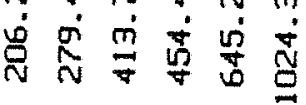

$+\sim \omega N N$ N

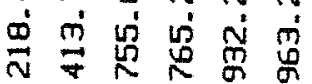

กิ

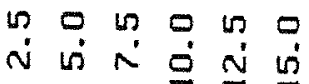




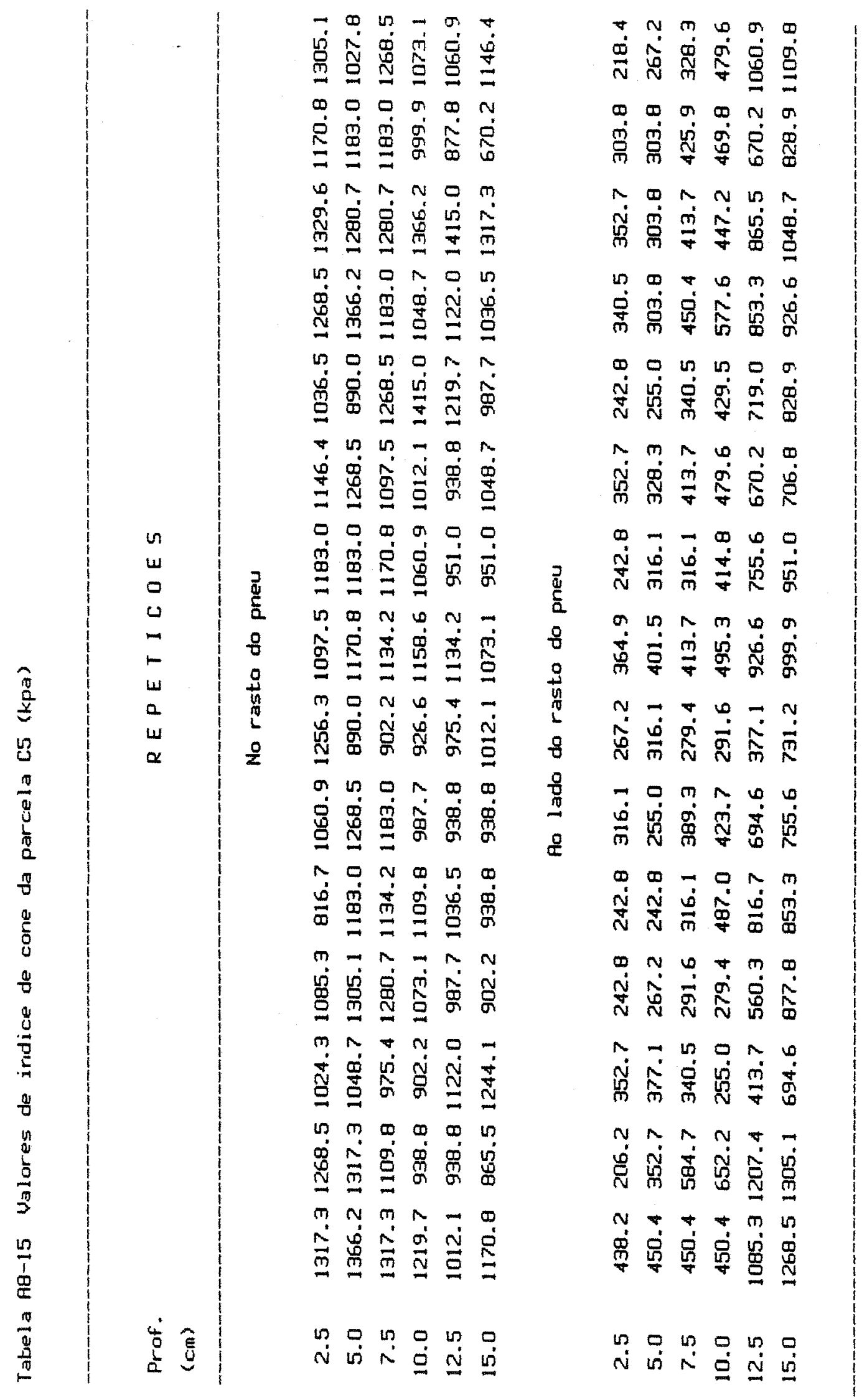




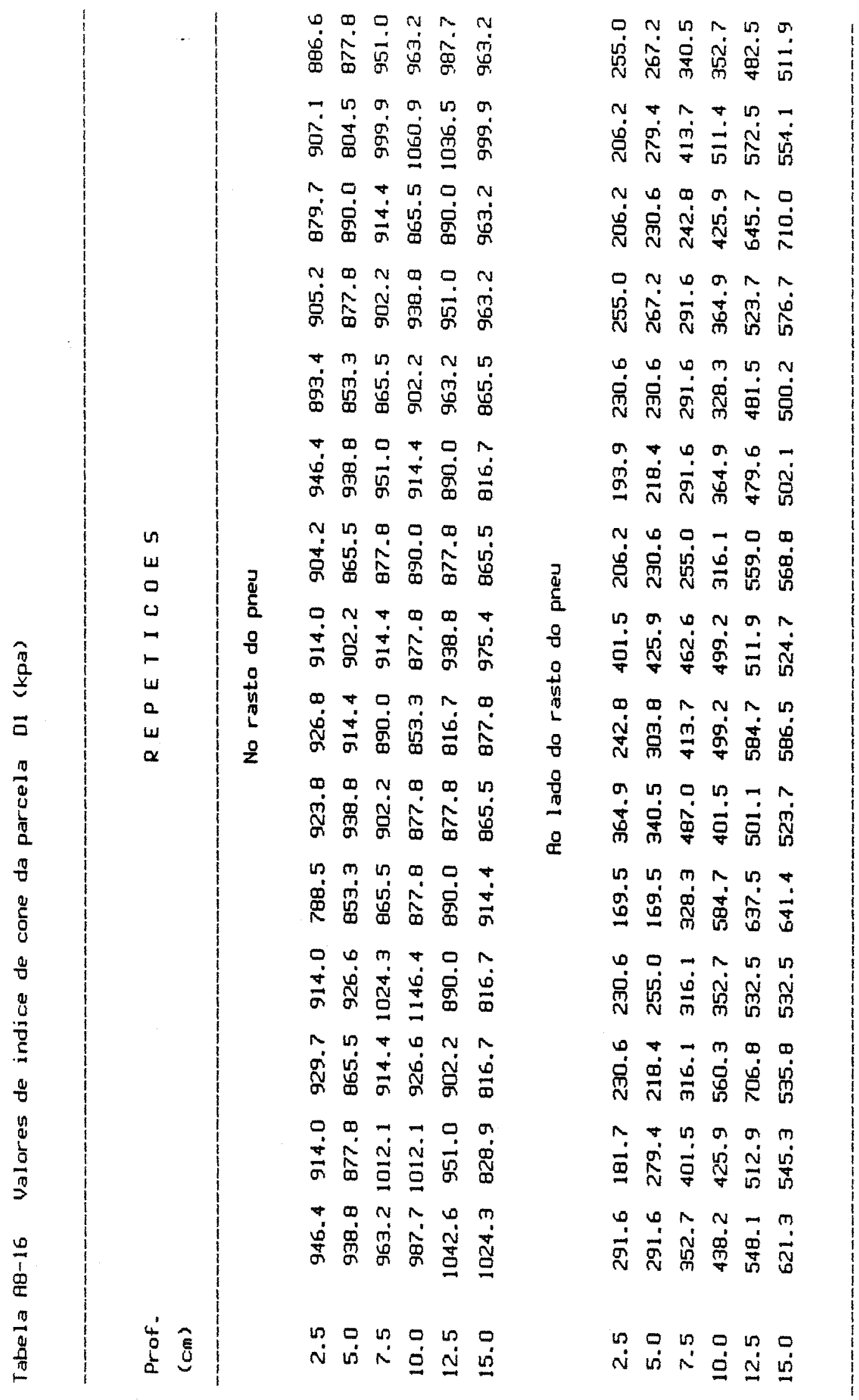




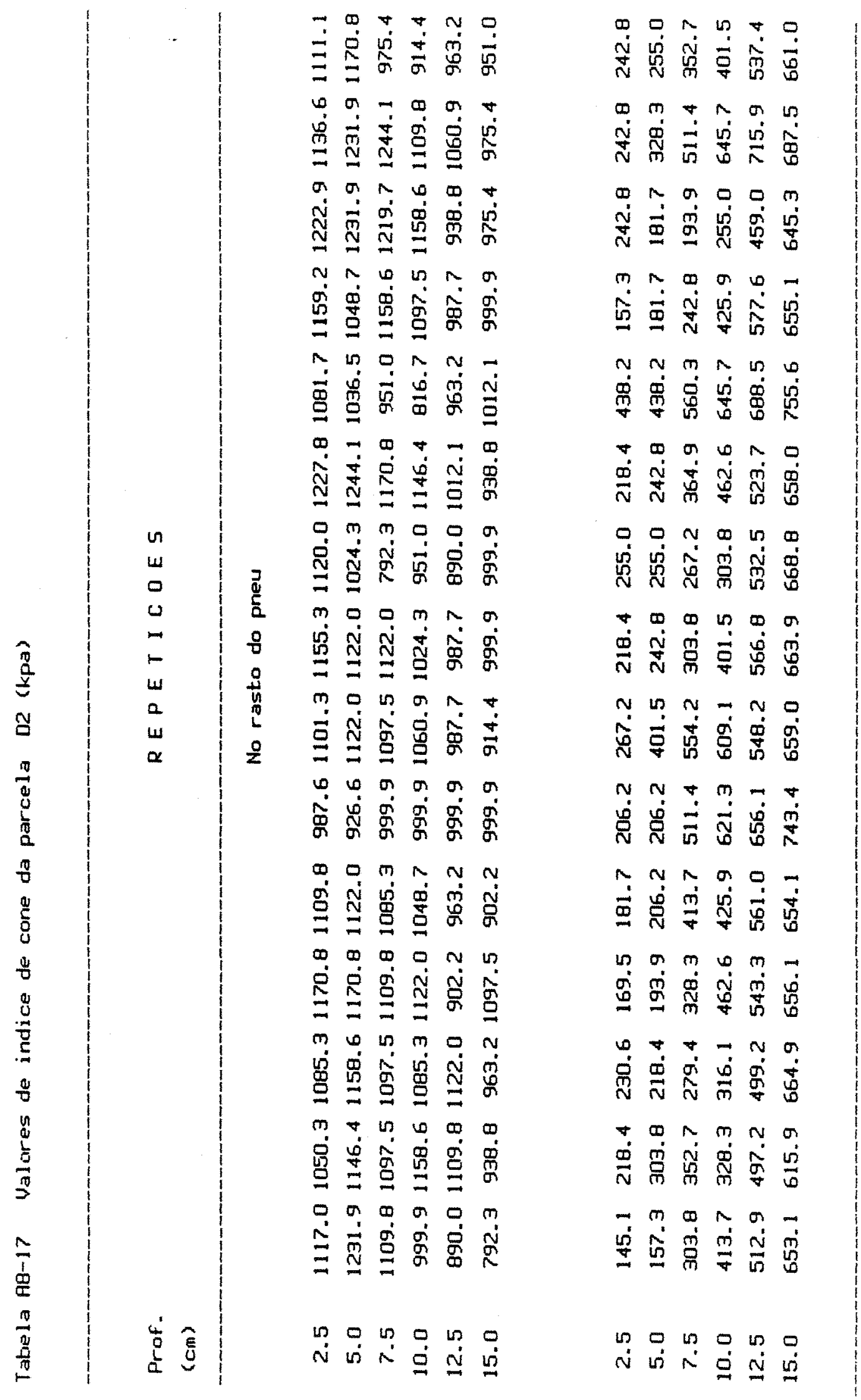




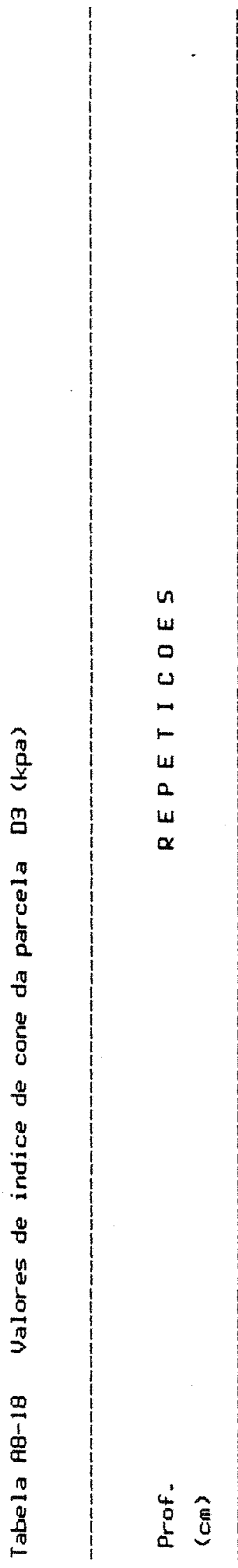

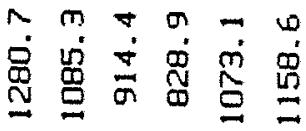

a $n+-1$

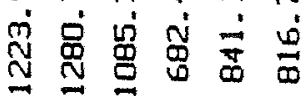

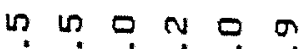

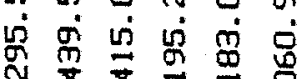

$\simeq \pm \pm \Xi \equiv \Xi$

$\Rightarrow m \sigma a$

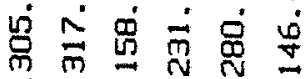

$\stackrel{m}{m} \approx \stackrel{N}{\sim}=$

(n) $\infty \sim \infty$ o n

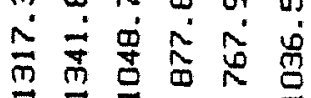

$m \sim \sim \omega \wedge \omega$

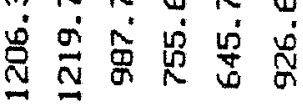

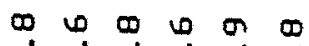

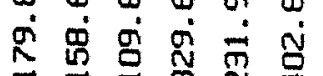

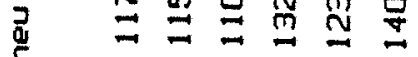

立 $\sim m \infty=$ un

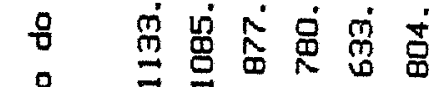

$\frac{9}{4}$

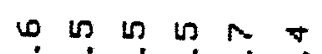

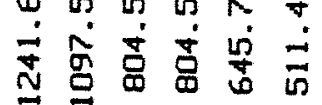

an $n \pi$

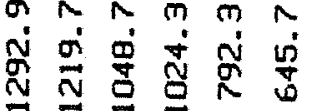

n 0 0

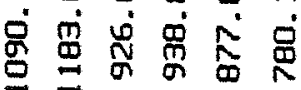

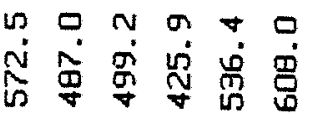

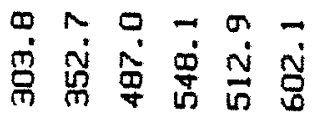

品离

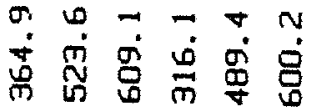

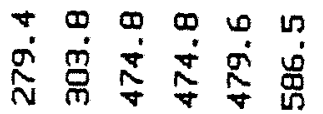

の $\infty$ o $\infty$ -

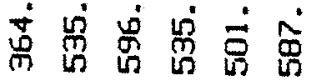

or 0 o $0 \mathrm{~m}$

ம் $\dot{\Omega} \dot{g} \dot{\vec{n}}$

$\equiv \equiv \sigma \infty$

$\sim \neg \infty$ on $N$

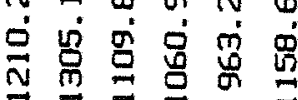

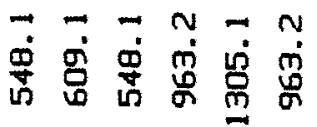

立

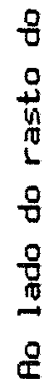

$\sim \infty N \sim \nabla$

营

u $\nabla=\nabla N$

ํํㅇ

$\infty \omega \pi n$ n

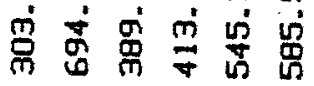

D $\rightarrow \sim N N$

ஸ゚

$\infty \square \div \sigma \div \omega$

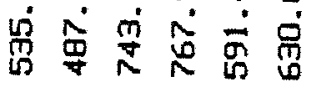

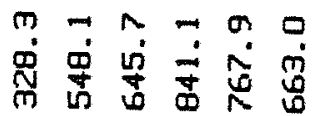

$0 \div \omega 0 \div \infty$

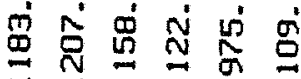

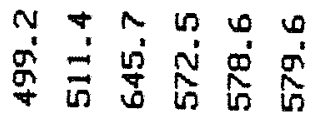

$\infty$ un a

$\Rightarrow$ un 0

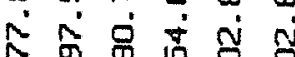

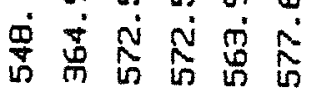

命总兽亭

ஸี 


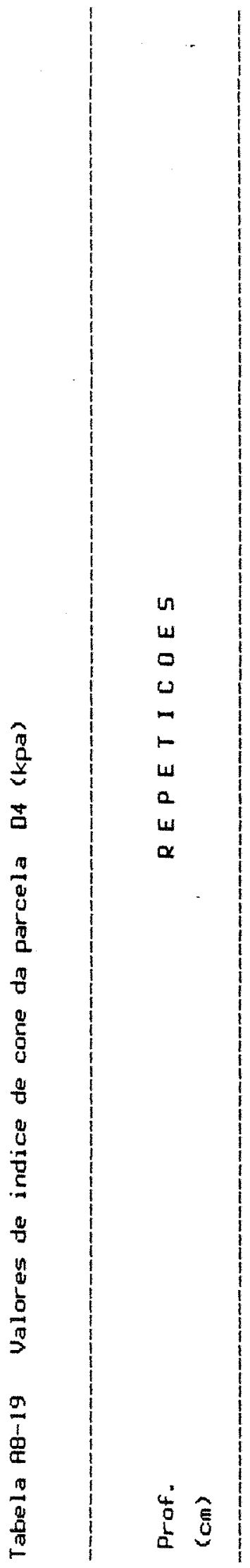

ヘُ

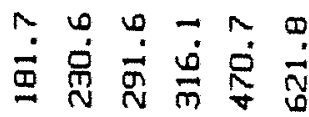

$m \cap \cap=0$

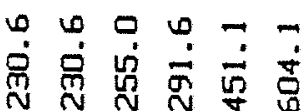

$\Xi$ 의

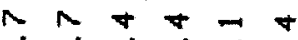

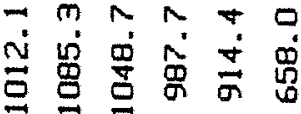

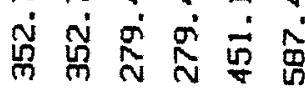

$m \rightarrow 0 \omega \infty$

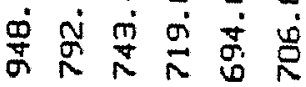

+ 0 กm

- 0 o r m n

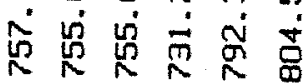

แ ก $\div-\infty$

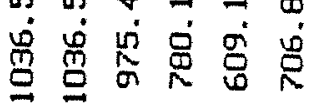

完总岗

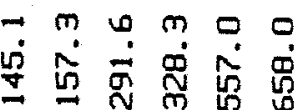

$0+-\infty-\infty$

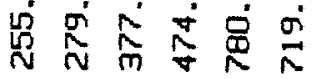

$0 \square \div=\sigma$

u a $m$ or or

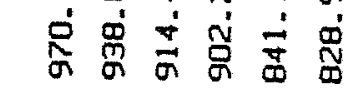

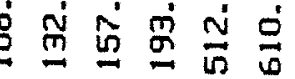

ก $N=-\infty$

苋兽导市离

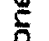

ก 2 U 0 \%

무

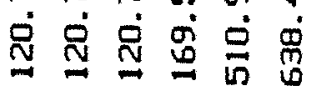

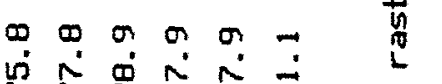

ง $\% N \infty N$

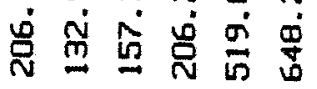

o 0 \& $\sigma 0$

ஸ்

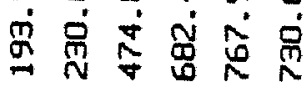

$+\infty+70$

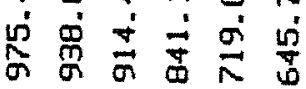

u 0 0 O N n

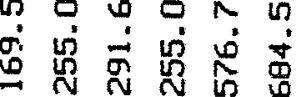

$N D N$ in 0 n

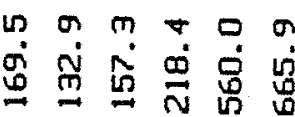

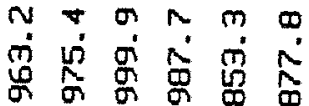

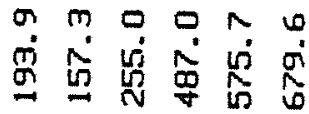

$\checkmark N \wedge N m$

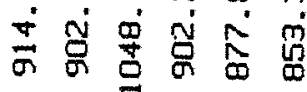

m or $m$ on $n$

$\infty \phi+N \infty$

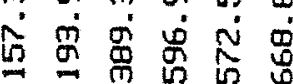

幖息宁

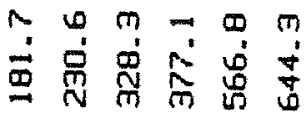

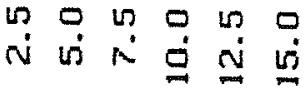

ڤั 


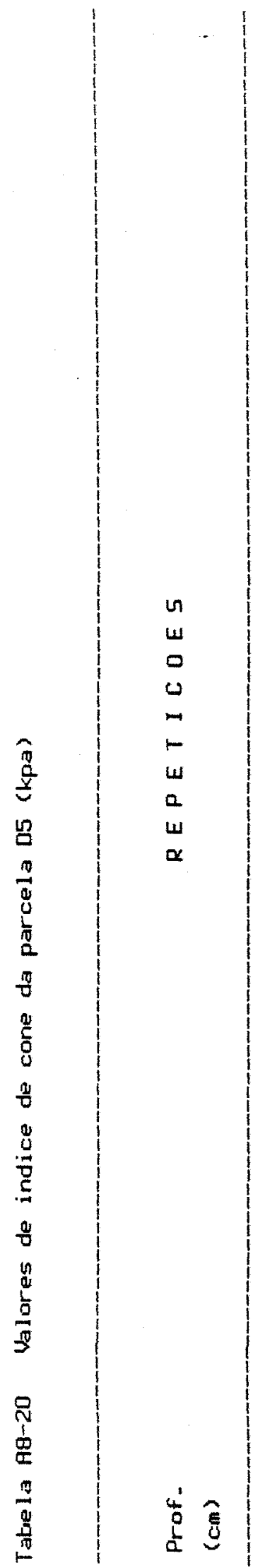

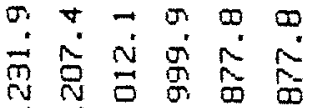

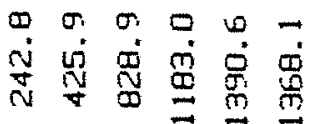

0 뭉

\% $\rightarrow \div \div 0$

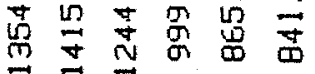

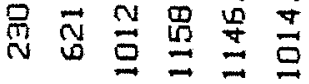

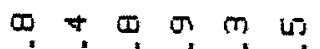

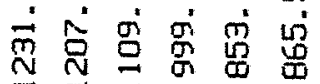

+ $N$ is $\overline{0} 0 \pi$

$\infty \sigma \nabla+\Omega$

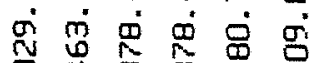

กั

DN $\forall+\infty$

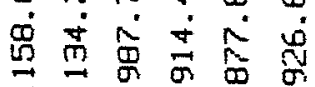

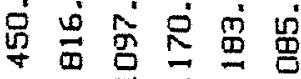

$=\equiv$ a d

$0-N+n$

o. on $\mathrm{n}$ ?

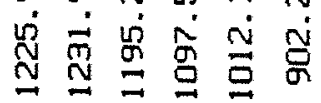

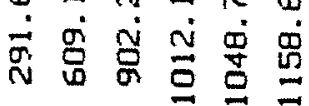

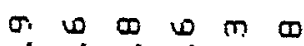

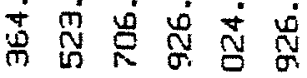

n $-\infty$ on

$\sigma 0 \geqslant \omega \pi$

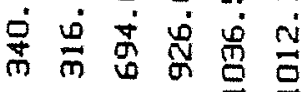

ர் 囱

$\sim \omega \sim \omega m$

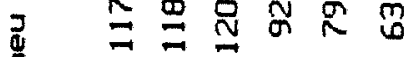

政

ก $+\omega \div 0$ แ

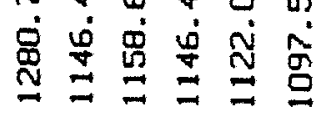

$\infty+\% \sigma \sigma \%$ in

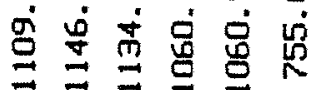

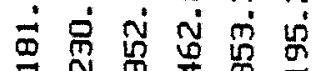

20

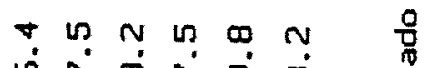

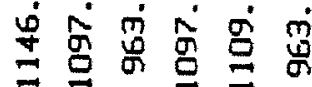

$\rightarrow \infty 0 N o$

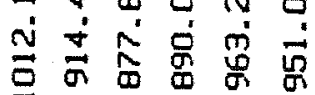

온

$\pi \rightarrow$ un 0

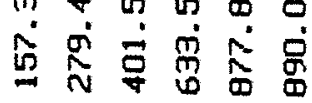

$\rightarrow N \infty$ in

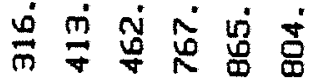

n m $\infty n-10$

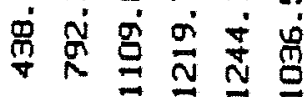

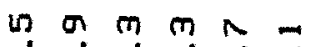

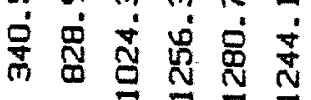

m $m$ 曲 n

$\sigma m+\sigma N \sigma$

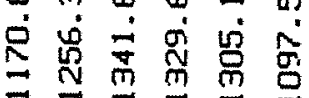

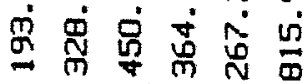

மก Un

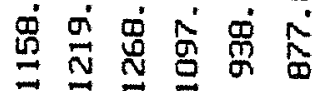

$m 0$ or $0 N m$

$+n-\sigma \sigma$

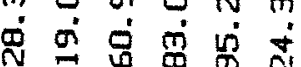

กิ $\cong \stackrel{0}{=}$

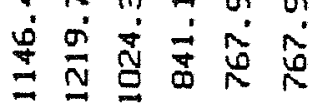

a $N=n$

$-\infty-+\infty$

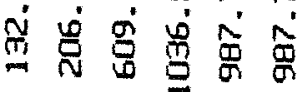

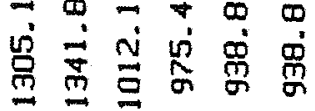

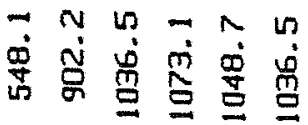

ஸ่

แั 
- APENDICE 9 :

Teste de tukey para as médias de
profundidade dentro de cada nível do fator patinagem,
realizado com os dados de indice de cone obtidos ao lado
do rasto do pneu.

TESTE DE TUKEY PARA MEDIAE DE PROFUHD

\begin{tabular}{|c|c|c|c|c|c|c|}
\hline WO.OREEH & NUL.TART. & WOHE & WHEAEFET. & MEDIAG & MENIAS ORIEINAIS & $5 \%$ \\
\hline 1 & $\varepsilon$ & 15.6 & 20 & 735.775000 & 735.775000 & a \\
\hline 2 & 5 & 12.3 & 20 & 680.349995 & 680.349955 & $s$ \\
\hline$\tilde{j}$ & 4 & 10.0 & 20 & 576.764998 & 576.764998 & $b$ \\
\hline 4 & 3 & 7.5 & 20 & 492.790001 & 492.790001 & 5 \\
\hline 5 & 2 & 5.0 & 20 & 371.310001 & $37 \div .310001$ & $\varepsilon$ \\
\hline 6 & $:$ & 2.5 & 20 & 317.600000 & 317.680000 & $\tau$ \\
\hline
\end{tabular}

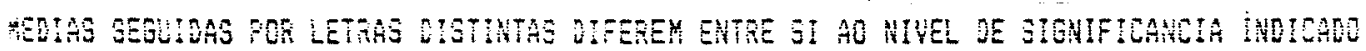
3.ห.S. $3 \%=91.71070$ 


\begin{abstract}
Teste de Tukey para as médias de profundidade dentro de cada nivel do fator patinagem. realizados com os dados de indice de cone obtidos na linha de centro do rasto do pneu
\end{abstract}

TESTE DE TUKE! PARA MEUAS JE PATHAG

\begin{tabular}{|c|c|c|c|c|c|c|}
\hline HW.OSEE & HUFIRAT. & NOME & NUMAREP. & ALDIAS & MEDIAS ORIGINATS & $5 \%$ \\
\hline : & 4 & 50 & 30 & 1000.230007 & 5000.230007 & $a$ \\
\hline$z$ & $i$ & 3 & 30 & 994.719995 & 994.719995 & $\dot{a}$ \\
\hline 3 & $\bar{z}$ & 10 & 30 & 734.650000 & 734.050000 & 0 \\
\hline 4 & \pm & 3 & 30 & 316.483327 & 916.483727 & b \\
\hline
\end{tabular}

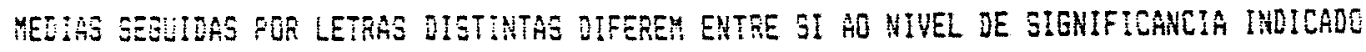
O....S. $z_{2}=55.0427$

TESTE UE TUEY PAFA MEDIAS DE FATIMAG

DENTRO DE 2.5 DO FATOR RROFWD

\begin{tabular}{|c|c|c|c|c|c|c|}
\hline autoongy & MUA.TART. & WOHE & WLAREET. & MENAS & MEDIAS ORIGINAIS & $3 y$ \\
\hline$!$ & $\dot{j}$ & 20 & $\vdots$ & 1079.459798 & 1079.4599996 & a \\
\hline 2 & 4 & 50 & 5 & 1078.180017 & 1078.580017 & a \\
\hline$z$ & 2 & $: 0$ & $\Sigma$ & 765.100000 & 965.100000 & $a$ \\
\hline$\frac{1}{4}$ & $\vdots$ & 0 & $\Xi$ & 904.397990 & 704.857998 & 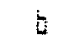 \\
\hline
\end{tabular}

TESTE IE FUEY FGFA YEDAAS DE FATMNG

DEVTHO UE 5.0 DO FATOR RRORLD

\begin{tabular}{|c|c|c|c|c|c|c|}
\hline Hu. Arrey & HUH. ThAT. & ngue & MHABEET. & YEVTAS & MEUIAS URISHATS & 5 \\
\hline . & 4 & 30 & $z$ & 1075.30007 & 0079.320007 & $\vdots$ \\
\hline$z$ & 8 & 20 & $\vdots$ & 2069,200005 & 1067.390005 & a \\
\hline$\Xi$ & $z$ & $\because$ & $\vdots$ & 360.34002 & 960.34000 & $\vdots$ \\
\hline 4 & $\vdots$ & $\dot{a}$ & $\vdots$ & $745.4400 \mathrm{~L}$ & 713.440015 & 5 \\
\hline
\end{tabular}




\section{CONTINUACAO :}

TEETE DE TUEE FARA MEDTAG DE PATHAE

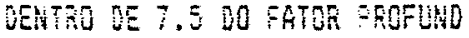

\begin{tabular}{|c|c|c|c|c|c|c|}
\hline HH. GAEY & BUA.PAAT. & WOHE & WU, AEFET. & MEDIAS & MENTS ORIGIVAS & $5 \%$ \\
\hline$-\cdots$ & . & & & & 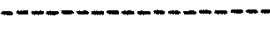 & \\
\hline : & 4 & 30 & $\vdots$ & 1027,500012 & 1027.500012 & 3 \\
\hline$E$ & 3 & 20 & 5 & 1021.200000 & 1022.200000 & j \\
\hline $\bar{z}$ & 2 & 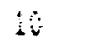 & 3 & 941.459905 & 741.459955 & $\dot{3}$ \\
\hline 4 & $\vdots$ & 0 & 5 & 927.260010 & 927.260010 & $a$ \\
\hline
\end{tabular}

TEETE DE TUKEY FARA MEDIAS DE FATHAG JEITAO DE 00.0 DO FATOR PROFIND

\begin{tabular}{|c|c|c|c|c|c|c|}
\hline WHA. MNEY & WUH.TRAT. & NOHE & HUM.REFET. & YEDIAS & MEDIAS OEIBIMAIS & $5 \%$ \\
\hline & & & & & & \\
\hline$\vdots$ & 4 & 30 & $\Sigma$ & 777.220007 & 977.220007 & 3 \\
\hline$\hat{3}$ & $j$ & 20 & $\Sigma$ & 758.519785 & 75E.519985 & $\dot{a}$ \\
\hline 3 & $t$ & 0 & 5 & 925.719903 & 925.719983 & 3 \\
\hline 4 & 2 & 10 & 5 & 919.460010 & 919.460010 & a \\
\hline
\end{tabular}

TESTE DE TUKEY PARA MEDAAS DE PATHAG DENTO DE 22.5 DO FATOR PROFUND

\begin{tabular}{|c|c|c|c|c|c|c|}
\hline :UH, BroE: & MEW TART. & WOHE & HUAREPE. & HEDIAS & HEDIAS OFIGIMAIS & $5 \%$ \\
\hline : & 4 & 30 & 5 & 927.780005 & 927.980005 & a \\
\hline 2 & $\vdots$ & $\mathrm{b}$ & $\Xi$ & $727.5: 9783$ & 727.517983 & $a$ \\
\hline$\xi$ & 3 & 20 & $\xi$ & 927.239778 & 927.239773 & $a$ \\
\hline 4 & 2 & 10 & $\bar{j}$ & $9: 7.500000$ & 919.500000 & $a$ \\
\hline
\end{tabular}

TEETE DE UUEY PARA HEDIAS DE FATIMAE DENTSO DE SE.O DO FATOR PROFUMD

\begin{tabular}{|c|c|c|c|c|c|c|}
\hline Hit.OSOE & AUW.TERT. & WOHE & WUM, GEET. & AEDIAE & MEDIAS OEISINAIS & $5 \%$ \\
\hline$\vdots$ & $\dot{x}$ & 30 & $\vdots$ & 712.520007 & 912.520007 & $\ddot{a}$ \\
\hline$i$ & 4 & 50 & 5 & 714.179795 & 911.179795 & $a$ \\
\hline$j$ & 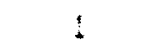 & 0 & 5 & 900.998998 & 900.097998 & $\mathrm{j}$ \\
\hline$\frac{2}{4}$ & 2 & $: 3$ & $\xi$ & 398.500000 & 898.500000 & $\dot{a}$ \\
\hline
\end{tabular}

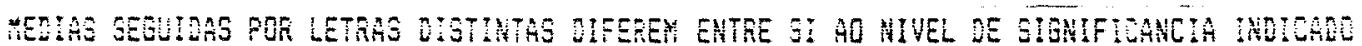
U..... 


\section{CONTINUACEAO :}

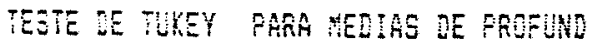

\begin{tabular}{|c|c|c|c|c|c|c|}
\hline NWW GRE & MUE.TFAT. & None & MHAREFT. & MEDIAS & MEDIAS ORIGIMAS & 5 \\
\hline$i$ & i & 2.5 & 20 & 1006.800003 & 1006.900005 & $\mathbf{j}$ \\
\hline 2 & 2 & 5.0 & 20 & 0005.620007 & 1005.620007 & $\mathrm{z}$ \\
\hline$j$ & 3 & $7 . z$ & 20 & 777.355002 & 777.355012 & is \\
\hline 4 & 4 & 00.0 & 20 & 745.227996 & 945.229796 & is \\
\hline 5 & 5 & $: 2.5$ & 20 & 925.559991 & 925.559991 & $b$ \\
\hline$s$ & $b$ & 15.0 & 20 & 705.574997 & 705.574797 & 5 \\
\hline
\end{tabular}

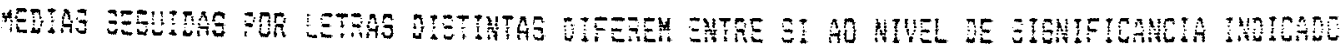
J.H.S. $5 \%=75.02779$

TESTE UE TUES PARA MEDIAS DE PROFLWD

DENTE DE O DO FATOR FATINAG

\begin{tabular}{|c|c|c|c|c|c|c|}
\hline WUH. OSDEN & HUH.TAAT. & Mone & WUM AEFET. & MEDIAS & MEDIAS ONIGINAIS & $5 \%$ \\
\hline & & & & & & \\
\hline 1 & $\xi$ & 2.5 & 5 & 727.519983 & 727.519733 & $\dot{a}$ \\
\hline 2 & 3 & 7.5 & $\bar{\xi}$ & 927.260010 & 927.260010 & $\dot{a}$ \\
\hline 3 & 4 & 00.0 & 5 & 925.7 .9783 & 925.719983 & $a$ \\
\hline 4 & 2 & $\Sigma 0$ & $\Xi$ & 713.440015 & 913.440015 & $a$ \\
\hline $\bar{j}$ & $\vdots$ & 2.5 & 5 & 904.859990 & 704.559998 & $a$ \\
\hline b & $b$ & 5.6 & $\xi$ & 700.099989 & 900.097980 & 3 \\
\hline
\end{tabular}

TESTE DE TUKEY PARA HENTAS DE PROFUMO DENTRO IE IO DO FATOR FATIMAE

\begin{tabular}{|c|c|c|c|c|c|c|}
\hline WH. SREF & M:JH.TFAT. & MOYE & MU.AEFET. & MEDIAG & HEDIAS ONISIMATS & $\xi \%$ \\
\hline i & $:$ & 2.5 & $\Sigma$ & 965.100000 & 965.100000 & $\dot{a}$ \\
\hline 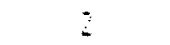 & 2 & 5.0 & $\Sigma$ & 760.340002 & 760.340002 & i \\
\hline 3 & 3 & 7.5 & 5 & 742.457985 & $94: .459985$ & a \\
\hline 4 & 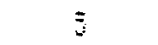 & +2.5 & $\xi$ & 919.500000 & 919.500000 & j \\
\hline$\Xi$ & $\div$ & 10.0 & $\varepsilon$ & 727.460010 & 919.460010 & a \\
\hline$\vdots$ & s & $15 . j$ & $\xi$ & 398.500000 & 998.500000 & $\mathrm{a}$ \\
\hline
\end{tabular}


CONTINUAÇAO :

-ESTE DE TLEE PARA HEDIAS DE BROFUND

DEHTRO IE 2O DO FATOR PATINAG

\begin{tabular}{|c|c|c|c|c|c|c|}
\hline WHA OROEY & WUK.TRET. & MOHE & HU SEPET. & HEDIAS & MEDIAS ORIGINATS & $5 \%$ \\
\hline$\dot{i}$ & $\vdots$ & 2.5 & 5 & 1077.459998 & 1077.459798 & a \\
\hline 2 & $z$ & 5.0 & $\xi$ & 1067.380005 & 1069.330005 & $a b$ \\
\hline$\tau$ & 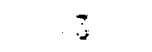 & 7.5 & 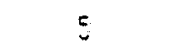 & 1028.200000 & 1023.200000 & abt \\
\hline 4 & 4 & 10.0 & 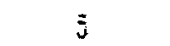 & 758.519983 & 958.519993 & abc \\
\hline 5 & 5 & 12.5 & $\Xi$ & 927.239978 & 927.237978 & be \\
\hline$b$ & $b$ & $\$ 5.0$ & 5 & 912.520007 & 912.520007 & $\varepsilon$ \\
\hline
\end{tabular}

TESTE DE TUKEY PARA HEDIAS DE PROFUUO

DENTRO JE 30 DO FATOR FATINAG

\begin{tabular}{|c|c|c|c|c|c|c|}
\hline Hu. OANEY & WUH.TAAT: & NOHE & :UUИ. REFET. & MEDIAS & MEDIAS ORIGIHAIS & $5 \%$ \\
\hline & & & & & $1070=5 A \cap 07$ & \\
\hline 1 & 2 & 5.0 & 5 & 1077.320007 & 1077.320007 & a \\
\hline 2 & $\vdots$ & 2.5 & 5 & 1073.180017 & 1078.180017 & $a$ \\
\hline 3 & 3 & 7.5 & 5 & 1027.500012 & 1027.500012 & $a b$ \\
\hline 4 & 4 & $\$ 0.0$ & 5 & 777.220007 & 777.220007 & at \\
\hline$\xi$ & 5 & 12.5 & 5 & 927.980005 & 927.780005 & $b$ \\
\hline$b$ & $b$ & 15.0 & $\overline{5}$ & 711.179995 & 911.179993 & $b$ \\
\hline
\end{tabular}

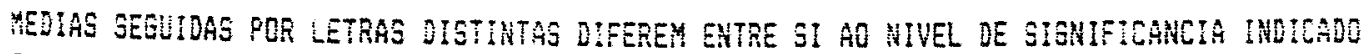
D.R.S. $5 \%=150.05557$ 
Teste de Tukey com os valores líquidos de índice de cone para as médias de patinagens, patinagem dentro de cada fator de profundidade, profundidade dentro de cada fator de patinagem.

TESTE DE TUKEY FARA MEDIAS DE PATHAO

\begin{tabular}{|c|c|c|c|c|c|c|}
\hline Whot.oricen & 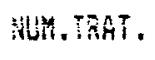 & nome & MH. REFET. & MEDIAS & MEDIAS DRIOINATS & $5 \%$ \\
\hline 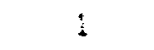 & 4 & 30 & BO & 476.633723 & 476.633327 & a \\
\hline 2 & 2 & $: 0$ & 30 & 437.293343 & $437.29334 j$ & ats \\
\hline$\Sigma$ & 3 & 20 & 30 & 427.420005 & 429.420005 & 20 \\
\hline 4 & 1 & 0 & 30 & 362.226664 & 362.226664 & $b$ \\
\hline
\end{tabular}

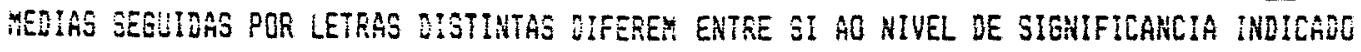
D.H.S. $5 \%=98.74757$

TESTE JE TUKE FARA MEUIAS JE PATINAG

DEMTE YE Z.S DO FATOR FROFUMD

\begin{tabular}{|c|c|c|c|c|c|c|}
\hline NUE GAOEY & HUF.TRAT. & WOHE & MUN.AEFET. & MEDIAS & MEDIAS ORIGINATS & $5 \%$ \\
\hline : & 4 & 30 & $\xi$ & 749.179980 & 749.179990 & $a$ \\
\hline 2 & 3 & 20 & $\xi$ & 725.320020 & 726.320020 & $a$ \\
\hline 3 & 2 & 10 & $\xi$ & 590.100029 & 590.180027 & a \\
\hline 4 & : & 0 & 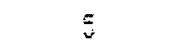 & 590.700000 & 590.700000 & i \\
\hline
\end{tabular}

TESTE JE TUEY FARA MEDIAG DE FATMAG

DENTA DE 5.0 DO FATOA FROFUND

\begin{tabular}{|c|c|c|c|c|c|c|}
\hline MUY BAREH & HUA.TAAT. & : & MUANEET. & MEDIAS & HEDIAS ORTSIHAIS & $5 \%$ \\
\hline$:$ & 4 & 30 & $\vdots$ & 723.700000 & 728.900000 & a \\
\hline 2 & 3 & 20 & $\Sigma$ & 650.720020 & 650.720020 & j \\
\hline 3 & 2 & $\$ 0$ & $\vdots$ & 630.320020 & 630.320020 & $a$ \\
\hline 4 & $\vdots$ & $\therefore$ & $s$ & 525.760010 & 526.960010 & a \\
\hline
\end{tabular}


CONTINUACAOO :

TESE DE TUKEY TRARA MENTAS OE PATHAG

DEWTAO DE 7.5 DO FATOK RROFUND

\begin{tabular}{|c|c|c|c|c|c|c|}
\hline Aut Grine: & MUY. TAAT. & Noure & nut.ancet. & HEDIAS & MEDIAS ORIGIHAIS & $5 \%$ \\
\hline$\vdots$ & 4 & 30 & $\xi$ & 550.320020 & 550.820020 & i \\
\hline$\Sigma$ & 3 & 10 & 5 & 513.150010 & 513.160010 & a \\
\hline$\vdots$ & 3 & 20 & 5 & 492.020020 & 492.520020 & $\vdots$ \\
\hline 4 & $i$ & 0 & 5 & 404.499976 & $404.49977 b$ & a \\
\hline \multicolumn{7}{|c|}{ 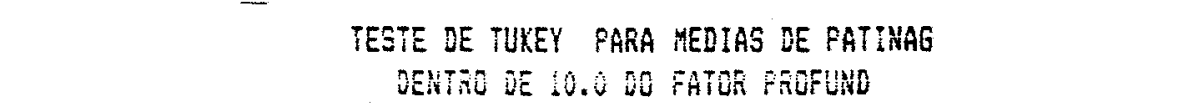 } \\
\hline WUE & 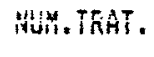 & HOHE & NUM.NEPET. & MEDIAS & MEDIAS ORIGINATS & $5 \%$ \\
\hline : & 4 & 30 & 5 & 326.739990 & 386.939990 & a \\
\hline$z$ & 2 & 10 & $\xi$ & 371.400000 & 371.400000 & a \\
\hline$j$ & 3 & 20 & 5 & 319.700000 & 319.900000 & a \\
\hline 4 & 1 & 0 & 5 & 286.700000 & 286.700000 & a \\
\hline
\end{tabular}

TESTE DE TUKEY FARA MEDTAS DE PATINAG

DENTFO DE 12.5 DO FATOR PROFUHD

\begin{tabular}{|c|c|c|c|c|c|c|}
\hline :H:H. GSOE: & MUY.TAAT. & :HOHE & NLY.ACPET. & MEDIAS & MEDIAS ORIBIMAIS & $5 \%$ \\
\hline$\vdots$ & 2 & :0 & $\xi$ & 256.519995 & 256.519995 & a \\
\hline 2 & 4 & 30 & $\Sigma$ & 250.437990 & 250.437990 & a \\
\hline$\xi$ & 3 & 20 & $\xi$ & 216.539990 & 216.539990 & $a$ \\
\hline 4 & $i$ & 0 & 5 & 211.039990 & 211.077990 & a \\
\hline
\end{tabular}

TESTE DE IUKEY FARA MEDIAS DE FATINAG

DENTIO DE LE.O DO FATOR PROFUNO

\begin{tabular}{|c|c|c|c|c|c|c|}
\hline Hä. SEE & 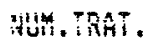 & YOHE & HUT.REFET. & MEDIAS & HEDIAS ORIGWAIS & $5 \%$ \\
\hline : & 4 & 30 & $\vdots$ & $\$ 93.519995$ & 193.519995 & $\mathrm{a}$ \\
\hline 2 & 3 & 20 & $\xi$ & 170.219793 & 170.219983 & $\mathbf{a}$ \\
\hline$:$ & 2 & $\hat{t} \hat{v}$ & $\xi$ & $\$ 2.180005$ & 162.190005 & a \\
\hline 4 & \pm & 0 & 5 & 555.460010 & 153.460010 & a \\
\hline
\end{tabular}

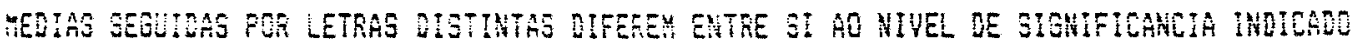
G.i.S. $241.981: 5$ 
CONTINUAGAO :

\begin{tabular}{|c|c|c|c|c|c|c|}
\hline HUY. ORDEY & WUH.TAAT, & NOME & MUH.REFET. & MEDIAS & MEDIAS ORIEINAIE & $5 \%$ \\
\hline & & & & & - & \\
\hline. \pm & $i$ & 2.5 & 20 & 689.095007 & 689.095007 & $\bar{a}$ \\
\hline 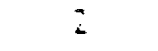 & $i$ & 5.0 & 20 & 634.275012 & 634.275012 & a \\
\hline$j$ & $j$ & 7.5 & 20 & 490.275006 & 490.275006 & $b$ \\
\hline 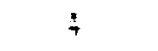 & 4 & 10.0 & 20 & 341.234998 & 341.234978 & $c$ \\
\hline 5 & 5 & 12.5 & 20 & 233.634791 & 233.634991 & $c d$ \\
\hline 6 & 6 & 15.0 & 20 & 169.844998 & 168.844978 & d \\
\hline
\end{tabular}

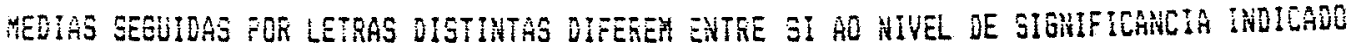
D.H.S. E: $=134.33822$

TESTE DE TUKEY PARA MEDIAS DE PRDFUND

DENTAO DE O DO FATOR PATINAG

\begin{tabular}{|c|c|c|c|c|c|c|}
\hline WU:.ORDES & HUW.TRAT. & MOHE & HUH.AEPET. & MEDIAS & MEDIAS ORIEINAIS & $5 \%$ \\
\hline : & $\vdots$ & 2.5 & 5 & 590.700000 & 590.700000 & à \\
\hline 2 & 2 & 5.0 & 5 & 526.760010 & 526.960010 & $a b$ \\
\hline 3 & 3 & 7.5 & 5 & $404.49997 t$ & 404.499976 & abc \\
\hline 4 & 4 & 10.0 & 5 & 236.700000 & 286.700000 & be \\
\hline 5 & 5 & 12.5 & 5 & 211.039990 & 211.039790 & 5 \\
\hline$\dot{b}$ & $b$ & 15.0 & 5 & 153.460010 & 153.460010 & E \\
\hline
\end{tabular}

TESTE DE TUKEY FARA MEUTAS DE PRORUND DENTIO SE 10 DO FATOR PATINAG

\begin{tabular}{|c|c|c|c|c|c|c|}
\hline WUS.URDEY & WUH. TRAT. & HOME & WUH ARPET. & MEDTAS & MEDIAS ORIG:HAR & $5 \%$ \\
\hline : & 1 & 2.5 & 5 & $690.10002 i$ & 690.130027 & $\mathrm{a}$ \\
\hline$z$ & 2 & 5.0 & $\xi$ & 630.320020 & 830.320020 & ab \\
\hline$z$ & $\dot{J}$ & 7.5 & 5 & 513.150010 & 513.160010 & 200 \\
\hline 4 & 4 & 10.0 & 5 & 371.400000 & 371.400000 & oed \\
\hline$\Sigma$ & 5 & 22.5 & $\Xi$ & 256.519995 & 256.519995 & ed \\
\hline$d$ & $b$ & $\$ 5 . \hat{~}$ & $\vdots$ & is2.:230005 & 162.180005 & $d$ \\
\hline
\end{tabular}


CONTI NUACAO :

TESTE UE TUYCY PARA MELIAS DE PROFUWO

DENTRE DE 20 DO FATOR PATHAG

\begin{tabular}{|c|c|c|c|c|c|c|}
\hline MUF.OKDEY & RHE TRAT. & WGME & WH. REPET. & MEDIẤ & MEDIAS URIEINAIS & $5 \%$ \\
\hline 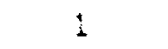 & $\vdots$ & 2.5 & 5 & 726.320020 & 726.320020 & a \\
\hline 2 & 2 & 5.0 & 5 & 650.920020 & 650.920020 & a \\
\hline$j$ & 3 & 7.5 & $\bar{j}$ & 492.520020 & 492.620020 & at \\
\hline 4 & 4 & 10.0 & $\xi$ & 317.900000 & 319.900000 & $b c$ \\
\hline 5 & 5 & 12.5 & 5 & 216.539990 & 216.539990 & c \\
\hline 6 & 6 & 15.0 & 5 & 170.219983 & 170.219783 & $\tau$ \\
\hline
\end{tabular}

TESTE DE TUKEY PARA MEUIAS DE PROFUND

DERTRO IE 30 DO FATOR PATINAG

\begin{tabular}{|c|c|c|c|c|c|c|}
\hline WHA. ORDEY & NUM.TRAT. & HOME & WUN. REPET. & MEDIAS & MEDIAS ORIGIHAIS & $5 \%$ \\
\hline $\mathfrak{1}$ & 1 & 2.5 & 5 & 749.179780 & 749.179780 & a \\
\hline 2 & 2 & 5.0 & $j$ & 728.700000 & 728.7000000 & $a$ \\
\hline 3 & 3 & 7.5 & 5 & 550.820020 & 550.820020 & ab \\
\hline 4 & 4 & 10.0 & $\xi$ & 386.9399790 & 386.939790 & be \\
\hline 5 & 5 & 12.5 & $\xi$ & 250.439990 & 250.439990 & $c$ \\
\hline$\dot{b}$ & 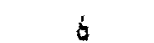 & 15.0 & $\xi$ & 195.317995 & 193.519995 & 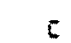 \\
\hline
\end{tabular}

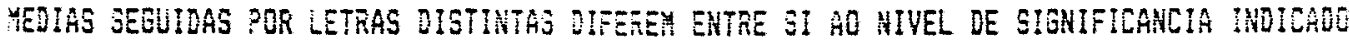
D.4.S. $5.5=268.67643$ 